\title{
Ortodoncia interceptiva durante la pandemia COVID-19: Urgencias y tratamientos prioritarios.
}

Asociación Latinoamericana de Odontopediatría. Equipo Interdisciplinario COVID-19

\section{Introducción}

A la presente fecha, los diferentes organismos de salud internacionales y locales han publicado recomendaciones, regulaciones y protocolos para atención odontológica durante de la pandemia COVID-19, ajustados a las diferentes etapas de la misma.

La Asociación Latinoamericana de Odontopediatría, en su misión apoyar y llevar la mejor información disponible a todos los colegas latinos, ha publicado guías prácticas y documentos de apoyo fáciles de utilizar y compartir con todo el personal odontológico que trabaje en ambiente hospitalario, clínicas gubernamentales, instituciones educativas y clínicas privadas, que presten atención a niños, adolescentes y pacientes en situación de discapacidad. ${ }^{1-3}$

Diferentes países se encuentran en diferentes etapas de la pandemia por lo que las recomendaciones pueden incluir limitar el tratamiento odontológico a los casos de urgencia o con necesidad de tratamiento prioritario. Esto puede implicar la suspensión temporal de los controles periódicos de ortodoncia interceptiva. El objetivo de esta revisión es proporcionar directrices en el manejo de la atención de pacientes con tratamiento de ortodoncia interceptiva el periodo de Pandemia por COVID-19, utilizando la literatura disponible y la opinión de los expertos. Son muchos los pacientes pediátricos que utilizan aparatos o que necesitan terapia a corto plazo, situaciones que requieren de planificación de tratamiento según la etapa de la pandemia en la cual se encuentre cada localidad.

Aunque los procedimientos de ortodoncia generalmente se consideran optativos, hay situaciones en cuales son prioritarios. Siendo así en este documento se busca definir el término de urgencias ortodóncicas durante el confinamiento COVID-19, determinando cuáles situaciones pueden ser manejadas en el hogar a través de la teleodontología y cuáles requieren la asistencia personal a la consulta odontológica. Igualmente, busca describir las maloclusiones que requieren tratamiento prioritario luego del confinamiento COVID-19, realizando algunas recomendaciones terapéuticas 
basadas en diferentes niveles de evidencia, para la etapa de dentición primaria o mixta temprana.

Las recomendaciones que a continuación se proponen están vinculadas a la situación excepcional de pandemia y pueden diferir de las prácticas clínicas habituales. No constituyen un protocolo clínico exhaustivo de todos los tratamientos posibles, sino una guía de orientación, sin sustituir regulaciones locales, protocolos específicos, ni leyes vigentes en cada país y son susceptibles a evolucionar y cambiar en función de la situación sanitaria. Se insta a los profesionales a realizar seguimiento a las actualizaciones que puede haber sobre este documento.

\section{Ortodoncia interceptiva en el marco de la pandemia COVID-19}

La Organización Mundial de la Salud declaró el descubrimiento de un nuevo coronavirus, llamado SARS-CoV-2 que no había sido identificado previamente en humanos. Posteriormente declaró pandemia por la enfermedad denominada COVID-19. ${ }^{4,5}$

El SARS-CoV-2, se puede encontrar en secreciones humanas como: sangre, saliva y heces. Por lo tanto, es capaz de transmitirse por contacto directo con un individuo infectado, así como a través de gotas o secreciones.6-8 Diversos estudios han reportado transmisión cruzada de COVID-19 entre los trabajadores de la salud. ${ }^{9,10}$

Todos los que asisten a un consultorio dental están directamente expuestos a la transmisibilidad de este virus en sus diferentes rutas. Por lo tanto, los
Odontólogos deben conocer la evidencia disponible para proporcionar un entorno seguro para ellos, su personal, sus pacientes y sus familias. ${ }^{1-3,11,12}$

Ante la recomendación de confinamiento durante la pandemia COVID-19, la odontología ha sido limitada a la atención de urgencias. Durante el tratamiento de ortodoncia se pueden producir lesiones de las mucosas bucales, perdida o fractura de aditamentos, perdida de retención de aparatos fijos, entre otras complicaciones que pudieran ser consideradas situaciones de urgencia.

La Ortodoncia Interceptiva requiere proximidad entre el odontólogo y el paciente e impide el distanciamiento recomendado de 2 metros. Añadido a esto, la mayoría de los pacientes que poseen tratamiento ortodóncico son niños, quienes han sido reportados en diversos estudios como portadores asintomáticos, elevando el riesgo de contagio. Entre las posibles fuentes de contaminación, se destacan: la saliva del paciente, aerosoles y materiales e instrumentos de ortodoncia. ${ }^{12}$

Para la planificación de la atención de pacientes en pandemia, en primer lugar, es necesario clasificar el paciente según su riesgo médico y de contagio (alto o bajo riesgo), ${ }^{13}$ identificar el tratamiento a realizar (urgencia que amerite consulta presencial en el consultorio), así como evaluar el momento (tiempo) en el cual se presenta la urgencia. Este último puede clasificarse en: atención durante el confinamiento y posterior a la etapa de confinamiento.

Durante el periodo de confinamiento (cuarentena) se recomienda posponer cualquier cita de control y restringir el 
tratamiento a casos de urgencias, que no pueden ser resueltos de forma remota por el paciente, siguiendo las directrices dictadas por la OMS y las autoridades locales. ${ }^{13}$

Una vez culminado el confinamiento, aún en periodo de pandemia o desescalada, se deben seguir protocolos de bioseguridad y seguir las recomendaciones para la atención. Esta condición requerirá una organización diferente durante varios meses y la gestión remota de pacientes podría llevarse a cabo de manera eficiente utilizando plataformas de teleodontología para ofrecer consultorías de atención médica. ${ }^{14}$

\section{Teleodontología}

Durante la pandemia se propone el manejo de urgencias de ortodoncia interceptiva siguiendo paso a paso una secuencia ordenada de teleodontología. La mayoría de los problemas comunes de ortodoncia, como aditamentos descementados y aparatos removibles o retenedores extraviados o fracturados pueden ser manejados vía remota a través de teleodontología. ${ }^{15}$

La teleodontología permite lograr un contacto directo y rápido entre paciente y odontólogo tratante, permitiendo trasmitir instrucciones sencillas para solventar cualquier urgencia susceptible a ser manejada sin cita presencial. ${ }^{16}$ Además, permite realizar seguimiento y control de los pacientes que se encuentran bajo tratamiento activo en situaciones en las que el paciente no puede ir a la clínica. ${ }^{17}$

El monitoreo por teleodondologia de rutina dependerá de la situación clínica a evaluar, el control de retención usualmente pudiera requerir una imagen cada uno o dos meses y el tratamiento activo una o dos fotos por semana. Debe explicársele a los reperesentantes y pacientes las características que deben cumplir las fotos para que sirvan de guía diagnóstica. ${ }^{18}$

El primer paso debe ser la asistencia virtual, mediante el uso de teleodontología. ${ }^{14}$ El segundo paso, es la realización del triage o tamizaje para determinar si es una urgencia e identificar si amerita una consulta presencial o la factibilidad de brindar apoyo para el manejo del paciente en su casa, describiendo las características y limitaciones que puede tener la atención a distancia. ${ }^{16-19}$ El odontopediatra debe guiar a los pacientes sobre cómo manejar urgencias en casa y registrar toda la asesoría indicada. ${ }^{11}$ La toma de fotografías en casa puede ser explicada directamente de forma telefónica o con apoyo audiovisual. ${ }^{20}$

Con el propósito de aumentar la participación en niños y mejorar la comunicación, se pueden utilizar escalas visuales o emojis, ampliamente utilizados en psicología y medicina para identificar el grado de dolor o medir los niveles de ansiedad, entre otros. ${ }^{19}$

Las ayudas audiovisuales se pueden convertir en material de apoyo ante diversas situaciones de urgencias ortodóncicas, a través de las cuales el especialista podrá explicar de una manera más sencilla el procedimiento, haciendo mucho más efectiva la comunicación, brindado seguridad y confianza a los padres/representantes a la hora de llevar a cabo el procedimiento y disminuyendo el miedo y la ansiedad, al familiarizarse con el procedimiento a realizar, ${ }^{11-21}$ además 
de permitir explicar las situaciones que el paciente experimentará en la consulta durante la etapa de confinamiento COVID-19. ${ }^{22}$

Si se confirma que la urgencia ortodóncica debe ser realizada de forma presencial, el tercer paso es descartar factores de contagio COVID-19 por medio de la realización de cuestionario sobre sus signos y síntomas de los últimos 14 días y solicitar el consentimiento informado para la realización del tratamiento. 3,16,19

Si el paciente contesta de forma positiva a una o más preguntas, es catalogado paciente de alto riesgo, se debe evaluar la opción de diferir la atención y de otorgarle apoyo virtual, y en el caso de no ser posible se recomienda la atención bajo un protocolo estricto con la incorporación de medidas adicionales, previa consulta con el médico tratante. ${ }^{23,24}$

Para los pacientes con antecedentes de COVID-19, el CDC recomienda actualmente que los pacientes puedan salir del aislamiento domiciliario cuando han pasado al menos 72 horas desde la recuperación (resolución de la fiebre sin el uso de medicamentos para reducir la fiebre y la mejora de la sintomatologia y 10 días desde el primer síntoma. ${ }^{25}$

En caso de necesitar exámenes radiográficos, las radiografías dentales extraorales, como la radiografía panorámica y la tomografía, son alternativas apropiadas durante el COVID-19.

\section{Urgencias dentales en ortodoncia interceptiva}

Una urgencia ortodóncica puede ser descrita como un problema relacionado con la mecánica ortodóncica que requiera atención pronta para la resolución de malestar físico severo (úlceras o irritación de las mucosas, labios y lengua), tratamiento de proceso infeccioso (abscesos periodontales asociados a los aditamentos), o de alteración psíquica (deterioro estético grave). ${ }^{14}$ Igualmente es de urgencia el seguimiento de mecánicas que, de permanecer sin control profesional, puedan perjudicar la integridad de los tejidos de soporte dental.

Cuando el especialista realiza la telecomunicación, se debe obtener el historial de salud del paciente para recoger síntomas o antecedentes relevantes para COVID-19. En el caso de que el paciente deba ser visto presencialmente, el historial médico también permitirá al especialista evaluar los posibles riesgos de trasmisión y asegurarse de que el consultorio clínico este equipado adecuadamente con el Equipo de Protección Personal (EPP).

A continuación, se presenta un flujograma de atención de pacientes con urgencias ortodóncicas durante la pandemia COVID-19 (Figura 1).

\section{Categorización y manejo de urgencias en ortodoncia}

Una vez realizada la teleconsulta y el triage, se puede identificar la situación de urgencia que requiere atención presencial, y dar prioridad utilizando criterio de urgencia.

Las urgencias ortodóncicas pueden clasificarse de acuerdo con el tipo de aparato utilizado por el paciente, los cuales pueden ser: fijos o removibles. ${ }^{14}$

Algunas de las urgencias que requieren 


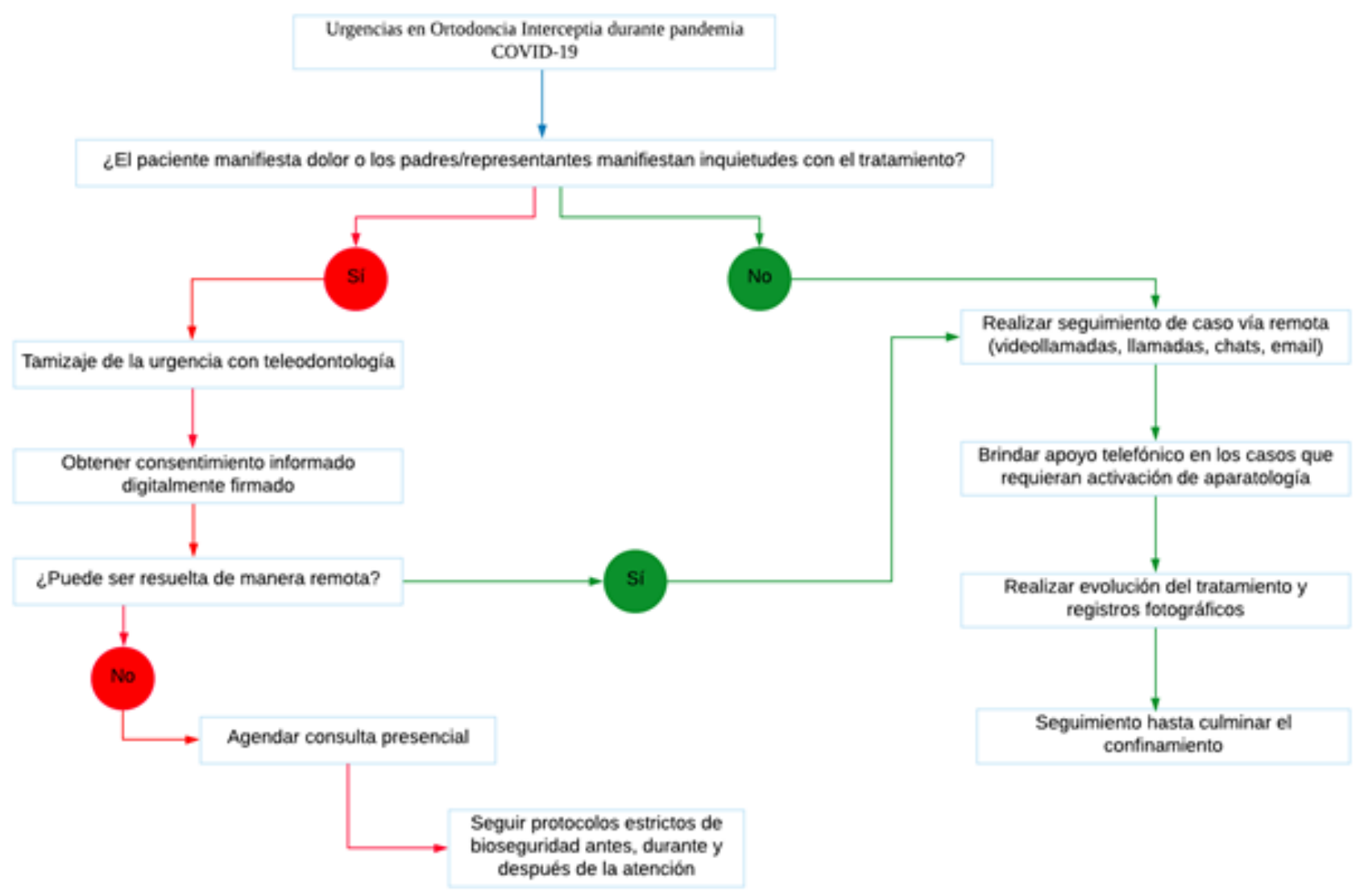

Figura 1: Flujograma de atención de urgencias en ortodoncia interceptiva durante la pandemia COVID-19..$^{11-13}$

la programación de una visita a la clínica dental, así como enfoques de abordaje, se destacan a continuación. ${ }^{11,13-15}$

- Dolor o molestia severa o trauma intraoral significativo por un arco/ alambre afilado asociado a un aparato fijo o retenedor adherido donde la aplicación de cera no ha podido proporcionar alivio.

- Banda rota, bracket o tubo de un aparato fijo que se ha soltado y por ende, existe posibilidad de inhalación de un cuerpo extraño.

- Desalojo parcial de una banda de ortodoncia o aparato fijo que no se puede volver a asentar.
- Traumatismos dentoalveolares en pacientes con aparatos ortodóncicos.

- Abscesos o procesos infecciosos asociados a los aparatos de ortodoncia.

- Complicaciones de procedimientos quirúrgicos recientes, relacionados con el tratamiento de ortodoncia.

- Dolor o malestar intensos condiciones en las cuales la aplicación de cera o uso de analgésicos no ha proporcionado alivio

- Tracción de dientes ectópicos o retenidos, con riesgo de anquilosis, sobreerupción o desplazamientos

- Otro problema muy frecuente, 
especialmentedurantelasfasesiniciales de la nivelación cuando se utiliza con ortodoncia fija, es el sobresaliente de alambre en los extremos distales, como puede pasar con el uso de la técnica $2 \times 4$, pueden causar traumatismo de tejidos blandos y úlceras.

El tratamiento de urgencia durante el periodo de confinamiento debe limitarse al recorte y ajuste de los alambres que causan traumas o la simple eliminación de cualquier componente del aparato suelto. Si el paciente rompe el aparato removible activo o tiene molestias notables al usarlo, se sugiere suspender el uso del aparato por el momento, con el fin de reducir las urgencias.

Si el paciente siente dolor, enrojecimiento o edema cerca de un aparato de ortodoncia fijo, debe descartarse que se trate de un absceso periodontal, entonces se sugiere cita presencial para eliminar la causa, por ejemplo, una banda debajo de la encía.

Las Tablas 1, 2 y 3 presentan algunas urgencias más comunes que pueden presentarse durante el confinamiento y sus diversas opciones de asesoramiento que puede impartir el especialista para que sean solventadas en casa. ${ }^{11,14,26}$

\section{Tabla 1: Asesoramiento ortodóncico en pacientes con aparatología fija durante la pandemia COVID-19}

\begin{tabular}{|l|l|}
\hline \multicolumn{1}{|c|}{$\begin{array}{c}\text { Urgencia y seguimiento de } \\
\text { ortodoncia interceptiva en } \\
\text { pacientes con aparatos fijos }\end{array}$} & Asesoramiento durante confinamiento COVID-19 \\
\hline $\begin{array}{l}\text { Aparatos fijos activados por el paciente } \\
\text { (expansores, maxilares, máscaras } \\
\text { faciales, etc). }\end{array}$ & $\begin{array}{l}\text { Realizar monitoreo con Teleodontología, solicitando } \\
\text { imágenes de forma periódica. } \\
\text { En casos de dudas o falta de colaboración, suspender } \\
\text { las activaciones con el objetivo de evitar futuras } \\
\text { urgencias. } \\
\text { En caso de verificar que se han logrado los objetivos } \\
\text { terapéuticos, suspender las activaciones }\end{array}$ \\
\hline $\begin{array}{l}\text { Aparatos fijos pre activados (péndulos, } \\
\text { barras transpalatinas, etc.) }\end{array}$ & $\begin{array}{l}\text { Realizar monitoreo con Teleodontología, solicitando } \\
\text { imágenes cada 15 días y realizar evaluaciones para } \\
\text { determinar necesidad de consulta presencial. } \\
\text { Si el paciente experimenta dolor o inflamación, debe } \\
\text { verse en la consulta como una urgencia y retirar el } \\
\text { dispositivo. }\end{array}$ \\
\hline $\begin{array}{l}\text { Expansor fijo o } \\
\text { Arco lingual/palatal } \\
\text { Lip bumper }\end{array}$ & $\begin{array}{l}\text { Realizar monitoreo con Teleodontología, solicitando } \\
\text { imágenes de forma periódica. } \\
\text { Si está parcialmente despegado y aún presente en } \\
\text { boca, reposicionar y suspender las activaciones hasta } \\
\text { la visita con el especialista. } \\
\text { Si se ha desalojado completamente, guardar en un } \\
\text { lugar seguro hasta la visita con el ortodoncista u } \\
\text { odontopediatra. }\end{array}$ \\
\hline
\end{tabular}


Tabla 2: Asesoramiento de urgencias ortodóncicas en pacientes con removible durante la pandemia COVID-19. 11, 14, 26

\begin{tabular}{|c|c|}
\hline $\begin{array}{l}\text { Urgencia y seguimiento de ortodoncia } \\
\text { interceptiva en pacientes con } \\
\text { aparatos removibles. }\end{array}$ & Asesoramiento durante confinamiento COVID-19 \\
\hline $\begin{array}{l}\text { Interferencia de algún diente, durante la } \\
\text { segunda fase de la dentición mixta, con } \\
\text { el aparato }\end{array}$ & $\begin{array}{l}\text { Solicitar foto al paciente. } \\
\text { Suspender su uso con el objetivo de evitar futuras } \\
\text { urgencias. }\end{array}$ \\
\hline $\begin{array}{l}\text { Fractura de aparatos funcionales o } \\
\text { molestias durante su uso. }\end{array}$ & $\begin{array}{l}\text { Solicitar foto al paciente. } \\
\text { Suspender su uso con el objetivo de evitar futuras } \\
\text { urgencias. }\end{array}$ \\
\hline $\begin{array}{l}\text { Lesiones de la mucosa producida por } \\
\text { asas del arco. }\end{array}$ & $\begin{array}{l}\text { Solicitar foto al paciente. } \\
\text { Indicar a padres/representantes a través de } \\
\text { Teleodontología, como realizar torque en el arco con } \\
\text { ligera presión con los dedos. } \\
\text { De no aliviar la presión de las asas sobre la mucosa, } \\
\text { suspender su uso para evitar futuras urgencias. }\end{array}$ \\
\hline $\begin{array}{l}\text { Aparatos removibles activados por el } \\
\text { paciente. }\end{array}$ & $\begin{array}{l}\text { Realizar monitoreo con Teleodontología, solicitando } \\
\text { imágenes de forma periódica. } \\
\text { En casos de dudas o falta de colaboración, suspender } \\
\text { las activaciones con el objetivo de evitar futuras } \\
\text { urgencias }\end{array}$ \\
\hline Placas activas desadaptadas. & $\begin{array}{l}\text { Solicitar foto al paciente. } \\
\text { Preguntar a través de Teleodontología, sobre la } \\
\text { frecuencia de uso. } \\
\text { Indicar cerrar el tornillo y probar ajuste de la placa. } \\
\text { Si la placa activa aún no adapta, suspender su uso } \\
\text { hasta la próxima consulta. }\end{array}$ \\
\hline Falta de retención de los aparatos. & $\begin{array}{l}\text { Solicitar foto al paciente. } \\
\text { Suspender su uso con el objetivo de evitar futuras } \\
\text { urgencias. } \\
\text { Una vez finalizado el confinamiento, el especialista } \\
\text { realizará los ajustes pertinentes. }\end{array}$ \\
\hline Retenedores fracturados. & $\begin{array}{l}\text { Solicitar foto al paciente. } \\
\text { Una vez finalizado el confinamiento, el especialista } \\
\text { tomará impresiones para nuevo aparato. } \\
\text { En caso de ruptura o pérdida de un retenedor y hay } \\
\text { riesgo de recidiva que comprometa irreversiblemente } \\
\text { el tratamiento, el clínico podría asignar una cita } \\
\text { presencial apenas lo considere oportuno. }\end{array}$ \\
\hline
\end{tabular}


Tabla 3: Asesoramiento de urgencias ortodóncicas en pacientes con aparatología fija para mecánicas de movimiento menor durante la pandemia COVID-19. ${ }^{11,14}$

\begin{tabular}{|c|c|}
\hline $\begin{array}{l}\text { Urgencia y seguimiento de } \\
\text { ortodoncia interceptiva en } \\
\text { pacientes con mecánicas de } \\
\text { movimiento menor. }\end{array}$ & Asesoramiento durante confinamiento COVID-19 \\
\hline $\begin{array}{l}\text { Irritación de labios o carrillos } \\
\text { por aditamentos. }\end{array}$ & $\begin{array}{l}\text { Solicitar foto al paciente. } \\
\text { Colocar una pequeña porción de cera de ortodoncia (cera de } \\
\text { alivio) sobre el aditamento (bracket, ligadura, arco) que está } \\
\text { causando irritación. } \\
\text { El dolor asociado a las lesiones traumáticas puede aliviarse } \\
\text { con la aplicación de anestesia tópica directamente sobre la } \\
\text { lesión usando un bastoncillo de algodón. } \\
\text { Programar cita presencial }\end{array}$ \\
\hline $\begin{array}{l}\text { Aditamento de ortodoncia } \\
\text { (bracket, tubo o banda) flojo/ } \\
\text { despegado. }\end{array}$ & $\begin{array}{l}\text { Solicitar foto al paciente. } \\
\text { Si el bracket ha girado alrededor del arco causando molestias, } \\
\text { puede posicionarse nuevamente con una pinza desinfectada } \\
\text { girándolo alrededor del arco en el punto donde contactan dos } \\
\text { dientes para proveer mayor espacio para la maniobra. } \\
\text { Si el bracket se utiliza como anclaje para elásticos } \\
\text { intermaxilares, detener su uso. } \\
\text { Si el bracket despegado es el último aditamento en el arco, } \\
\text { puede: deslizar el bracket a través del arco y retirarlo. } \\
\text { Si una banda o un bracket permanece al ras con el diente, se } \\
\text { puede dejar en observación, si corre riesgo de caer en cavidad } \\
\text { bucal o lacerar la mucosa, el paciente puede tratar con } \\
\text { cuidado de quitarlo con pinzas de cejas. }\end{array}$ \\
\hline $\begin{array}{l}\text { Arco sobresaliente al final del } \\
\text { bracket/tubo. }\end{array}$ & $\begin{array}{l}\text { Solicitar foto al paciente. } \\
\text { Colocar cera de ortodoncia o cera de alivio. } \\
\text { Usar un bastoncillo de algodón o un borrador de lápiz limpio } \\
\text { para empujar el arco contra el diente. } \\
\text { Si la molestia es producto del deslizamiento del arco de } \\
\text { un extremo a otro de la arcada, utilizar una pinza de cejas } \\
\text { desinfectada para desplazar el arco hacia atrás hasta que } \\
\text { sienta comodidad en ambos lados. } \\
\text { Si el arco es sumamente irritante, programar cita presencial }\end{array}$ \\
\hline Desalojo de ligadura metálica. & $\begin{array}{l}\text { Solicitar foto al paciente. } \\
\text { Si la ligadura metálica se ha soltado, retirarla con una pinza } \\
\text { desinfectada. } \\
\text { Si la ligadura no está floja, pero sobresale puede ser doblada } \\
\text { hacia abajo con un bastoncillo de algodón o con un borrador } \\
\text { de lápiz limpio. }\end{array}$ \\
\hline $\begin{array}{l}\text { Tragar un aditamento de } \\
\text { ortodoncia. }\end{array}$ & $\begin{array}{l}\text { Mantener la calma. Debido al pequeño tamaño de estos } \\
\text { aditamentos, al ingeridos eventualmente pasaran al tracto } \\
\text { digestivo. } \\
\text { Confirmar que el paciente no presente dificultad respiratoria } \\
\text { o que haya experimentado tos al momento de tragar el } \\
\text { aditamento. De haberse presentado estos síntomas indicar al } \\
\text { paciente que debe dirigirse al departamento de emergencias } \\
\text { de un hospital. }\end{array}$ \\
\hline
\end{tabular}




\section{Bioseguridad}

Al momento de brindar atención odontológica al paciente en la consulta, deben cumplirse rigurosamente todas las medidas de bioseguridad recomendadas por los organismos de salud, con el nivel más alto de protección personal, desinfección de las superficies, ventilación adecuada, disminución de generación de aerosoles y descontaminación de instrumentos recomendados por todos los organismos internacionales. ${ }^{111-13,24,27-31}$

\section{Prioridades en ortodoncia interceptiva en tiempos de COVID-19}

En el periodo de confinamiento la recomendación es limitar la atención presencial a urgencias y evitar comenzar tratamientos. Una vez culminado el confinamiento, deben tomarse en consideración aquellos casos que requieren atención ortodóncica prioritaria.

La Ortodoncia Interceptiva abarca el tratamiento de maloclusiones en dentición primaria y mixta, para el paciente en crecimiento, teniendo como objetivo eliminar características desfavorables al desarrolloapropiadodelaoclusión. ${ }^{32}$ Existe evidencia científica que avala el abordaje de algunas maloclusiones en esta etapa, para minimizar su complejidad, promover el crecimiento y desarrollo apropiado de los maxilares de los tejidos de soporte, eliminar hábitos nocivos y minimizar la necesidad de terapias ortodóncicas complejas, obtener mejor respuesta a la modificación del crecimiento para lograr cambios esqueléticos y disminuir la severidad de maloclusiones. ${ }^{33-36}$

La presencia de maloclusiones puede afectar de forma negativa la calidad de vida relacionada con salud bucal, incluso, los niños pueden sufrir acoso escolar y presentar baja autoestima. ${ }^{37,38} \mathrm{La}$ presencia de overjet aumentado y mordida profunda se han asociado con una menor calidad de vida asociada con salud bucal, y mientras más severa es la maloclusión, mayor es impacto negativo sobre la calidad de vida. ${ }^{37-41}$ También ha sido comprobado que la presencia de overjet aumentado puede predisponer a padecer traumatismos dentales, y que el tratamiento ortodóntico temprano para reducir la protrusión de incisivos superiores disminuye la incidencia de daños por trauma. ${ }^{42}$

El objetivo en la planificación del tratamiento en este momento es implementar mecánicas que permitan reducir las citas de seguimiento, sin poner en peligro los resultados esperados. Este tipo de enfoque podría ser de gran ayuda en el manejo de todos los dispositivos removibles ortopédicos dentofaciales y de los tratamientos de ortodoncia que necesitan poco mantenimiento en el consultorio. ${ }^{43}$

Sobre la base de la evidencia disponible hasta la fecha, puede establecerse que las situaciones prioritarias que requieren tratamiento de ortodoncia interceptiva, para evitar efectos adversos en el desarrollo de la dentición, promover un correcto desarrollo de los tejidos de soporte y promover el correcto crecimiento maxilofacial (Tabla 4).

\section{Mordida cruzada posterior funcional}

La mordida cruzada posterior se caracteriza por la oclusión de las cúspides vestibulares de caninos, premolares $o$ molares superiores en posición lingual en relación con sus antagonistas inferiores, ${ }^{65}$ y tiene una prevalencia media entre el 7 y el $23 \%$ en la dentición primaria y mixta 
Tabla 4: Impacto negativo de las maloclusiones en el paciente pediátrico. ${ }^{41,44-64}$

\begin{tabular}{|l|l|}
\hline Maloclusión & Impacto de la maloclusión en el paciente pediátrico \\
\hline Mordida Cruzada Posterior & $\begin{array}{l}\text { Crecimiento facial asimétrico } \\
\text { Asimetría de los músculos faciales } \\
\text { Modificación articular ATM }\end{array}$ \\
\hline Mordida Cruzada Anterior. & $\begin{array}{l}\text { Afección periodontal, recesión gingival } \\
\text { Aumento en severidad de la maloclusión } \\
\text { Disminución de la altura facial anterior } \\
\text { Crecimiento mandibular descontrolado } \\
\text { Cambio en el eje de rotación mandibular Estética }\end{array}$ \\
\hline $\begin{array}{l}\text { Hábitos Persistentes - Mordida } \\
\text { Abierta Asociada. }\end{array}$ & $\begin{array}{l}\text { Overjet Excesivo } \\
\text { Pérdida de espacio en la arcada inferior } \\
\text { Mordida cruzada posterior } \\
\text { Mordida abierta anterior }\end{array}$ \\
\hline Overjet Aumentado. & $\begin{array}{l}\text { Instauración de hábitos } \\
\text { Traumatismos dentoalveolares } \\
\text { Afección periodontal } \\
\text { Enfermedad periodontal } \\
\text { Acoso escolar }\end{array}$ \\
\hline Erupción Ectópica o Apiñamiento & $\begin{array}{l}\text { Estética, afección del autoestima e impacto negativo en } \\
\text { la calidad de vida } \\
\text { Enfermedad periodontal. } \\
\text { Severo. } \\
\text { Erupciones ectópicas }\end{array}$ \\
\hline Bruxismo. & $\begin{array}{l}\text { Asociado con atricción y p érdida de la dimensión } \\
\text { vertical } \\
\text { Hipertrofia de músculos de la masticación } \\
\text { Trastornos temporomandibulares }\end{array}$ \\
\hline Dientes Primarios Anquilosados. & $\begin{array}{l}\text { Infraoclusión } \\
\text { Retención prolongada de dientes primarios } \\
\text { Pérdida significativa de la longitud del arco } \\
\text { Defectos periodontales severos } \\
\text { Dificultad en la erupción del sucesor permanente }\end{array}$ \\
\hline
\end{tabular}

respectivamente. ${ }^{66}$ Los factores de riesgo más comúnmente relacionados con esta condición son la postura inferior de la lengua, que desorganiza el equilibrio muscular entre la lengua y los músculos buccinadores, generando una deficiencia transversal del maxilar, además de la respiración bucal, que modifica el mecanismo de crecimiento transversal de la mandíbula, colapsando más el maxilar y con paladar más profundo, así como hábitos posturales como apoyar las manos en un lado de la cara durante horas prolongadas.

La mordida cruzada posterior funcional se caracteriza por desviación mandibular hacia el lado cruzado con la consiguiente desviación de la línea media inferior al lado del cruce por un contacto prematuro generalmente entre los caninos primarios en el lado que manifiesta la mordida cruzada. ${ }^{67}$ (Figura 2)

Durante el examen clínico, se debe guiar 


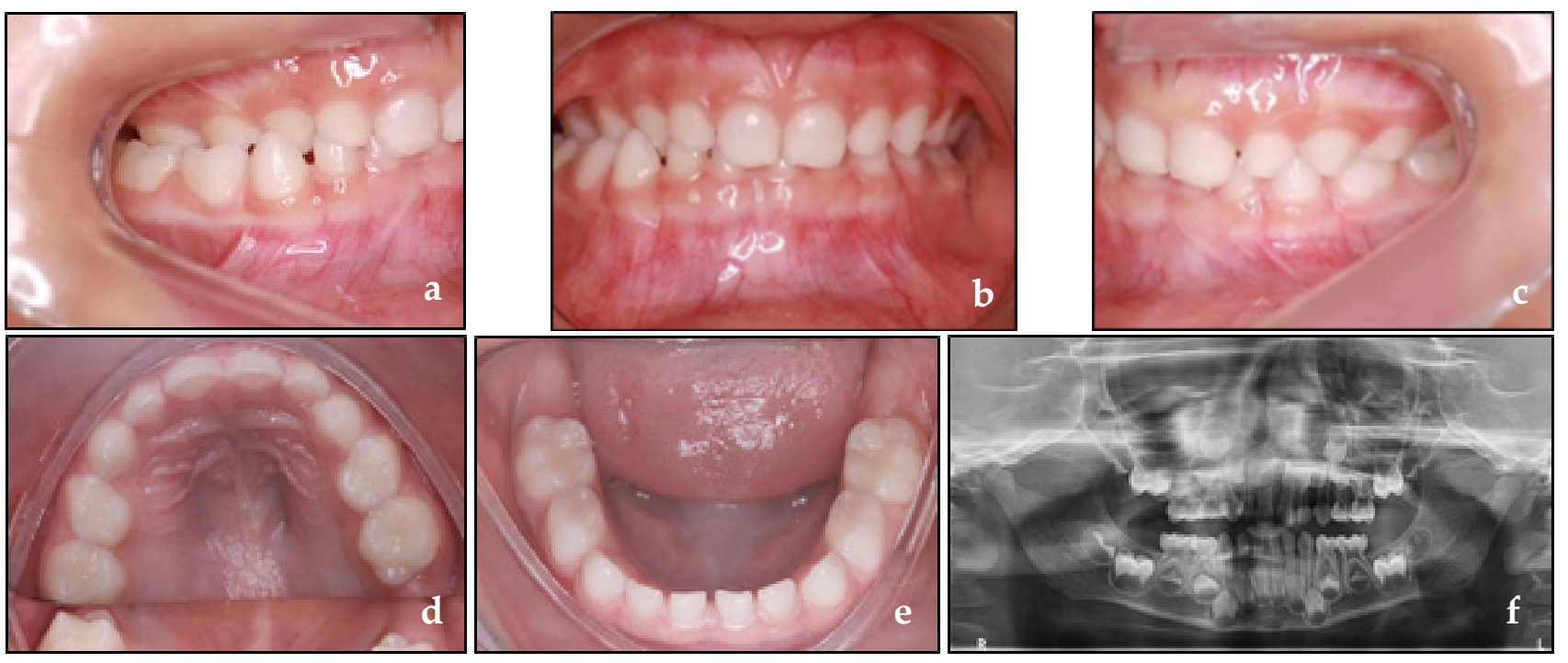

Figura 2: Mordida cruzada funcional, cruzada unilateral $(a, b, c)$, desviación de línea media inferior $(b, f)$, maxilar con distancia transversal menor que mandibula $(d, e)$.

la mandíbula del niño a una posición centrada, donde se observará la línea media inferior coincidente con la superior, el deficiencia transversal del maxilar con mordida cruzada bilateral, así como posición inestable de la mandíbula que lleva al niño a buscar contacto oclusal desplazando hacia lado cruzado, es decir, se observa una doble mordida con diferencia entre la Relación Céntrica (RC) y Intercuspidación Máxima Habitual (IMH) y el movimiento condilar asimétrico. ${ }^{68}$ Esta situación puede producir cambios musculares importantes a medio plazo, cambios en la posición articular y puede generar crecimiento facial asimétrico y asimetría de los músculos de la cara. Por estas razones, se requiere un enfoque tan pronto como se diagnostica, ${ }^{35}$ con la recomendación de intervención temprana en las guías de práctica clínica de las asociaciones de ortodoncia en todo el mundo. ${ }^{44,45}$

Las terapias ortodóncicas para la corrección de la mordida cruzada primero priorizan la eliminación del contacto prematuro por el desgaste oclusal de los caninos. Si este procedimiento no resuelve el problema, se indican las medidas terapéuticas. En los casos de expansores removibles de menor magnitud con recubrimiento oclusal se pueden utilizar, y siempre que sea posible el uso de expansores fijos tipo Haas, ${ }^{69}$ Hyrax $^{70}$ o McNamara. ${ }^{71}$

En la corrección de la mordida cruzada posterior, ya sea funcional o no, se debe considerar la necesidad de la eliminación de agentes etiológicos, con orientaciones por parte del odontopediatra $\mathrm{u}$ ortodoncista así como con la acción interdisciplinaria incluyendo terapia de lenguaje $y$ otorrinolaringólogo.

Desde la perspectiva del momento de la pandemia, se pueden considerar dos alternativas, la primera de ellas es la orientación preventiva en el sentido de la eliminación de hábitos asociados. En el caso del desgaste oclusal, una opción es utilizar la pieza de mano en baja velocidad 
con irrigación por goteo para disminuir la generación de aerosoles.

Durante el tratamiento con mecánicas de expansión, seguir periódicamente por teleodontología las activaciones del aparato expansor realizadas por los padres, para que se determinar el momento para detener las mismas.

\section{Mordida cruzada anterior}

Entre las maloclusiones que requieren un tratamiento temprano se encuentra la mordida cruzada anterior. Esta maloclusión debe diagnosticarse lo antes posible y se evaluarán los componentes dentales, funcionales y esqueléticos que serán decisivos en la elección de las mecánicas de ortodoncia y la definición del pronóstico y el tiempo de seguimiento después de que se evalúe el tratamiento. Sobre la base de estos criterios, la mordida cruzada anterior se puede clasificar como: mordida anterior dental, pseudo clase III y Clase III esquelética. ${ }^{72}$

\section{Mordida cruzada anterior dental.}

La mordida anterior dental se caracteriza por el cruce de uno o dos incisivos, ${ }^{73}$ y la relación de molares y caninos de clase I o plano terminal recto en molares primarios además de una adecuada relación maxilomandibular (Figura 3).

La mordida cruzada dental anterior tiene la etiología asociada con factores ambientales, comola retención prolongada de dientes primarios y trauma dental. Esta condición, a pesar de su baja complejidad, requiere un enfoque tan pronto como se diagnostica, evitando así cambios periodontales como recesión gingival, y el desarrollo de alteraciones funcionales que pueden conducir a pseudo clase III.

El tratamiento de la mordida cruzada anterior dental se puede realizar con aparatos removibles, mediante el uso de resortes digitales, tornillos expansores, $\mathrm{y}$, cuando sólo se cruza un elemento dental, se pueden adoptar maniobras preventivas con dispositivos simples como paletas de madera. ${ }^{74,75}$
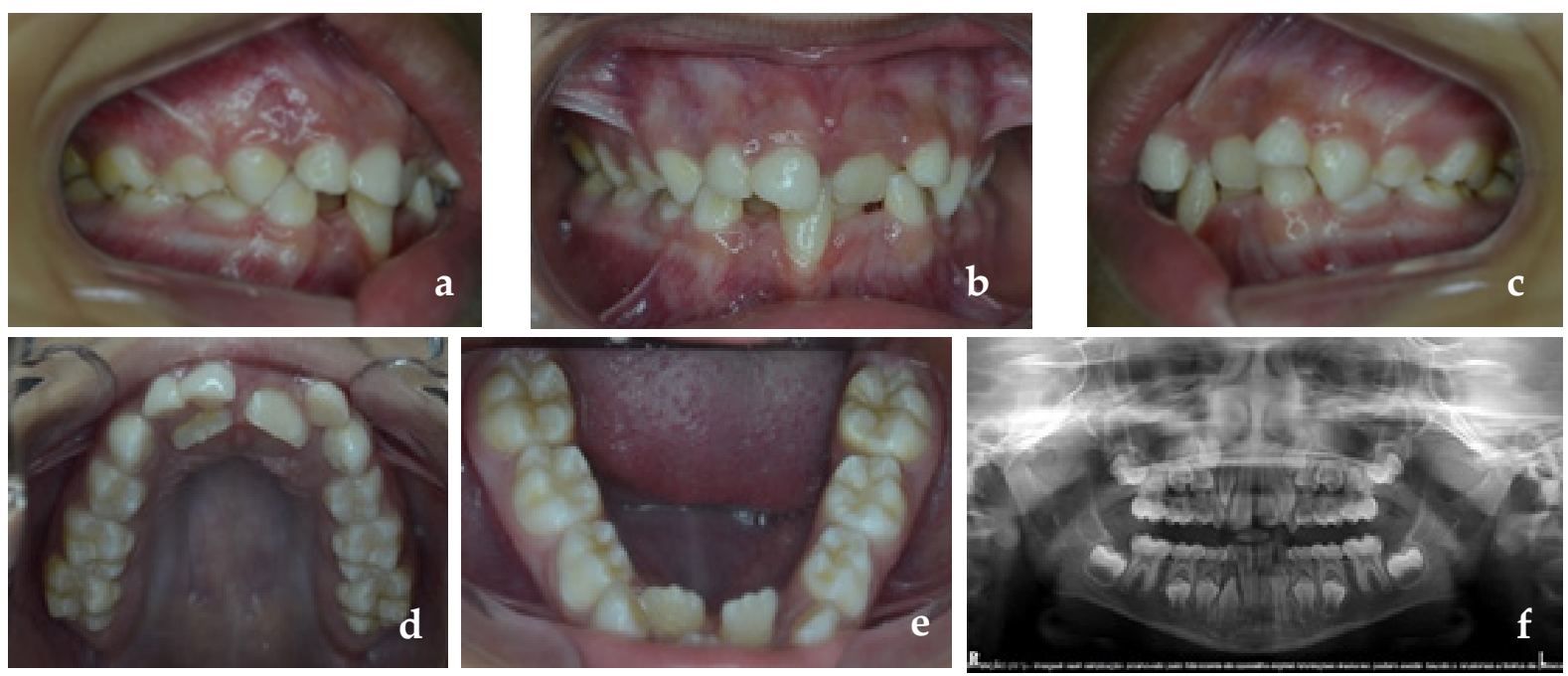

Figura 3. Mordida cruzada anterior dental, hay una relación de clase I posterior y cruce dental de los incisivos centrales superiores y trauma oclusal con recesión gingival en el incisivo inferior $(a, b, c)$, atresia maxilomandibular $(d, e)$ y retención prolongada de dientes primarios $(d, f)$. 
Una vez más, es importante el monitoreo periódico con teleodontología de las expansiones realizadas por los padres (cuando se utiliza un tornillo expansor) con respecto al grado de activación, es necesario definir el tiempo para interrumpir la activación del expansor.

\section{Pseudo-clase III}

La pseudo clase III, también llamada clase III funcional o neuromuscular, se caracteriza por la presencia de la mordida cruzada anterior en función de las interferencias oclusales. ${ }^{76}$ Esta alteración se presenta como diagnóstico clínico diferencial de la Clase III esquelética, y ocurre por la discrepancia entre la intercuspidación máxima habitual (MIH) y la relación céntrica $(\mathrm{CR}){ }^{73,77}$
En el examen clínico, en la posición $\mathrm{MIH}$, existe una relación de molares y caninos en la clase III, y al posicionar al paciente en CR, la relación molar se convierte en clase I y se verificará la presencia del contacto oclusal que genera el deslizamiento mandibular al anterior. ${ }^{78}$ En estos casos, las inclinaciones linguales se encuentran generalmente en los incisivos superiores, y la presencia de desgaste en estos elementos dentales, además de inclinación vestibular en los incisivos inferiores debido a la postura mandibular. ${ }^{77}$ (Figura 4).

La pseudo clase III se presenta como factores etiológicos erupción ectópica de los incisivos superiores, ${ }^{78}$ pérdida temprana de los molares primarios superiores, alteraciones funcionales, como respiración oral y anomalías en la posición lingual, así como alteraciones neuromusculares. ${ }^{76}$
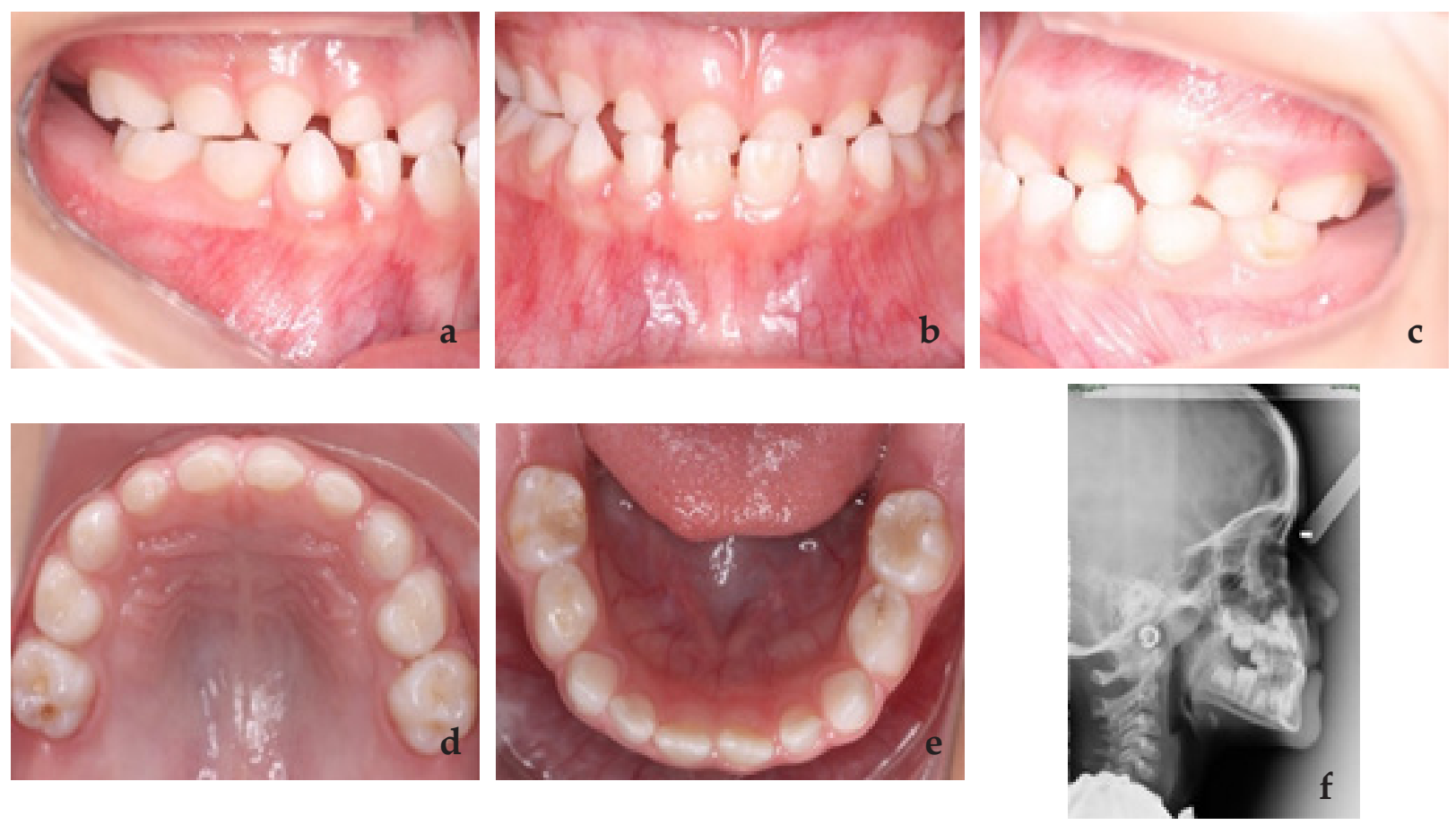

Figura 4. Pseudo classe III, escalón mesial de los segundos molares deciduos en máxima intercuspidacion $(a, c)$, mordida cruzada anterior (b), desgaste incisal de los incisivos superiores (d), inclinación vestibular de incisivos inferiores y lingual de incisivos superiores (f). 
El enfoque de ortodoncia en estos casos está relacionado con la eliminación de la interferencia oclusal y corrección de la posición incisiva, mediante el uso de dispositivos removibles como el aparato Eschler, expansores, plano inclinado de Croll, aparatos funcionales o pistas directas. Deben realizarse tan pronto como se diagnostique, ya que la persistencia de esta maloclusión puede conducir al desarrollo de la oclusión esquelética III. ${ }^{73}$, 78,79

En casos de dentición mixta, el desgaste oclusal no es una opción, ya que la interferencia es generalmente entre los incisivos permanentes.

Se recomienda implemertar la terapia individualizada requerida por el paciente, en conjunto con el seguimiento por teleodontología para definir el momento de interrupción de la activación del expansor.

\section{Clase II I esquelética}

La clase esquelética III es una maloclusión caracterizada por una relación maxilar mandibular alterada, perfil cóncavo $\mathrm{y}$, en la mayoría de los casos, presencia de mordida cruzada anterior. Puede ser producida por retrognatismo maxilar, protusión mandibular o la combinación de ambas 80 y tiene prevalencia de 3 a $26 \%{ }^{81}$ que varía entre las poblaciones de todo el mundo y con criterios diagnósticos, siendo más frecuente en los países asiáticos. ${ }^{82}$

Desde el punto de vista etiológico, la clase esquelética III puede estar relacionada con factores hereditarios ${ }^{83}$ (especialmente casos de prognatismo mandibular) y factores ambientales, como la respiración oral, alteraciones funcionales y la presencia de mordida anterior o de clase III no tratada.
Basado en la combinación de componentes óseos anteroposteriores y sagitales, el pronóstico del tratamiento puede ser más o menos favorable. ${ }^{46}$ Entre los factores de pronóstico, se puede mencionar que la mayor implicación mandibular, el crecimiento vertical de la cara y el deterioro funcional, hace más negativo el pronóstico. ${ }^{47}$

El momento de comenzar el tratamiento puede contribuir al mejor o peor pronóstico, siendo la dentición primaria y mixta el tiempo óptimo, ya que el establecimiento de la correcta relación maxilo-mandibular puede contribuir al crecimiento adecuado del crecimiento facial. ${ }^{48}$ En términos generales, cuando sólo hay afectación debido a la deficiencia maxilar leve, la intervención temprana puede ser útil. Cuando el problema es el crecimiento mandibular excesivo o deficiencias maxilares de moderadas a graves, el seguimiento para correcciones cuando haya culminado del crecimiento está más indicado.

El estándar de oro del tratamiento para la Clase III de origen maxilar es la aplicación de fuerzas ortopédicas mediante expansores fijos asociados a la máscara facial. La posibilidad de incluir protocolos con el uso de anclaje esquelético, permite ampliar el grupo de edad de corrección. ${ }^{84}$ 85

Teniendo en cuenta que la Clase III es una maloclusión que tiende a empeorar con la edad y que trae numerosos problemas estéticos y funcionales, la intervención precoz, tan pronto como el niño está maduro para la aceptación del tratamiento (Figura 5), puede contribuir en gran magnitud a un buen resultado. Valela pena destacar la importancia del seguimiento después del tratamiento periódico hasta la finalización del crecimiento facial debido 

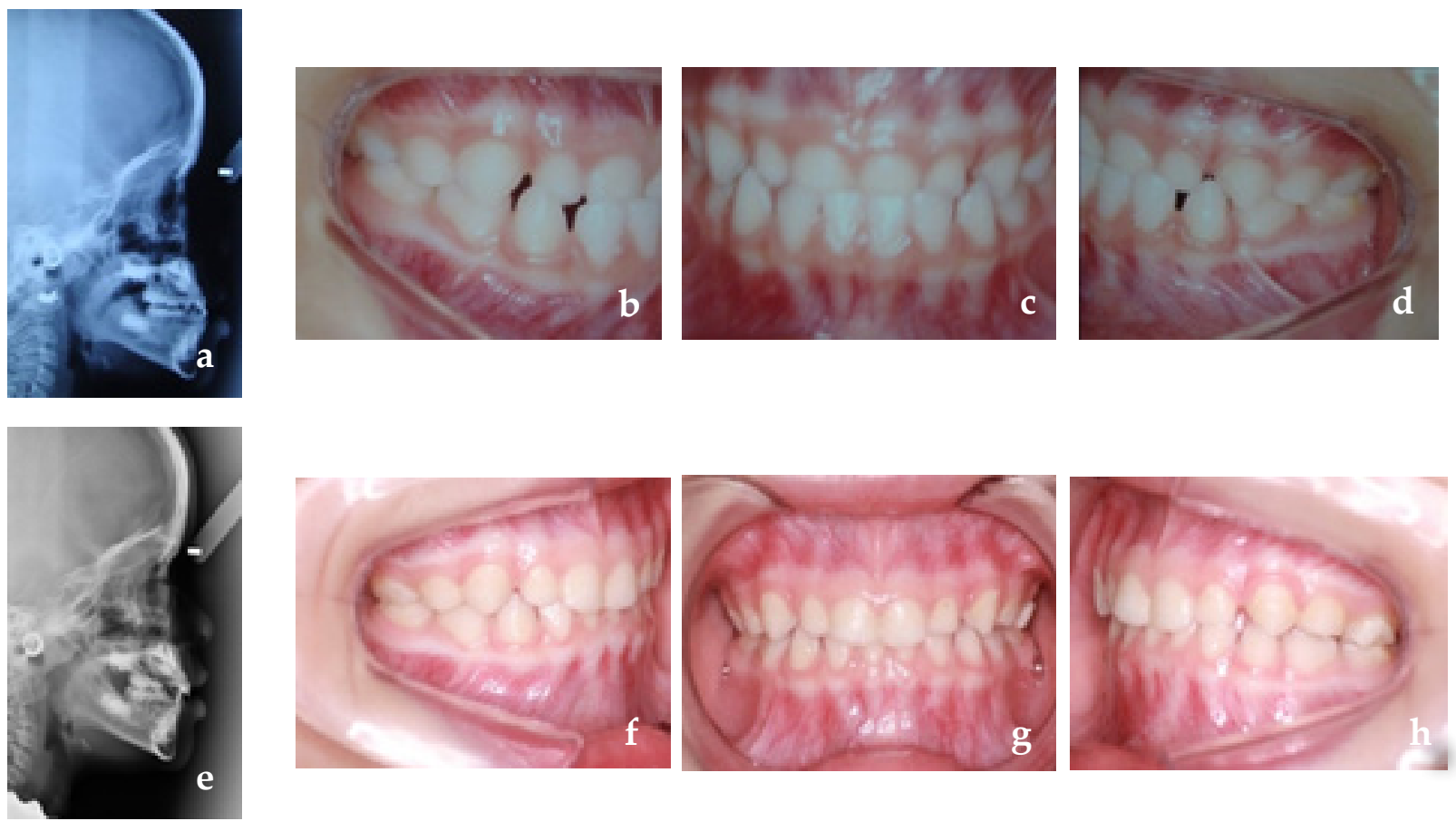

Figura 5. Clase III esquelética diagnosticada en edad temprana. Se observa retrognatismo maxilar (a), relación de mordida cruzada anterior y escalón mesial de molares y caninos $(b, c, d)$; Post tratamiento con uso de máscara facial y disyuntor maxilar, mejora en la relación maxilo-mandibular (e) corrección de mordida cruzada y relación dentaria posterior $(f, g, h)$.

a las posibilidades de recurrencia en la mordida cruzada, debido al crecimiento mandibular. ${ }^{49}$

Dado el escenario actual de la pandemia, el enfoque ortopédico de clase III se puede monitorear a través de consultas virtuales, especialmente cuando el período activo de expansión ya se ha completado y el paciente está en la fase de uso de la máscara facial. En esta etapa, se debe realizar la monitorización de overjet y se puede supervisar a intervalos mensuales.

En caso de duda, con el diagnóstico que probablemente tenga implicación mandibular sería mejor no intervenir inmediatamente, esperando para tratar el caso. Se debe considerar el riesgo de falta de un seguimiento correcto, añadido a la alta probabilidad de que la modificación esquelética no sea suficiente para evitar un tratamiento adicional.

\section{Hábitos persistentes - Mordida abierta asociada}

La literatura muestra que existe una relación consolidada entre el desarrollo de ciertas características oclusales y los hábitos alimenticios y uso de succión no nutritiva en niños. ${ }^{50-52,86} \mathrm{El}$ uso diario del chupón y el hábito de succión digital pueden estar asociados con overjet excesivo, pérdida de espacio en el arco inferior, mordida cruzada psoterior y mordida abierta anterior, afectando el desarrollo armonioso de estructuras 
orofaciales..$^{50-53}$ Algunas de estas características se pueden ver en la Figura 6.

La lactancia materna es un factor protector en la aparición de maloclusiones y los niños que experimentan lactancia materna exclusiva durante más de seis meses tienen una menor probabilidad de hábitos de succión no nutritiva. ${ }^{50,52,86}$

La mordida abierta anterior también muestra una asociación con factores sociodemográficos, como asistir a un preescolar público, tener un mayor número de residentes en el hogar, menor nivel de educación de la madre, menores ingresos familiares y edad del cuidador menor o igual a 30 años. ${ }^{53}$

Hay diferentes intervenciones que pueden contribuir a la intercepción del hábito de succión no nutritivo. Los aparatos de ortodoncia, como el arco palatino y la rejilla palatina, se puede utilizar solos o en combinación con una intervención psicológica. ${ }^{87,88}$

El uso de la rejilla palatina en pacientes en crecimiento muestra un aumento significativo en la sobremordida en comparación con los controles no tratados, independientemente del diseño del dispositivo, y este resultado se mantiene estable incluso después de unos años de seguimiento. Es el tratamiento más eficaz según los estudios disponibles en la literatura actual. ${ }^{88}$

Teniendo en cuenta el escenario de la pandemia de COVID-19, el compromiso de los padres y tutores en el proceso de eliminación del hábito de succión no nutritiva de los niños y la disponibilidad del odontopediatra responsable del caso, a través de la teleodontología, puede estar contribuyendo a factores para modificar esta condición. Además, saber que los factores psicológicos están directamente relacionados con estos hábitos, la ayuda de un psicólogo, si se trata de un niño sujeto a situaciones que despiertan algún tipo de inestabilidad emocional, es de considerable relevancia.

Dado que estos dispositivos son independientes, es decir, no hay riesgo de sobrecorrección, el uso de la misma en la
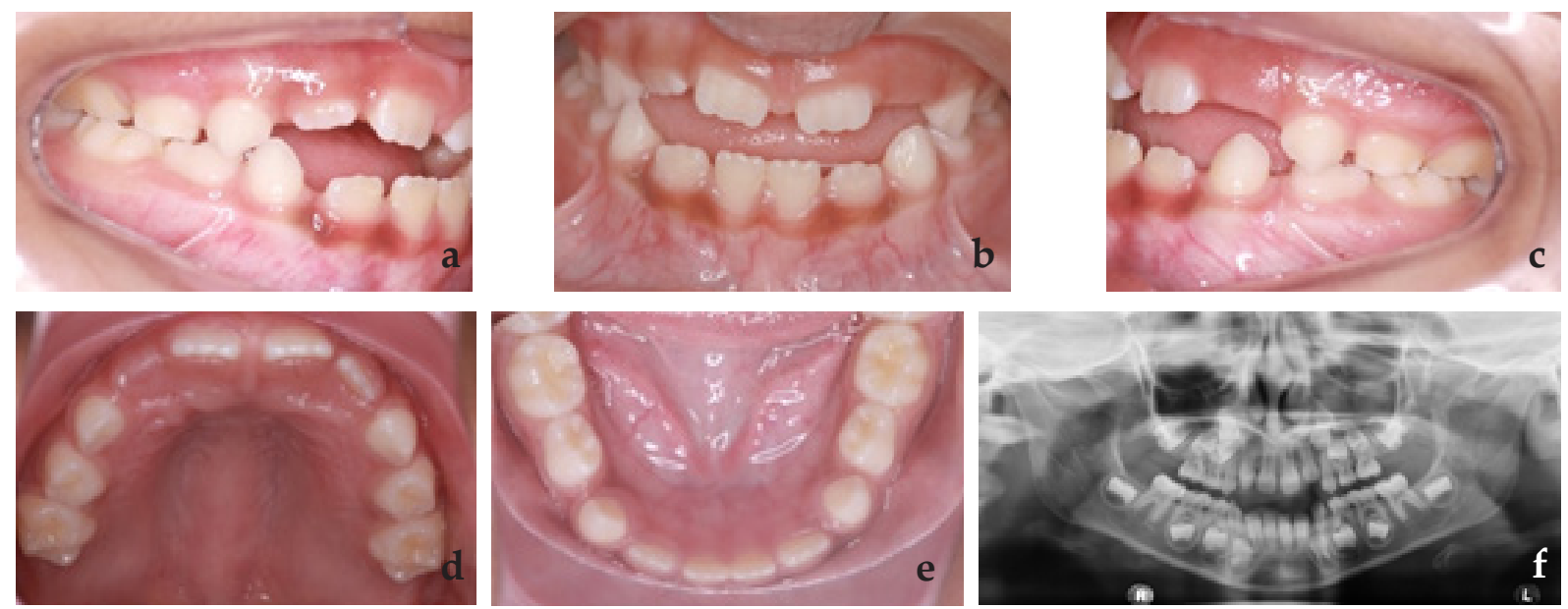

Figura 6. Mordida abierta anterior asociada a hábito de succión de chupete. 
pandemia se hace más fácil. Es probable que aunque la teleconsulta indique la corrección del hábito, la necesidad de ver al paciente y retirar el dispositivo, no sea urgente.

\section{Reducción de overjet}

Los incisivos superiores protruidos son un problema común en niños en todo el mundo, son más propensos a los traumatismos dentales y su apariencia puede causar baja autoestima y afectar la calidad de vida relacionada con salud bucal. La corrección de esta condición constituye uno de los tratamientos más frecuentes llevados a cabo por Odontopediatras y Ortodoncistas. ${ }^{37-42}$

El overjet aumentado (mayor a $4 \mathrm{~mm}$ ) puede estar relacionado con maloclusiones Clase II, que pueden cursar numerosas combinaciones de componentes dentales (protrusión de dientes incisivos superiores, hábitos, etc.) y esqueletales (deficiencia de crecimiento mandibular, crecimiento maxilar excesivo, combinación de ambos). Los factores etiológicos pueden ser hereditarios o ambientales (hábito de succión de dedos, succión de chupete, succión del labio, respiración bucal, entre otros). ${ }^{54-56}$

Las fracturas dentales son tres veces más probables de ocurrir en niños con overjet aumentado, por lo que es importante considerar su tratamiento temprano. Al mismo timepo es bueno ser conciente que un factor mas importnate que la reduccion del overjet en si es el manejo preventivo de actividades de riesgo que predisponen a imapctos directos sobre los dientes. Además se puede producir deglución atípica, falla en el sellado labial, acumulación de biopelícula dental, gingivitis y lesiones iniciales de caries dental tipo mancha blanca (ICDAS 1 y 2). Esta incapacidad de realizar el cierre labial puede resultar vergonzoso para muchos pacientes y la sociedad puede etiquetarlos como poco atractivos, haciéndolos blanco de burlas o acoso escolar (bullying) afectando su calidad de vida. ${ }^{54,56}$

Las opciones terapéuticas incluyen: ortodoncia interceptiva, ortopedia funcional $\mathrm{u}$ ortodoncia correctiva, dependiendo de la evaluación clínica, cefalométrica y funcional. ${ }^{54}$ La elección de las mecánicas para el tratamiento de este tipo de maloclusión dependerán del tipo de maloclusión, la edad del paciente, su grado de colaboración y del nivel socioeconómico del núcleo familiar. En algunos casos la simple observacion y monitoreo es una opcion razonable.

Durante el confinamiento padres/ representantes pueden buscar ayuda por el aspecto físico del niño que afecta su calidad de vida. Durante la teleconsulta se puede indagar sobre los componentes hereditarios o ambientales que pueda presentar la maloclusión. En este escenario, explicar de forma sencilla a los padres/representantes la naturaleza de la maloclusión y alertarlos sobre las probabilidades de injurias dentales en los incisivos protruidos. Durante la etapa de confinamiento se puede orientar por teleodontología al paciente y a sus representantes referente a la cesación de hábitos de parafuncionales y la reeducación miofuncional, así como reforzar los correctos hábitos de higiene oral.

Se puede recomendar el uso de protectores bucales en niños en edad escolar. Sin 
embargo, es importante destacar que el uso del protector bucal es único y exclusivo para la prevención del trauma dentoalveolar ${ }^{89}$ y que su uso no reduce la sobremordida al compararlo con la utilización de ortodoncia para corrección de la maloclusión.

Si bien los padres/representantes acuden a los especialistas con el objetivo de mejorar la calidad de vida del paciente de manera temprana, no existe contraindicación alguna de posponerlo hasta culminar la pandemia COVID- 19 o, incluso, hasta que la maloclusión pueda ser corregida en una sola fase del tratamiento, para lo cual existe un alto nivel de evidencia científica. $^{47}$

En aquellos casos donde los pacientes se encuentran en tratamiento, el especialista indicara a través de teleodontología los pasos a seguir según cada mecánica. Las placas activas removibles y los aparatos de ortopedia funcional pueden ser activados en el hogar bajo las indicaciones del especialista con sus debidos registros y consentimiento informado.

\section{Corrección de dientes con erupción ectópica o apiñamiento severo}

El apiñamiento dentario es frecuente $y$, en casos severos o con erupción ectópica, no se autocorrige. ${ }^{57,90-92}$ Puede afectar la estética del y dificultar la higiene dental del sector anterior, siendo difícil alcanzar la zona interproximal de los dientes apiñados con el cepillado y con el uso de la seda dental, por lo que la acumulación de biopelicula y cálculo podrá evolucionar en enfermedad periodontal (gingivitis) y aumentará el riesgo a caries del paciente. ${ }^{58}$
El objetivo en etapas tempranas es disminuir la discrepancia diente/arco y lograr que los dientes permanentes puedan ubicarse apropiadamente en el arco dental, siendo estos movimientos estables. Esto puede lograrse a través de terapias que aumenten el espacio disponible o que disminuyan el espacio requerido: proinclinación de incisivos mandibulares, expansión transversal de la arcada, distalización del primer molar permanente, desgaste selectivo de dientes primarios y permanentes, mantenimiento de la longitud del arco, exodoncias guiadas, exodoncias seriadas, entre otros. ${ }^{59}$

Durante el confinamiento es posible controlar los aparatos fijos (pasivos y preactivados) destinados a mantener $\mathrm{o}$ aumentar (según sea el caso) la longitud de la arcada a través de la teleodontología. De igual forma, es posible controlar las expansiones transversales de placas activas removibles siempre que los padres/ representantes sean colaboradores con el envío de fotografías y registros. En el caso de expansores fijos, es recomendable monitorear exhaustivamente o detener las activaciones por parte del paciente con el objetivo de prevenir futuras urgencias. El especialista debe hacer espacial énfasis en la higiene bucal reforzando las técnicas de cepillado y uso de seda dental para prevenir la enfermedad periodontal y caries dental. (Tabla 1)

En los pacientes que requieran exodoncias guiadas o seriadas, pueden realizarse controles de manera remota. Se debe tener precaución en el momento adecuado para el control radiográfico para prevenir erupción ectópica de los dientes permanentes. Las exodoncias pueden realizarze en una sola vista para reducir el 
riesgo de exposición del paciente. Deben mantenerse monitoreos para el control y guía de erupción, según cada paciente y, en el caso de necesitar postponer tratamiento por medidas de confinamiento, considerar el uso de aparatos que eviten pérdida de longitud del arco o erupción ectópica de los dientes permanentes. ${ }^{93}$

\section{Dientes primarios anquilosados}

La retención prolongada de los dientes primarios puede estar relacionada con múltiples factores. Aunque no tiene su etiología bien definida, se han propuesto varias teorías, como anquilosis, predisposicioón genética, la deficiencia en el crecimiento óseo alveolar, problemas metabólicos, inflamación o infección, alteración en interacción entre la resorción normal y la reparación del tejido duro que se produce en los molares primarios durante la erupción de los dientes sucesores y fallas en la erupción pasiva de los dientes. ${ }^{62}$

La anquilosis de los dientes primarios puede producir infraoclusión. Ocurre con mayor frecuencia en la mandíbula en comparación con el maxilar, y entre ellos, los molares son los dientes de este grupo con una mayor prevalencia de retención prolongada. ${ }^{62-64}$

La literatura sugiere que en los casos de anquilosis de dientes primarios, uno de los principales enfoques que se pueden adoptar es el seguimiento, ya que a menudo la exfoliación del diente ocurre espontáneamente. Si no se produce exfoliación, la extracción se convierte en una alternativa importante y necesaria.

El odontopediatra debe considerar la extracción con el mantenimiento del espacio adecuado si el sucesor permanente presenta una trayectoria de erupción alterada, que obstaculizará la resorción del primario, si el diente primario presenta un retraso considerable en la exfoliación, o si está en infraoclusión severa, con dientes adyacentes muy inclinados, que pueden causar la pérdida clínicamente significativa de la longitud del arco y dificultar la erupción del sucesor permanente. ${ }^{64}$ Un problema importante es el desarrollo de un defecto periodontal vertical grave en los casos de molares retenidos con inclinación de los dientes adyacentes en la corona en la infraoclusión.

En el escenario actual, el seguimiento de la exfoliación esperada de un diente primario anquilosado debe hacerse a través de consultas a distancia. Es pertinente que el odontopediatra conozca el período esperado de exfoliación e instruya a los padres del niño a reportar cualquier cambio. En el marco de la pandemia es poco probable que un retraso en el desarrollo de alguna acción sea crítico y esperar un tiempo prudencial para realizar tratamiento es una opción apropiada.

\section{Control del bruxismo}

El bruxismo ha sido definido como una actividad repetida de la musculatura masticatoria, caracterizada por apretar o rechinar los dientes, o apretar o impulsar la mandíbula. Por lo general es cíclico en niños. Presenta dos manifestaciones: bruxismo en vigilia y bruxismo del sueño, respondiendo a dos expresiones circadianas distintas, dependiendo del momento de ocurrencia de la actividad. 
Esta definición fue avalada por la Asociación Americana de Medicina del Sueño. ${ }^{94-95}$

De acuerdo con la evidencia, la prevalencia del bruxismo en niños presenta una gran variación, fluctuando entre un 5\% a 40\% en la población mundial, además se describe que va disminuyendo con la edad. ${ }^{60,61}$

El motivo de consulta más frecuente por parte de padres/representantes es el ruido intenso y repetido que producen sus hijos, durante el rechinamiento dentario, especialmente en la noche. Este puede producir problemas dentales y neuromusculares, entre los que seincluyen: atrición dentaria, fracturas dentales o de restauraciones, enfermedad periodontal, borrosidad de la lámina dura, hipertrofia de los músculos masticatorios, y trastornos temporomandibulares. ${ }^{60,} 61 \mathrm{La}$ severidad de los síntomas será dependiente de la duración, la frecuencia y la intensidad.

Debido a que el bruxismo es una actividad parafuncional multifactorial, su tratamiento debe ir enfocado a solucionar los factores etiológicos. Considerando la regulación central del bruxismo, los múltiples factores concomitantes, y las diferentes manifestaciones clínicas, es indiscutible que cada paciente debe ser individualmente evaluado y tratado. Los enfoques actuales se focalizan en el manejo de los síntomas y la prevención de complicaciones, siendo muy amplio el espectro de alternativas, para utilizar en forma individual o combinada. ${ }^{95}$ Una opción de tratamientoincluyeno intervenir sino educar, evitar el uso indiscriminado de aparatos para tratar el bruxismo, y más bien diferer tratamiento sólo si progresa en un Trastorno temporonmandiular.
Durante la pandemia COVID-19 se han generado cambios en las rutinas familiares, afectando a los niños ya que, para mantener el distanciamiento personal, durante el período de confinamiento las actividades escolares presenciales han sido suspendidas, los niños deben permanecer en casa y no pueden tener actividades físicas al aire libre. Sumado a esto, la ansiedad de los padres puede ser manifestada en el hogar, generando ansiedad en los niños.

Existen distintas modalidades terapéuticas para el bruxismo en niños, y en la literatura no hay un consenso único al respecto. Algunos autores señalan que entre las alternativas se encuentran: educación del paciente y la familia, estrategias dentarias (férulas oclusales en dentición primaria, ortodoncia interceptiva $u$ ortopedia funcional si hay maolcusión existente), terapias psicosociales de apoyo (cambio de hábitos y reducir el estrés y la ansiedad del paciente), quirúrgicas (para pacientes con obstrucción severa de la vía área y apnea del sueño) y farmacológicas (mejorar los niveles de estrés y ansiedad y aumentar la cantidad de horas del sueño y su calidad). ${ }^{60,61,95}$

La educación del paciente y la familia se orienta a establecer rutinas del sueño y control de otros hábitos orales diurnos tales como onicofagia, masticación de objetos y chicle. ${ }^{95}$

El diagnóstico del bruxismo puede ser realizado a través de la teleodontología. Su tratamiento dependerá de la severidad y de la edad del paciente. El especialista debe hacer una anamnesis minuciosa para determinar hábitos en la rutina del sueño que pueden ser modificados 
durante la época de confinamiento. Si al momento de la teleconsulta el especialista determina necesidad de tratamiento multidisciplinario, se puede orientar a los padres/representantes a realizar consultas a través de la telemedicina para terapias psicológicas o evaluación por parte del otorrinolaringólogo, según sea el caso.

\section{Consideraciones especiales en ortodoncia interceptiva durante la pandemia COVID-19 para la mecánica ortodóncica}

Aunque el panorama mundial se torne complicadocon respecto a los profesionales de la salud específicamente en el área de la odontología, existen maloclusiones que tienen un carácter prioritario y que no deben dejarse desatendidas, pudiendo cambiar la manera en la que se practica la ortodoncia. ${ }^{93}$

Debe considerarse que, una vez levantado el confinamiento, es posible que de producirse aumento en el número de casos se podrían volver a tomar medidas de confinamiento. Por tal razón los especialistas deben estar preparados para los efectos de la ortodoncia sin supervisión. Se debe reconsiderar el uso de cualquier mecanismo de ortodoncia que sin estricto control periódico, pueda generar efectos perjudiciales. ${ }^{93}$

La expansión maxilar aún es posible, pero bajo estrecha vigilancia, sobre todo en los casos de expansión maxilar rápida. El especialista debe instruir a los padres/ representantes, de manera clara, los objetivos del tratamientodeexpansión.Una vez que la expansión se haya completado es esencial retener los resultados logrados, y evitar que una sobreactivación puede crear una vestibularización indeseada de los molares. Por esta razón, se prefieren las mecánicas de expansión lenta, ya que son más seguras y no crean cambios abruptos en cortos períodos de tiempo, reduciendo así la posibilidad de urgencias ortodónticas. ${ }^{93}$

Los pacientes que usen aparatos funcionales removibles pueden ser monitoreados de forma remota a través de videoconferencias. Además, el uso de estos aparatos puede reducirse una vez se alcancen los objetivos de tratamiento. ${ }^{93}$

Los aparatos fijos están asociados a una alta tasa de fracturas (sobre todo en pacientes pequeños y poco colaboradores), la cual requiere un mayor número de visitas de urgencia en comparación con el uso de aparatos removibles..$^{93}$

En aquellos pacientes que entre en una fase deretenciónseprefiereeluso deretenedores removibles sobre los fijos, de forma de evitar la contaminación innecesaria con aerosoles. Es recomendable, entregar al paciente un set adicional de retenedores removibles en caso de pérdida o fractura de los mismos, sobre todo durante y ante un nuevo confinamiento por COVID-19.93

Se recomienda minimizar los procedimientos generadores de aerosoles, tales como: remoción de cemento, eliminación de materiales adhesivos, ameloplastias, micrograbado, desgastes interproximales y limpiezas con ultrasónido. Evitar el uso de la jeringa triple y reemplazar el secado con aire por secado con gasa o torundas de algodón. ${ }^{96}$

\section{Consideraciones finales}

Estas recomendaciones han sido realizadas de forma independiente $y$ voluntaria 
por los investigadores de diferentes universidades y de la Asociación Latinoamericana de Odontopediatría, con arbitraje de pares, libres de conflicto de interés.

Las presentes recomendaciones están basadas en la mayor evidencia disponible hasta la fecha siendo el COVID-19 una enfermedad emergente. Se realizarán las actualizaciones necesarias conforme al estado de la ciencia al respecto y a la evolución de la enfermedad.

El grupo de expertos responsables de la curaduría se mantiene activo y en constante monitoreo de la información publicada referente a COVID-19 para realizar las actualizaciones $y$ anexos necesarios.

\section{Autores}

Desarrollo de este artículo liderado por: Marina Tavares Costa Nóbrega (Canada), Rosa Helena Wanderley Lacerda (Brasil), Carlos Flores-Mir (Canadá), Andrea Virgina González Carfora (Chile), Luzia Ana Da Silva de Carballo (Venezuela), como parte del Equipo Interdisciplinario COVID-19 de la Asociación Latinoamericana de Odontopediatría.

Equipo Interdisciplinario COVID-19 de la Asociación Latinoamericana de Odontopediatría: Jenny Abanto (Brasil), Mariana Armada (Argentina), Paola Beltri
(España), Marisol Carrillo Tabakman (Paraguay), Haydée Casaretto (Argentina), Jorge Luis Castillo (Perú), Mónica Gladys Cesetti (Argentina), Bertha Angélica Chávez González (Perú), Ana Claudia Rodrigues Chibinski (Brasil), Salomon Alberto Cohen (Argentina), Olga Cortés Lillo (España), Luzia Ana Da Silva de Carballo (Venezuela), Gonzalo De la Fuente Alvarez (Chile), Renée Di Nallo (Argentina), María Débora Elizabeth Dricas (Argentina), Sandra Echevarria (Brasil), Piedad Cecilia Echeverry Marin (Colombia), Laura Fedelli (Argentina), Carlos Flores-MIr (Canadá), Andrea Virgina González Carfora (Chile), Lina María Hernández Salas (Colombia), Francisco José Hernández Restrepo (Colombia), Maria Teresa Ibañez Rodriguez (Bolivia), José Carlos Pettorossi Imparato (Brasil), Alejandra Lipari Valdés (Chile), Daniela Madrigal López (Costa Rica), Daniela Catalina Martínez Camus (Chile), María Gabriela Martínez Vásquez (Venezuela), A. Carolina Medina Díaz (Venezuela), Kelly Maria Silva Moreira (Brasil), Elías M. Morón (Estados Unidos de América), Martha Mutis (Estados Unidos de América), Camila Palma (Perú), Gladys Mabel Peña (Argentina), Adriana Pistochini (Argentina), Paloma Planells (España), Gabriel Politano (Brasil), Matias RiosErazo (Chile), Adriana Maria Rubiano Pinzon (Colombia), Karla Mayra Rezende (Brasil), Rosa Gabriela Rondón (Venezuela), Gabriela Scagnet (Argentina), Rosemary Sogbe de Agell (España), Marina Tavares Costa Nóbrega (Canadá), Jorgelina Valente (Argentina), Ernesto Venegas De Herrera (República Dominicana), Rosa Helena Wanderley Lacerda (Brasil), Ana Clara Zabala (Argentina), Gabriel Zambrano (Venezuela).

Información completa del Grupo Interdisciplinario COVID-19 de la Asociación Latinoamericana de Odontopediatría

\section{Referencias bibliográficas}

1. Asociación Latinoamericana de Odontopediatría. Grupo COVID-19. Ruta de atención para procedimientos de Odontología Pediátrica durante la etapa de confinamiento o cuarentena de la pandemia COVID-19. Rev Odon toped Latino. 2020; 10(2): https://www.revistaodontopediatria.org/ediciones/2020/2/art-1/.

2. Asociación Latinoamericana de Odontopediatria. Tratamiento de la enfermedad de caries en época de COVID-19: protocolos clínicos para el control de aerosoles. Rev Odontoped Latino. 2020 abril; 10(2): https://www.revistaodontopediatria.org/ediciones/2020/2/art-2/\#.

3. Asociación Latinoamericana de Odontopediatría ALOP. Modelos de Consentimiento Informado para la Atención de Urgencias en tiempos de COVID-19. [Online].; 2020. Disponible en: https://www.alopodontopediatria.org/noticias/consentimiento-informado-indicados-especialmente-atenci\%C3\%B3n-emergencias-odontologicas/. 
4. Lu R, Zhao X, Li J, Niu P, Yang B, Wu H. Genomic characterisation and epidemiology of 2019 novel coronavirus: implications for virus origins and receptor binding. Lancet. 2020; 395.

5. Yang Y, Peng F, Wang R, Guan K, Jiang T, Xu G, et al. The Deadly Coronaviruses: The 2003 SARS Pandemic and the 2020 Novel Coronavirus Epidemic in China. J Autoimmun. 2020; 109.

6. Guo Y, Cao Q, Hong Z, Tan Y, Chen S, Jin H, et al. The origin, transmission and clinical therapies on coronavirus disease 2019 (COVID-19) outbreak- A n update on the status. Mil Med Res. 2020; 7(1): 1-10.

7. Zhang W, Du R, Li B, Zheng X, Yang X, Hu B, et al. Molecular and serological investigation of 2019-nCoV infected patients: implication of multiple shedding routes. Emerg Microbes Infect. 2020; 9(1): 386-9.

8. Zhpu P, Yang X, Wang X, Hu B, Zhang L, Zhang W, et al. A pneumonia outbreak associated with a new coronavirus of probable bat origin. Nature. 2020; 579(7798): 270-273.

9. Liu M, Cheng S, Xu K, Yang Y, Cheng S, Xiao H, et al. Use of personal protective equipment against coronavirus disease 2019 by healthcare professionals in Wuhan, China: cross sectional study. J Hosp Infect. 2020; 105: m2195.

10. Ge Z, Yang L, Xia J, Fu X, Zhang Y. Possible aerosol transmission of COVID-19 and special precautions in dentistry. J Zhejiang Univ Sci B. 2020; 21(5): 361-368.

11. Suri S, Vandersluis Y, Kochhar A, Bhasin R, Abdallah M. Clinical Orthodontic Management During the COVID-19 Pandemic. Angle Orthod. 2020; 10.2319: 033120-236.

12. Turkistani KA. Precautions and recommendations for orthodontic settings during the COVID-19 outbreak: A review. Am J Orthod Dentofacial Orthop. 2020.

13. Matus $C$, Nemeth $M$, Inostroza M. Atención de Pacientes en Tratamiento de Ortodoncia Durante la Pandemia COVID-19 (SARS-CoV-2). Presentación de un Algoritmo. Int J Odontostomat. 2020; 14(4): 489-494.

14. Caprioglio A, Pizzetti G, Zecca P, Fastuca R, Maino G, Nanda R. Management of orthodontic emergencies during 2019-NCOV. Prog Orthod. 2020; 21.

15. Royal College Of Surgeons of England. Recommendations for Orthodontics during COVID-19 pandemic. [Online].; 2020. Disponible en: file:///C:/Users/nebn8/Downloads/Orthodontics\%20COVID19.pdf.

16. Asociación Latinoamericana de Odontopediatría. Teleodontología: Aplicación a la Odontopediatría durante la pandemia COVID-19. Rev Odontoped Latino. 2020; 10(2).

17. Kravitz ND, Burris B, Mayordomo D, Dabney CW. Teledentistry Ortodoncia de bricolaje y Monitoreo de tratamiento remoto. J Clin Orthod. 2016; 50: 718-726.

18. Asociación Latinoamericana de Odontopediatría. ALOP como tomar fotos bucales a los niños. [Online].; 2020 [cited 2020 julio. Disponible en: https://www.youtube.com/watch?v=CFypzRbaKwQ.

19. Saccomanno SV, Quinzi V, Sarhan S, Laganà S. Perspectives of Tele-Orthodontics in the COVID-19 Emergency and as a Future Tool in Daily Practice. Eur J Paediatr Dent. 2020; 21(2): 157-162.

20. Asociación Latinoamericana de Odontopediatría. ALOP como tomar fotos bucales a los niños. julio 11, 2020. Available at: https://www.youtube.com/watch?v=CFypzRbaKwQ. Revisado julio 2020.

21. British Orthodontic Society BOS. Patients' Home Videos Repairs. [Online].; 2020 [cited 2020 jumio. Disponible en: https://www.bos.org.uk/COVID19-BOS-Advice/Patients-Advice/Patients-Home-Videos-Repairs.

22. Asociación Latinoamericana de Odontopediatría. Estrategias Psicoconductuales e información para Odontólogos y pacientes que requieran procedimientos de Odontología Pediátrica durante la etapa de la pandemia COVID-19. Rev Odontoped Latinoam. 2020; 10(2).

23. Asociación Colombiana de Infectología. Consenso Colombiano de atención, diagnóstico y manejo de la infección por SARS-CoV-2/COVID-19 en establecimientos de atención de la salud. 2da Edición. Recomendaciones basadas en el consenso de expertos e informadas en la evidencia. Infectio. 2020; 24(3): S2.

24. Consejo General de Dentistas de España / Association Dentaire Française. COVID-19 Guía practica en base a las recomendaciones de expertos validados. [Online].; 2020.

25. Centers for Disease Control and Prevention CDC. I think or know I had COVID-19, and I had symptoms. [Online].; 2020 [cited 2020 junio. Disponible en: https://www.cdc.gov/coronavirus/2019-ncov/ifyou-are-sick/end-home-isolation.html?CDC_AA_refVal=https\%3A\%2F\%2Fwww.cdc.gov\%2Fcoronavirus\%2F2019-ncov\%2Fprevent-getting-sick\%2Fwhen-its-safe.html.

26. Lucea A. El manejo de las urgencias en ortodoncia. Ortodoncia clínica. 2003; 6(3): 159-164.

27. Dave M, Seoudi N, Coulthard P. Urgent dental care for patients during the COVID-19 pandemic. The Lancet. 2020 Abril 3; DOI:https://doi.org/10.1016/S0140-6736(20)30806-0. 
28. Mallineni SK, Innes NP, Raggio DP, Araujo MP, Robertson MD, Jayaraman J. Coronavirus Disease (COVID-19): Characteristics in children and considerations for dentists providing their care. Int J Paed Dent. 2020 abril 6;: doi: 10.1111/ipd.12653.

29. American Dental Association (ADA). Interim Guidance for Minimizing Risk of COVID-19 Transmission. [Online].; 2020 [cited 2020 abril 8. Disponible en: https://www.ada.org/ /media/CPS/Files/COVID/ADA_ COVID_Int_Guidance_Treat_Pts.pdf?utm_source=adaorg\&utm_medium=covid-resources-lp\&utm_ content=cv-pm-ebd-interim-response\&utm_campaign=covid-19?utm_source=adaorg\&utm_medium=adanews\&utm_content=cv-pm-ebd-interi.

30. Consejo General de Dentistas de España. Informe Técnico II del Consejo General de Dentistas de España: Desafíos emergentes del nuevo Coronavirus COVID-19 en la clínica dental. ; 2020.

31. Cochrane. COVID-19 Dental Services Evidence Review (CoDER) Working Group. Recommendations for the re-opening of dental services: a rapid review of international sources. [Online].; 2020 [cited 2020 Mayo 15. Disponible en: https://oralhealth.cochrane.org/sites/oralhealth.cochrane.org/files/public/uploads/covid19_dental_review_16_may_2020_update.pdf.

32. Al Nimri K, Richardson A. Interceptive orthodontics in the real world of community dentistry. Intl J Paed Dent. 2000;(10): 88-108.

33. Sunnak R, Johal A, Fleming P. Is orthodontics prior to 11 years of age evidence-based? A systematic review and meta-analysis. J Dent. 2015; 43(5): 477-86.

34. Tecco S, Baldini A, Nakas E, Primozic J. Orthodontics in Growing Patients: Clinical/Biological Evidence and Technological Advancement. Biomed Res Int. 2018 Biomed Res Int;: 10-3.

35. Fleming P. Timing orthodontic treatment: early or late? Aust Dent J. 2017; 62: 11-9.

36. Rapeepattana S, Thearmontree A, Suntornlohanakul S. Etiology of malocclusion and dominat orthodontic problems in mixed dentition: A cross-sectional study in a group pf Thai children aged 8-9 years. J Int Soc Prev Community Dent. 2019; 9(4): 383-9.

37. Seehra J, Fleming PS, Newton T, Di Biase AT. Bullying in orthodontic patients and its relationship to malocclusion, self- esteem and oral health-related quality of life. J Orthod. 2011; 38: 247-256.

38. Dutra SR, Pretti H, Martins MT, Bendo CB, Vale MP. Impact of malocclusion on the quality of life of children aged 8 to 10 years. Dental Press J Orthod. 2018; 23(2): 46-53.

39. Agou S, Locker D, Steiner DL, Tompson B. Impact of self-esteem on the oral-health-related quality of life of children with malocclusion. Am J Orthod Dentofacial Orthop. 2008; 134: 484-489.

40. Araki M, Yasuda Y, Ogawa T, Tumurkhuu T, Ganburged G, Bazar A, et al. Associations between Malocclusion and Oral Health-Related Quality of Life among Mongolian Adolescents. Int J Environ.Res Public Health. 2017; 14: 902: doi:10.3390/ijerph14080902.

41. Kragt L, Dhamo B, Wlovius EB, Ongkosuwito EM. The impact of malocclusions on oral health-related quality of life in children - a systematic review and meta-analysis. Clin Oral Invest. 2016; 20: 1881-194.

42. Batista KBSL, Thiruvenkatachari B, Harrison JE, O'Brien KD. Orthodontic treatment for prominent upper front teeth (Class II malocclusion) in children and adolescents. Cochrane Database of Systematic Reviews. 2018;: DOI: 10.1002/14651858.CD003452.pub4.

43. Maspero C, Abate A, Cavagnetto D, El Morsi M, Fama A, Farronato M. Available technologies, applications and benefits of teleorthodontics. A review of the literature and possible applications during the COVID-19 pandemic. J. Clin. Med. 2020; 9(6): E-1981.

44. ANAES. Indications de l'Orthoped'die Dento-Faciale et Dento-Maxilo-Faciale. 2002..

45. American Association of Orthonontists AAO. linical Practice Guidelines for Orthodontics and Dentofacial Orthopedics. 2008.

46. Reyes B, Baccetti T, McNamara JJ. An Estimate of Craniofacial Growth in Class III Malocclusion. Angle Orthod. 2006; 76(4): 577-84.

47. Salazar L, Pidrahita M, Alvarez E, Santamaria A, Manrique R, Oliveira O. Effect of face mask therapy on mandibular rotation considering initial and final vertical growth pattern: A longitudinal study. Clin Exp Dent Res. 2019; 5(4): 343-9.

48. Amat P. Early Treatment for Class III Malocclusions: The Facts. Orthod Fr. 2013; 84(1): 41-52.

49. Li N, Zhang W, Shi H, Zhang J. The stability of soft tissue changes in patients with skeletal Angle Class III malocclusion after orthodontic-orthognathic treatments. Shanghai J Stomatol. 2009; 18(4): 350-4.

50. Chen X, Xia B, Ge L. Effects of breast-feeding duration, bottle-feeding duration and non-nutritive sucking habits on the occlusal characteristics of primary dentition. BMC Pediatr. 2015; 15(1): 1-9.

51. Schmid K, Kugler R, Nalabothu P, Bosch C, Verna C. The effect of pacifier sucking on orofacial structures: a systematic literature review. Prog Orthod. 2018; 19(1). 
52. Ling H, Sum F, Zhang L, Wan C, Yan K, Wong H, et al. The association between nutritive, non-nutritive sucking habits and primary dental occlusion. BMC Oral Health. 2018; 18(1): 1-10.

53. Cesarino M, Babosa E, Franca M, Castro C, Martins S, Granville-Garcia A. Association between psychological factors, socio-demographic conditions, oral habits and anterior open bite in five-year-old children. Acta Odontol Scand. 2018; 76(8): 553-8.

54. Achmad M. Overjet problems at the growing child, case report using the twin block appliance. J Dentomaxillofac Sci. 2017; 2(1): 49-53.

55. Silva-Esteves J, Aliaga R, Aliaga A. Tratamiento de una maloclusión Clase II División 1 en dentición mixta. Odontol Pediatr. 2013; 12(1).

56. Cirgic E. Studies of treatment effects, cost assessment and patient perceptions - a comparison of two removable functional appliances. 2017. https://gupea.ub.gu.se/bitstream/2077/50856/1/gupea_2077_50856_1. pdf.

57. Quinzi V, Caruso S, Mummolo S, Nota A, Angelone A, Mattei A, et al. Evaluation of Lower Dental Arch Crowding and Dimension after Treatment with Lip Bumper versus Schwarz Appliance. A Prospective Pilot Study. Dent J. 2020; 8(34).

58. Indriyanti R, Hidajat S, Maskoen A, Riyanti E. Predisposing factors analysis of mandibular anterior tooth crowding in the mixed dentition period by the tooth size and dental arch width. Padjadjaran journal of dentistry. 2018; 30(3): 207-213.

59. Tokarevich I, Rublevsky D. Mandibular Incisor crowding in the mixed dentition. Advances in etiology, early diagnosis, and orthodontic treatment. Dental Science ad practice. 2014; 5(5).

60. Firmani M, Reyes M, Becerra N, Flores G, Weitzman M, Espinosa P. Bruxismo de sueño en niños y adolescentes. Rev chil pediatri. 2015; 86(5).

61. Rojas D, Teran K, Alvarez C. Bruxismo del sueño en niños: actualización de la literatura. Odontol Pediatr. 2017; 25(3): 209-216.

62. Arhakis A BE. Etiology, Diagnosis, Consequences and Treatment of Infraoccluded Primary Molars. Open Dent J. 2017; 10(1): 714-9.

63. Aktan A, Kara I, Sener I, Bereket C, Kirtay M, Ertugrul M, et al. An evaluation of factors associated with persistent primary teeth. Eur J Orthod. 2012; 34(2): 208-12.

64. Tieu L, Walker S, Major M, Flores-Mir C. Management of ankylosed primary molars with premolar successors: A systematic review. J Am Dent Assoc. 2019; 144(6): 602-11.

65. Bjoerk A KASB. A method for epidemiological registration of malocclusion. Acta Odontol Scand. 1964; 22: $27-41$.

66. Kecik D, Kocaderel I, Saatci I. Evaluation of the treatment changes of functional posterior crossbite in the mixed dentition. Am J Orthod Dentofac Orthop. 2007; 131(2): 202-15.

67. Meyers D, Baranie J, Bell R, Williamson E. Condylar position in children with functional posterior crossbites: before and after crossbite correction. Pediatr Dent. 1980; 2(3): 190-4.

68. Lippold C, Stamm T, Meyer U, Vegh A, Moiseenko T, Danehs G. Early treatment of posterior crossbite - a randomised clinical trial. Trials. 2013; 14(1): 1-10.

69. Hass A. Rapid expansion of the maxillary dental arch and nasal cavity by opening the mid-palatal suture. Angle Orthod. 1961; 31: 73-90.

70. Farronato G, Maspero C, Esposito L, Briguglio E, Giannini L. Rapid maxillary expansion in growing patients. Hyrax versus transverse sagittal maxillary expander: a cephalometric investigation. Eur J Prthod. 2011; 33(2): 185-9.

71. McNamara JJ. Maxillary transverse deficiency. Am J Orhod Dentofac Orthop. 2000; 117: 567-70.

72. Proffit W FH. Contemporary Orthodontics. 5th ed.: Mosby; 2012.

73. Rodrigues M, Rodrigues R, Pedron P, De Castro A, De Lima R, Dala J. Early treatment of Class III malocclusion: 10-year clinical follow-up. J Appl Pral Sci. 2001; 19(4): 431-9.

74. Rodrigues R. Ortodontia preventiva e interceptadora. Mito ou realidade. 1st ed.: DentalPress; 2013.

75. González Carfora AV, Teixeira VH, Medina Diaz AC. Corrección de mordida cruzada anterior de origen dental y recesión gingival en dentición mixta temprana. Reporte de caso. Rev Odontoped Latinoam. 2019;: https://www.revistaodontopediatria.org/ediciones/2019/2/art-10/.

76. Negi K, Sharma K. Treatment of pseudo Class III malocclusion by modified Hawleys appliance with inverted labial bow. J Indian Soc Pedod Prev Dent. 2011; 29(1): 57-61.

77. Di Palma E, Tepedino M, Chimenti C, Tartaglia G, Sforza C. Longitudinal effects of rapid maxillary expansion on masticatory muscles activity. J Clin Exp Dent. 2017; 9: 635-40. 
78. Pereira H, Batista J, Neto J. Anterior crossbite treatment in the primary dentition: Three case reports. Int Orthod. 2018; 16(3): 514-29.

79. Bielli L, Dela K, Marcantonio E, Lunardi N, Isper A. Correção da mordida cruzada anterior funcional com terapia de pistas diretas de planas- relato de caso. Rev Faculdade Odontol Lins. 2012; 22(2): 45-50.

80. Jaradat M. An Overview of Class III Malocclusion (Prevalence, Etiology and Management). Br J Med Res. 2018; 25(7): 1-13.

81. Alhammadi M, Halboub E, Fayed M, Labib A, El-Saaidi C. Global distribution of malocclusion traits: A systematic review. Dental Press J Orthod. 2018; 23(6): 1-10.

82. Ngan P, Moon W. Evolution of Class III treatment in orthodontics. Am J Orthod Dentofac Orthop. Am J Orthod Dentofac Orthop. 2015; 148(1): 22-36.

83. Vieira A. Orthodontics and Genetics. Dental Press J Orthod. 2019; 24(2): 92-7.

84. Muthukumar K, Vijaykumar N, Sainath M. Management of skeletal Class III malocclusion with face mask therapy and comprehensive orthodontic treatment. Contemp Clin Dent. 2016; 7(1): 98-102.

85. Moon W. Class III treatment by combining facemask (FM) and maxillary skeletal expander (MSE). Semin Orthod. 2018; 24(1).

86. Abreu E, Coelho C, Gomes L, Costa C, Seabra M, Balbinot J, et al. Breastfeeding Versus Bottle Feeding on Malocclusion in Children: A Meta-Analysis Study. J Hum Lact. 2018; 34(4): 768-88.

87. Borrie F, Bearn D, Innes N, Iheozor-Ejiofor Z. Interventions for the cessation of non-nutritive sucking habits in children. Cochrane Database Syst Rev. 2015; 2015(3).

88. Neuppmann M, Guimaraes L, Martins N, Rodrigues M, Flores-Mirs C. Effectiveness of open bite correction when managing deleterious oral habits in growing children and adolescents: A systematic review and meta-analysis. Eur J Orthod. 2017; 39(1): 31-42.

89. Brierley C, DiBiase A, Sandler P. Early Class II treatment. Australian Dental Journal. 2017; 62(1 Suppl): 4-10.

90. Ocampo A, Parra N, Botero M. Guía de erupción y extracción seriada: una mirada desde el desarrollo de oclusión. Rev Nac Odontol. 2013; 9(edición especial): 25-35.

91. M R. Tratamiento precoz del apiñamiento dental en dentición mixta: procedimientos de intervención no habituales sin tocar los dientes permanentes. Rev Esp Ortod. 2003; 33: 203-14.

92. Santiesteban F, Gutiérrez M, Gutiérrez J. Crowding severity associated with dental mass. Revista mexicana de ortodoncia. 2016; 4(3): e163-e165.

93. Srirengalakshmi M, Venupagal A, Pangilinan P, Manzano P, Arnold J, Ludwig B, et al. Orthodontics in the COVID-19 Era: The Way Forward. Part 2 Orthodontic Treatment Considerations. J Clin Orthod. 2020; 54(6).

94. Bertrand P, Black D, Carlson C. American Academy of Orofacial Pain Guidelines for Assessment, Diagnosis, and Management. Quintesence Publ Co. 2008; 22: 190-200.

95. Hermida M, Cortese S, Kalil S, Ferreira R, Spatakis L. Tratamiento del bruxismo del sueño en niños. Rev Odontop Latino. 2020; 10(1).

96. Park J, Kim J, Kai A, Rogowski L, Liu A. Journal of Clinical Orthodontics. [Online].; 2020 [cited 2020 Julio 11. Disponible en: https://www.jco-online.com/covid19-resources/post-covid-19-clinical-and-management-guidelines-for-orthodontic-practices/.

Recibido: 10/06/2020

Aceptado: 30/06/2020

Correspondencia: e-mail: editor@revistaodontopediatria.org 


\section{Ortodontia interceptiva durante a pandemia de Covid-19: emergências e tratamentos prioritários.}

\section{Introdução}

Até o momento, as diferentes organizações internacionais e locais de saúde publicaram recomendações, regulamentos e protocolos para atendimento odontológico durante a pandemia do COVID-19, ajustados aos diferentes estágios da pandemia.

Devido à natureza sem precedentes dessa pandemia e a rápida evolução do COVID-19, a suspensão temporária de exames periódicos, como no caso da ortodontia, é um processo longo e contínuo, cujas informações disponíveis sobre o gerenciamento da ortodontia interceptiva durante a pandemia são limitadas. Surge a necessidade de gerar informações científicas disponíveis e que possam orientar o odontopediatra no atendimento ao paciente.

A Associação Latino-Americana de Odontopediatria, em sua missão de apoiar e trazer as melhores informações disponíveis para todos os colegas latinos, publicou guias práticos e documentos de suporte fáceis de usar e compartilhar com toda a equipe odontológica que trabalha em ambientes hospitalares, clínicas governamentais, instituições clínicas educacionais e privadas, que prestam atendimento a crianças, adolescentes e pacientes com deficiência. ${ }^{1,2,3}$

O objetivo deste documento é fornecer diretrizes no tratamento de pacientes com tratamentos ortodônticos interceptivos durante o período pandêmico COVID-19, usando a literatura disponível e a opinião dos especialistas.

O tratamento de más oclusões em pacientes pediátricos por meio da Ortodontia Interceptiva, incluindo diferentes abordagens terapêuticas da ortopedia dentofacial, com dispositivos fixos e removíveis, ortopedia maxilar intraoral e extraoral e funcional, tem sido amplamente apoiado na literatura. Muitos pacientes pediátricos carregam dispositivos ou precisam de terapia de curto prazo, situações que requerem planejamento de tratamento de acordo com o estágio da pandemia em que cada localidade se encontra.

A Ortodontia Interceptiva requer proximidade entre o dentista e o paciente e evita o distanciamento social recomendado. Somado a isso, a maioria dos pacientes que fazem tratamento ortodôntico são crianças, relatadas em vários estudos como portadoras assintomáticas, aumentando o risco de contágio. Entre as possíveis fontes de contaminação, destacam-se: saliva do paciente, aerossóis gerados e materiais e instrumentos utilizados. ${ }^{4}$

Embora os procedimentos ortodônticos sejam geralmente considerados opcionais, há situações em que são necessários. Assim, este documento procura definir o termo de emergências ortodônticas durante o confinamento COVID-19, determinando 
quais situações podem ser gerenciadas em casa por teleodontologia e quais requerem assistência pessoalmente em uma consulta odontológica. Da mesma forma, descreve as más oclusões que requerem tratamento prioritário após o confinamento com COVID-19 e faça algumas recomendações terapêuticas, com base em diferentes níveis de evidência, para o estágio inicial da dentição primária ou mista.

As recomendações propostas abaixo estão ligadas à situação excepcional de uma pandemia e podem diferir das práticas clínicas normais. Eles não constituem um protocolo clínico exaustivo de todos os tratamentos possíveis, mas um guia de orientação, sem substituir os regulamentos locais, protocolos específicos ou as leis em vigor em cada país e estão sujeitos a evolução e mudança dependendo da situação de saúde. Orientamos os profissionais a acompanhar as atualizações.

\section{Ortodontia interceptiva no âmbito da pandemia COVID-19}

A definição de coronavírus inclui uma variedade de vírus que afetam as vias aéreas. ${ }^{5}$ Em 9 de janeiro de 2020, a Organização Mundial de Saúde declarou a descoberta de um novo coronavírus, chamado SARS-CoV-2, que nunca havia sido identificado em seres humanos. Posteriormente, em 11 de fevereiro, a doença respiratória derivada da infecção por SARS-CoV-2 foi denominada COVID-19. ${ }^{6}$

O SARS-CoV-2 pode ser encontrado em secreções humanas como: sangue, saliva e fezes. Portanto, é capaz de ser transmitido por contato direto com um indivíduo infectado, bem como por gotas ou secreções produzidas pelo mesmo indivíduo. ${ }^{7,8,9}$

Vários estudos relataram a transmissão cruzada de COVID-19 entre profissionais de saúde. ${ }^{10} \mathrm{~A}$ doença pode ser transmitida de um profissional de saúde para outro, de um profissional de saúde para um paciente ou de paciente para paciente com a mesma facilidade. ${ }^{11}$

Todos que frequentam um consultório odontológico são expostos diretamente à transmissibilidade desse vírus em suas diferentes rotas. Portanto, os dentistas devem estar cientes das evidências disponíveis para proporcionar um ambiente seguro para si, sua equipe, seus pacientes e suas famílias. ${ }^{1-4,12}$

Dada a forte recomendação de confinamento durante a pandemia do COVID-19, a odontologia limitou-se apenas aos cuidados de emergência. É sabido que a ortodontia pode gerar desconforto no paciente e que também pode ocorrer em algumas ocasiões; lesões nas mucosas bucais, perda ou fratura de acessórios, perda de contenções ortodônticas, entre outros. Essas desvantagens do tratamento geram ansiedade no paciente e em seus parentes e envolvem uma visita extra ao consultório odontológico.

Para planejar o atendimento de pacientes na pandemia, primeiramente é necessário classificá-lo (risco alto ou baixo), identificar o tratamento a ser realizado (urgência que requer consulta presencial no consultório) e avaliar o momento (tempo) em que surge a urgência. Estes últimos podem ser classificados em: cuidados durante 
o confinamento e após o estágio de confinamento. ${ }^{13}$

Durante o período de confinamento (quarentena), recomenda-se adiar qualquer consulta de rotina e restringir o tratamento a casos de emergência, que não podem ser resolvidos remotamente pelo paciente, seguindo as diretrizes da OMS e das autoridades locais. ${ }^{13}$

Uma vez concluído o confinamento, mesmo em um período de pandemia ou desaceleração, os protocolos de biossegurança e as recomendações de cuidados devem ser seguidas. Essa condiçãoexigiráumaorganizaçãodiferente por vários meses e o gerenciamento remoto do paciente poderá ser realizado com eficiência usando plataformas de teleodontologia para oferecer assistência em saúde. ${ }^{14}$

\section{Teleodontologia}

A melhor maneira de lidar com emergências ortodônticas interceptivas é seguir uma sequência ordenada passo a passo.

Com essa experiência, a teleodontologia tem sido usada como uma ferramenta para obter contato direto e rápido entre o paciente e o dentista em tratamento, conseguindo transmitir instruções simples que podem apoiar os pacientes e ajudar a resolver qualquer emergência. ${ }^{15}$ Infelizmente, durante o confinamento, as situações de emergência persistem e é importante que o dentista saiba como essas emergências podem ser avaliadas e tratadas sem a presença física do paciente e do núcleo familiar na consulta.

Considerando que, após o confinamento, haverá um aumento no número de pacientes que necessitam de atendimento odontológico, optou-se por expor as más oclusões que devem ser priorizadas nessa fase, uma vez que o crescimento e desenvolvimento imediato do paciente dependerão de seu tratamento imediato.

Vários estudos descreveram a teleodontologia como uma ferramenta eficaz que permite manter o controle do tratamento em situações nas quais o paciente não pode ir à clínica. ${ }^{16}$

Contrin et al., ${ }^{17}$ realizaram um estudo sobre o nível de ansiedade e preocupação dos pacientes ortodônticos brasileiros em relação à pandemia de COVID-19 e o impacto desse período nas consultas e tratamento. Observou-se que $60 \%$ dos pacientes estudados estão dispostos a ir a uma consulta ortodôntica durante a pandemia, apresentando atraso no tratamento como principal preocupação. $\mathrm{O}$ nível médio de ansiedade relacionado ao impacto da pandemia no tratamento ortodôntico foi de 4,04, sendo 0 sem ansiedade e 10 sendo extrema ansiedade.

O monitoramento rotineiro da teleodontologia dependerá da situação clínica a ser avaliada, o controle de retenção geralmente exige uma imagem a cada um ou dois meses e o tratamento ativo de uma ou duas fotos por semana.

O primeiro passo deve sempre ser a assistência virtual, e o WhatsApp ou software similar pode ser considerado uma boa ferramenta para fazer isso. A assistência virtual pode ser feita através do uso de fotos, vídeos ou videochamadas. ${ }^{14}$

O segundo passo, é recomendável realizar uma triagem remota por telefone, videochamada, e-mail ou outras 
modalidades on-line, entre o paciente ou seus pais. O problema será identificado e determinará se é uma emergência ou não, e identificar se justifica uma consulta presencial ou há viabilidade de fornecer suporte para o gerenciamento do paciente em casa. ${ }^{16,18}$

Para aumentar a participação de crianças e melhorar a comunicação, os emojis podem ser usados. $^{18}$ Amplamente utilizado em psicologia e medicina para identificar o grau de dor ou medir os níveis de ansiedade, entre outros. $\mathrm{O}$ uso de emojis nos serviços de mensagens instantâneas e nos chats de aplicativos é útil para facilitar a comunicação com os pacientes.

Os recursos audiovisuais podem ser uma fonte de apoio para os odontopediatras para seus pacientes e pais/responsáveis, que podem ser facilmente distribuídos por meio de mensagens instantâneas. Com isso, é possível antecipar as situações que o paciente experimentará na consulta durante o estágio de confinamento do COVID-19, o que facilitará a adaptação à consulta. Este material de suporte foi desenvolvido pela Associação Latino-Americana de Odontopediatria $^{19}$ e está disponível no link: https://www.revistaodontopediatria. o r g / e d i c i o n e s / $2020 / 2$ / a r t 5/\#art1\%23anexos-es

Da mesma forma, oespecialista podecontar com recursos audiovisuais disponíveis nos sites das associações ortodônticas assim que determinar que a emergência pode ser resolvida em casa. ${ }^{12}$ Os auxílios audiovisuais podem ser convertidos em material de apoio para várias situações de emergência ortodôntica, através das quais o especialista poderá explicar o procedimento de maneira mais simples, tornando a comunicação muito mais eficaz, proporcionando segurança e confiança aos pais/responsáveis ao realizar o procedimento e reduzir o medo e a ansiedade, familiarizando-se com o procedimento a ser realizado. Estes estão disponíveis em: https://www.bos.org.uk/ COVID19-BOS-Advice/Patients-Advice/ Patients-Home-Videos-Repairs. ${ }^{20}$

O terceiro passo, solicitando o consentimento informado para autorizar esta modalidade de tratamento, sob o esquema de consulta presencial. 3, 15, 18 $\mathrm{O}$ odontopediatra deve orientar os pacientes sobre como lidar com emergências em casa e registrar todos os conselhos indicados. ${ }^{12}$

Posteriormente, se for confirmado que a emergência ortodôntica deve ser atendida pessoalmente, um questionário deve ser enviado ao paciente que deve responder sim ou não, a uma série de perguntas sobre seus sinais e sintomas nos últimos 14 dias.

Se o paciente responder positivamente a uma ou mais perguntas e for classificado como paciente de alto risco, a opção de adiar o atendimento e fornecer suporte virtual deve ser avaliada e, se isso não for possível, o atendimento sob um protocolo rigoroso com a incorporação de medidas adicionais é recomendado. ${ }^{21,22}$ Entre eles, a admissão imediata ao consultório, sendo atendida com a porta fechada e sem a presença de outros pacientes ao mesmo tempo, resolvendo estritamente a emergência, evitando o uso de aerossóis e medidas espaciais de biossegurança.

Para pacientes com histórico de COVID-19, é recomendado que os pacientes sejam liberados do isolamento domiciliar quando se passaram pelo menos 72 horas desde a recuperação (resolução da febre 
sem o uso de medicamentos para sua redução e melhora da sintomatologia). ${ }^{12}$

Se exames radiográficos forem necessários, radiografias odontológicas extraorais, como radiografia panorâmica e tomografia, são alternativas apropriadas durante o COVID-19.

\section{Emergências dentárias em ortodontia interceptiva}

Uma emergência ortodôntica pode ser descrita como um problema que surge de um aparelho ortodôntico no qual é necessária uma visita não programada para resolver o problema, ${ }^{14}$ que pode estar associado a um desconforto físico grave (irritação da mucosa, lábios e língua), processo infeccioso, alteração psíquica (deterioração estética grave) de um paciente em tratamento e por ação forçada nos dentes ou maxilares que podem ter sérias consequências para a conclusão da terapia ortodôntica. ${ }^{23}$ Em uma emergência, o paciente deve entrar em contato com clínica por telefone ou por teleodontologia, para discutir várias maneiras de resolver o problema em casa. Quase todas as emergências ortodônticas podem ser gerenciadas através do aconselhamento apropriado por um profissional de saúde qualificado.

Os problemas ortodônticos mais comuns, como: bráquete ou tubos descolados e aparelhos removíveis ou contenções perdidos ou fraturados, podem inicialmente ser gerenciados remotamente por meio de uma chamada ou consulta por vídeo. ${ }^{24}$ Dessa maneira, é dada ênfase especial ao uso da teleodontologia, para alcançar o melhor diagnóstico possível por meio da triagem e, assim, ser capaz de determinar se a orientação do paciente/ responsável é viável para solucionar a emergência. ou se há necessidade de cuidados no consultório odontológico. ${ }^{15}$

No caso de emergências ortodônticas, o especialista deve primeiro tentar gerenciar a emergência por telefone ou remotamente. Um consentimento dado por meio de conversa ao telefone ou eletronicamente deve ser obtido para fornecer orientações dessa maneira. O especialista deve registrar todos as orientações dadas para manter registros da evolução do tratamento, como seria feito regularmente. ${ }^{12,15}$

Quando o profissional utiliza telecomunicações, o histórico de saúde do paciente deve ser obtido para coletar sintomas ou histórico relevante para o COVID-19. Caso o paciente deva ser visto pessoalmente, o histórico médico também permitiráaoespecialistaavaliarospossíveis riscos de transmissão e garantir que o consultório clínico esteja adequadamente equipado com Equipamento de Proteção Individual (EPI). A seguir, é apresentado um fluxograma para o atendimento de pacientes com emergências ortodônticas durante a pandemia de COVID-19 (Figura 1).

\section{Categorização e gerenciamento de emergências em ortodontia}

Uma vez realizada a teleconsulta e a triagem, a situação de emergência que requer cuidados presenciais pode ser identificada e priorizada usando o critério de urgência.

As emergências ortodônticas podem ser classificadas de acordo com o tipo de dispositivo utilizado pelo paciente, 


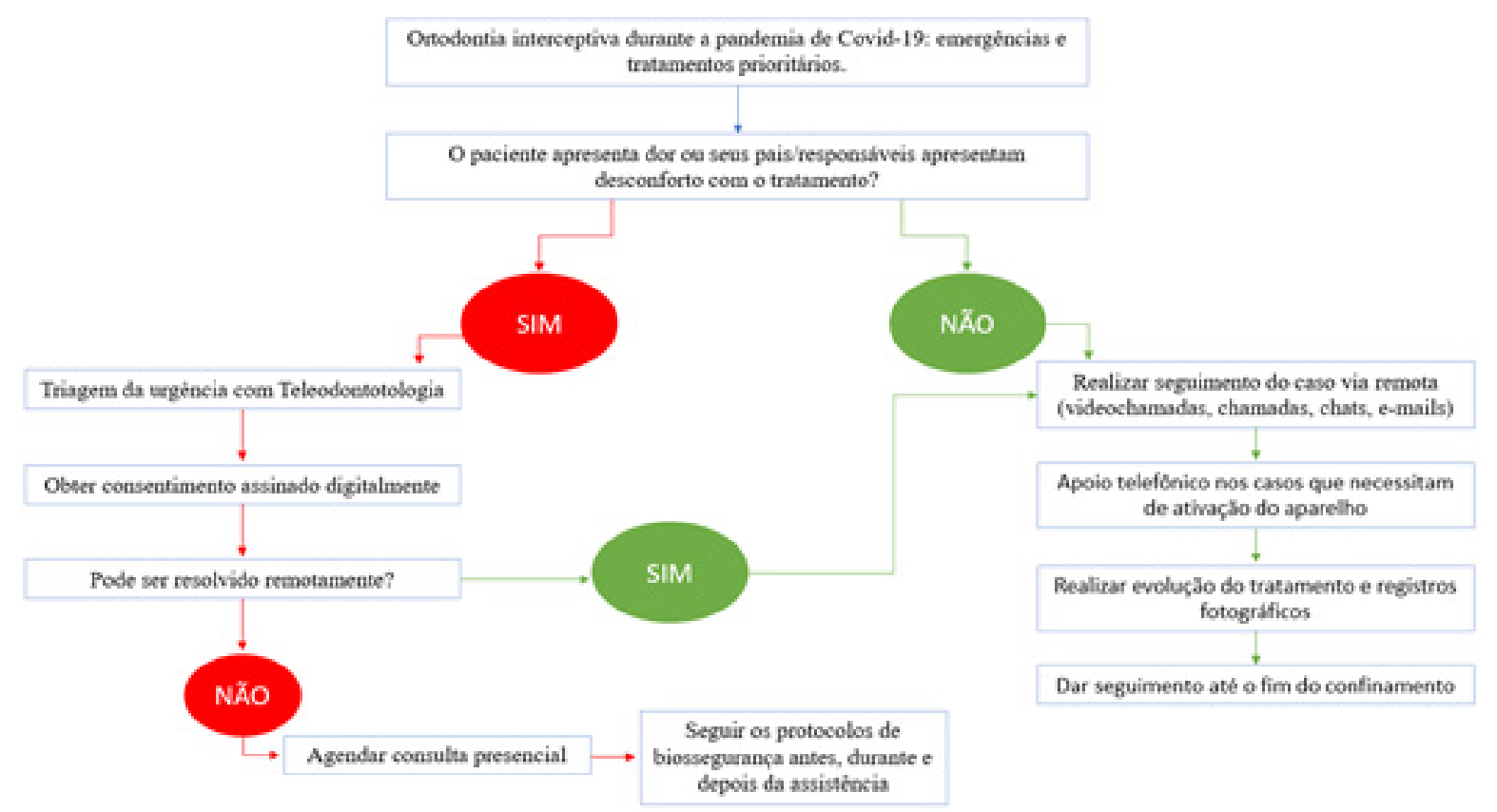

Figura 1: Fluxograma do atendimento de emergências em ortodontia interceptiva durante a pandemia do COVID-19 4, 12, 13.

que pode ser: fixo ou removível. ${ }^{14}$ Como mencionado acima, a maioria dessas emergências pode ser resolvida em casa por meio do conselho fornecido pelo especialista remotamente durante o confinamento. O especialista também pode fornecer a seus pacientes e representantes links para informações relacionadas a como resolver a emergência por meio de recursos audiovisuais que podem estar disponíveis nos sites de associações ortodônticas profissionais. ${ }^{12}$

Algumas das emergências que exigem agendamento de uma visita à clínica odontológica são destacadas abaixo. 12, 13, 14, 24

- Dor intensa, desconforto ou trauma intraoral significativo de um arco/fio afiado associado a um aparelho fixo ou retentor associado onde a aplicação de cera falhou em proporcionar alívio.

- Banda, bráquete ou tubo quebrado de um aparelho fixo que se soltou e, portanto, existe a possibilidade de inalação de um corpo estranho.

- Desajuste parcial de uma banda ortodôntica/ TPA / quadrihélice / RME / lingual que não pode ser recolocada.

- Traumatismo dentoalveolar em pacientes com aparelhos ortodônticos.

- Abscessos ou processos infecciosos associados a aparelhos ortodônticos.

- Complicações de procedimentos cirúrgicos recentes relacionados ao tratamento ortodôntico.

- Dor intensa ou desconforto, nas quais a aplicação de cera ou o uso de analgésicos não proporcionou alívio.

- Tração de dentes ectópicos ou retidos, com risco de anquilose, erupção excessiva ou deslocamento.

- Outro problema muito frequente, especialmente durante os estágios iniciais de nivelamento, quando 
realizado com ortodontia fixa, é a protrusão de fio nas extremidades distais, nos quais eles podem causar trauma e úlceras nos tecidos moles.

$\mathrm{O}$ tratamento de emergência durante o período de confinamento deve limitar-se a cortar e apertar os fios causadores de trauma ou a simples remoção de qualquer componente solto do aparelho. Se o paciente quebrar o dispositivo removível ativo ou sentir desconforto significativo ao usá-lo, é recomendável suspender o uso do dispositivo por enquanto, a fim de reduzir emergências.

Se o paciente sentir dor, vermelhidão ou edema próximo a um aparelho ortodôntico fixo, deve-se descartar que se trata de um abscesso periodontal, sugerindo uma consulta pessoal para eliminar a causa, por exemplo, uma banda sob a gengiva.
As Tabelas 1, 2 e 3 apresentam algumas das emergências mais comuns que podem surgir durante o confinamento e suas várias opções de aconselhamento que podem ser dadas pelo especialista para serem resolvidas em casa. ${ }^{12,14,25}$

\section{Biosegurança}

Ao prestar atendimento odontológico ao paciente no consultório, todas as medidas de biossegurança recomendadas pelos órgãos de saúde devem ser rigorosamente seguidas, com o mais alto nível de proteção pessoal, desinfecção de superfície, ventilação adequada e descontaminação

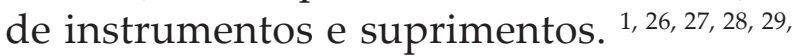
$30,31,32,33,34,35$

A minimização da produção de aerossóis é enfatizada e só deve ser usada quando

Tabela 1: Orientação para emergências ortodônticas em pacientes com aparelhos fixos durante a pandemia de COVID-19. 12, 14,25

\begin{tabular}{l|l}
$\begin{array}{l}\text { Urgência ortodôntica em pacientes com } \\
\text { aparelhos fixos: expansores, arcos linguais/ } \\
\text { transpalatinos, placas labio-ativas, etc. }\end{array}$ & $\begin{array}{l}\text { Orientação durante o confinamento devido ao } \\
\text { COVID-19 }\end{array}$ \\
$\begin{array}{l}\text { Dispositivos fixos ativados pelo paciente } \\
\text { (expansores maxilares, máscaras faciais, } \\
\text { etc.). }\end{array}$ & $\begin{array}{l}\text { Suspenda ativações para evitar emergências } \\
\text { futuras. }\end{array}$ \\
\hline $\begin{array}{l}\text { Dispositivos fixos pré-ativados (barras } \\
\text { transpalatinas, etc.) }\end{array}$ & $\begin{array}{l}\text { Tire fotos a cada 20-40 dias. Se o paciente sentir } \\
\text { dor ou inflamação, isso deve ser visto na consulta } \\
\text { como uma emergência e o dispositivo deve ser } \\
\text { removido. }\end{array}$ \\
\hline $\begin{array}{l}\text { Expansor fixo ou arco lingual / palatal } \\
\text { quebrado ou frouxo. }\end{array}$ & $\begin{array}{l}\text { Solicite uma foto do paciente. } \\
\text { Se estiver parcialmente descolado e ainda } \\
\text { presente na boca, reposicione e suspenda as } \\
\text { ativaçôes até a visita com o especialista. } \\
\text { Se tiver sido completamente desajustado, } \\
\text { mantenha-o em local seguro até a visita ao } \\
\text { ortodontista ou odontopediatra. }\end{array}$ \\
\hline
\end{tabular}


Tabela 2: Aconselhamento para emergências ortodônticas em pacientes com dispositivo removível durante a pandemia de COVID-19. ${ }^{12,14,25}$

\begin{tabular}{|c|c|}
\hline $\begin{array}{l}\text { Emergência ortodôntica em } \\
\text { pacientes com aparelhos removíveis. }\end{array}$ & $\begin{array}{l}\text { Orientação durante o confinamento devido ao } \\
\text { COVID-19 }\end{array}$ \\
\hline $\begin{array}{l}\text { Interferência de um dente, durante a } \\
\text { segunda fase da dentição mista, com } \\
\text { o aparelho }\end{array}$ & $\begin{array}{l}\text { Solicite uma foto do paciente. } \\
\text { Suspenda o seu uso para evitar emergências } \\
\text { futuras. }\end{array}$ \\
\hline $\begin{array}{l}\text { Fratura ou desconforto do aparelho } \\
\text { funcional durante o uso. }\end{array}$ & $\begin{array}{l}\text { Solicite uma foto do paciente. } \\
\text { Suspenda o seu uso para evitar emergências } \\
\text { futuras. }\end{array}$ \\
\hline $\begin{array}{l}\text { Lesões da mucosa causadas por } \\
\text { partes do arco. }\end{array}$ & $\begin{array}{l}\text { Solicite uma foto do paciente. } \\
\text { Instrua os pais / responsáveis por } \\
\text { videochamada sobre como torcer o arco com } \\
\text { uma leve pressão dos dedos. } \\
\text { Se a pressão das alças na mucosa não for } \\
\text { aliviada, suspenda seu uso para evitar } \\
\text { emergências futuras. }\end{array}$ \\
\hline $\begin{array}{l}\text { Dispositivos removíveis ativados } \\
\text { pelo paciente. }\end{array}$ & $\begin{array}{l}\text { Suspenda ativações para evitar emergências } \\
\text { futuras. }\end{array}$ \\
\hline Placas ativas incompatíveis. & $\begin{array}{l}\text { Solicite uma foto do paciente. } \\
\text { Pergunte por videochamada sobre a frequência } \\
\text { de uso. } \\
\text { Instrua para fechar o parafuso e testar o ajuste } \\
\text { da placa. } \\
\text { Se a placa ativa ainda não se adaptar, suspenda } \\
\text { seu uso até a próxima consulta. }\end{array}$ \\
\hline Falta de retenção dos dispositivos. & $\begin{array}{l}\text { Solicite uma foto do paciente. } \\
\text { Suspenda o seu uso para evitar emergências } \\
\text { futuras. }\end{array}$ \\
\hline Contenções fraturadas. & $\begin{array}{l}\text { Solicite uma foto do paciente. } \\
\text { Sugira ao paciente a compra on-line de } \\
\text { elementos de contenção pré-formados, o que } \\
\text { permite remessas rápidas. } \\
\text { Quando a contenção estiver concluída, o } \\
\text { especialista fará novas impressões ou scanners. } \\
\text { No caso de ruptura ou perda de uma } \\
\text { contenção e existe o risco de recidiva que } \\
\text { compromete irreversivelmente o tratamento, o } \\
\text { cirurgião-dentista pode marcar uma consulta } \\
\text { pessoalmente o mais rápido possível. }\end{array}$ \\
\hline
\end{tabular}


Tabela 3: Aconselhamento de emergências ortodônticas em pacientes com aparelhos fixos para pequenos movimentos durante a pandemia de COVID-19. ${ }^{12,14}$

\begin{tabular}{|c|c|}
\hline $\begin{array}{l}\text { Emergência ortodôntica em } \\
\text { pacientes com aparelhos fixos } \\
\text { para pequenos movimentos }\end{array}$ & Orientação durante o confinamento devido ao COVID-19 \\
\hline $\begin{array}{l}\text { Irritação nos lábios ou bochechas } \\
\text { devido a acessórios. }\end{array}$ & $\begin{array}{l}\text { Solicite uma foto do paciente. } \\
\text { Coloque uma pequena porção de cera ortodôntica (cera de alívio) } \\
\text { sobre o acessório (braquete, ligadura, arco) que está causando } \\
\text { irritação. } \\
\text { A dor associada a lesões traumáticas pode ser aliviada com a } \\
\text { aplicação de anestesia tópica diretamente na lesão, usando um } \\
\text { cotonete. }\end{array}$ \\
\hline $\begin{array}{l}\text { Pilar ortodôntico solto / } \\
\text { desconectado (bráquete, tubo ou } \\
\text { banda). }\end{array}$ & $\begin{array}{l}\text { Solicite uma foto do paciente. } \\
\text { Se o bráquete girou em torno do arco, causando desconforto, ele } \\
\text { pode ser reposicionado com uma pinça desinfetada, girando-o } \\
\text { em torno do arco no ponto em que dois dentes entram em contato } \\
\text { para proporcionar mais espaço para manobra. } \\
\text { Se o bráquete for usado como um gancho para elásticos } \\
\text { intermaxilares, interrompa seu uso. } \\
\text { Se o bráquete descolado for o último acessório do arco, você } \\
\text { pode: deslizá-lo pelo arco e removê-lo ou cortar o arco no último } \\
\text { ponto com um bráquete anexado e removê-lo cuidadosamente da } \\
\text { boca. } \\
\text { Se uma banda ou bráquete permanecer nivelado com o dente, } \\
\text { ele poderá ser deixado em observação; se houver risco de cair } \\
\text { na cavidade oral ou lacerar a mucosa, o paciente pode tentar } \\
\text { removê-lo cuidadosamente com uma pinça de sobrancelha.. }\end{array}$ \\
\hline $\begin{array}{l}\text { Arco saliente no final do } \\
\text { bráquete / tubo. }\end{array}$ & $\begin{array}{l}\text { Solicite uma foto do paciente. } \\
\text { Aplique cera ortodôntica ou cera de alívio. } \\
\text { Use um cotonete ou uma borracha limpa para lápis para } \\
\text { empurrar o arco contra o dente. } \\
\text { Se o desconforto for causado pelo deslizamento do arco de uma } \\
\text { extremidade a outra, use um pinça de sobrancelha para mover o } \\
\text { arco para trás até que você se sinta confortável dos dois lados. } \\
\text { Se o arco for extremamente irritante, você pode cortá-lo com um } \\
\text { cortador de unhas desinfectado com extremo cuidado para não } \\
\text { engolir o segmento de corte. } \\
\text { Se o fio lacerar o tecido mole, o paciente ou profissional pode usar } \\
\text { um cortador de unhas estéril para cortá-lo se o especialista não } \\
\text { conseguir fazer a consulta presencial. }\end{array}$ \\
\hline Liberação de ligadura metálica. & $\begin{array}{l}\text { Solicite uma foto do paciente. } \\
\text { Se a ligadura de metal se soltar, remova-a com uma pinça } \\
\text { desinfectada. } \\
\text { Se a ligadura não estiver solta, mas se sobressair, poderá ser } \\
\text { dobrada com um cotonete ou uma borracha limpa para lápis. }\end{array}$ \\
\hline $\begin{array}{l}\text { Aspiração um acessório } \\
\text { ortodôntico. }\end{array}$ & $\begin{array}{l}\text { Manter a calma. Devido ao pequeno tamanho desses acessórios, } \\
\text { quando ingeridos, eles acabam passando para o trato digestivo. } \\
\text { Confirme se o paciente não apresenta problemas respiratórios } \\
\text { ou tosse ao engolir o dispositivo. Se esses sintomas ocorrerem, } \\
\text { instrua o paciente a ir ao departamento de emergência de um } \\
\text { hospital. }\end{array}$ \\
\hline
\end{tabular}


nenhuma outra opção estiver disponível. Cumpra o mais alto nível de proteção individual, desinfecção de superfícies, ventilação adequada e descontaminação de instrumentos e suprimentos. ${ }^{13}$

Com base nisso, algumas medidas para reduzir o risco de contágio incluem:

1. Mantenha o paciente ciente das recomendações das agências que regulam os serviços de saúde em geral e, mais especificamente, os serviços odontológicos. 1, 22, 26, 31

2. Comunicação ativa com o paciente, esclarecendo tudo o que pode ser feito sem a necessidade de uma visita pessoal ao consultório odontológico, podendo acessar o profissional por e-mail ou telefone para qualquer dúvida.

3. Faça uso da teleodontologia através de telefonemas ou videochamadas, em caso de emergência que possa ser evitada em casa.

4. Forneça cuidados seguros, com exames telefônicos anteriores para confirmar os sintomas negativos do COVID-19, sem contato com uma pessoa infectada e sem viajar nos últimos 14 dias.

5. Evite o uso de aerossóis, sempre com todos os equipamentos de segurança individuais e com os protocolos atualizados de desinfecção e esterilização. ${ }^{4,12}$

\section{Prioridades em ortodontia interceptiva em tempos COVID-19}

No período de confinamento, a recomendação, em muitos casos, é evitar o início de tratamentos. No entanto, diferentes países estão em diferentes estágios da pandemia. Uma vez concluído o confinamento, os casos que requerem atendimento ortodôntico prioritário devem ser considerados.

Algumas situações podem ser realmente prejudicadas pela falta de consultas presenciais, como certos cenários em que é necessária uma intervenção ortodôntica precoce, por meio de ortodontia interceptiva, e o atraso dessa ação pode ter consequências negativas. Como exemplo, há situações em que o paciente pode se beneficiar de uma melhor resposta à modificação do crescimento em indivíduos mais jovens, aproveitando um período mais longo para causar alterações esqueléticas significativas. ${ }^{36,37,38}$

A identificação precoce de certas situações oclusais contribui para reduzir a gravidade de más oclusões futuras, ${ }^{39}$ o que requer intervenção assim que são diagnosticadas. Algumas dessas condições serão descritas ao longo deste trabalho e, na medida do possível, recomendações são propostas durante a pandemia.

A Ortodontia Interceptiva engloba o tratamento de más oclusões na dentição primária e mista para o paciente em crescimento, com o objetivo de eliminar características desfavoráveis ao desenvolvimento adequado da oclusão. ${ }^{40}$ Existem evidências científicas que apoiam a abordagem de algumas más oclusões nesse estágio, para minimizar sua complexidade, promover o crescimento e o desenvolvimento adequado dos tecidos de suporte maxilar, eliminar hábitos nocivos e minimizar a necessidade de terapias ortodônticas complexas.

O objetivo é reduzir as consultas desnecessárias de acompanhamento, 
mantendo o monitoramento regular, sem comprometer os resultados esperados, por exemplo, avaliar as ativações a serem realizadas no parafuso expansor palatino. Esse tipo de abordagem pode ser de grande ajuda no gerenciamento de todos os dispositivos ortopédicos removíveis dentofaciais e tratamentos ortodônticos que precisam de pouca manutenção no consultório. ${ }^{41}$

A presença de más oclusões pode afetar negativamente a qualidade de vida relacionada à saúde bucal, mesmo as crianças podem sofrer bullying devido à baixa autoestima. ${ }^{42,43} \mathrm{~A}$ presença de maior overjet e mordida profunda tem sido associada a uma menor qualidade de vida associada à saúde bucal, e quanto mais grave a má oclusão, maior o impacto negativo na qualidade de vida. ${ }^{42,} 43,44,45$ A relação inversa entre qualidade de vida e gravidade da má oclusão, dependendo da idade e do ambiente cultural do paciente, foi evidenciada por revisões sistemáticas e meta-análises. ${ }^{46}$ Também foi comprovado que a presença de overjet aumentado pode predispor a traumatismos dentários e que o tratamento ortodôntico precoce para reduzir a protrusão dos incisivos superiores reduz a incidência de danos ao trauma ${ }^{47}$ (tabela 4 ).

Com base nas evidências disponíveis até o momento, pode-se estabelecer que situações prioritárias que requerem tratamento ortodôntico interceptivo, para evitar efeitos adversos no desenvolvimento da dentição, promover o desenvolvimento correto dos tecidos de suporte e promover o crescimento maxilofacial correto incluem:

- Correção da mordida cruzada posterior.
- Correção da mordida cruzada anterior.

- Erradicação de hábitos persistentes associados à mordida aberta.

- Tratamento de dentes decíduos anquilosados.

- Redução de overjet.

- Correção de dentes com erupção ectópica ou apinhamento severo

- Controle do bruxismo.

\section{Mordida cruzada posterior funcional}

A mordida cruzada posterior é caracterizada por oclusão das cúspides vestibulares de caninos, pré-molares e / ou molares superiores ocluindo na posição lingual e em relação aos seus antagonistas inferiores, ${ }^{70}$ com prevalência média de 7 a 23\% na dentição primária e mista, respectivamente. ${ }^{71}$ Os fatores de risco mais comumente relacionados a essa condição são a postura inferior da língua, que desorganiza o equilíbrio muscular entre a língua e os músculos bucinadores, gerando uma deficiência transversal da maxila, além da respiração bucal, isso modifica o mecanismo de crescimento transversal da mandíbula, colapsando ainda mais a maxila e com um palato mais profundo, além de hábitos posturais, como descansar as mãos em um lado do rosto por longas horas.

A mordida cruzada posterior funcional é caracterizada por desvio mandibular para o lado cruzado, com consequente desvio da linha média inferior para o lado do cruzamento devido ao contato prematuro geralmente entre os caninos primários do lado que mostra a mordida cruzada. ${ }^{72}$ (Figura 2) 
Tabela 4: Impacto negativo das más oclusões no paciente pediátrico.

\begin{tabular}{|c|c|}
\hline Má oclusão & Impacto no paciente pediátrico \\
\hline $\begin{array}{l}\text { Mordida cruzada posterior } \\
\text { funcional. }\end{array}$ & $\begin{array}{l}\text { Crescimento facial assimétrico. }{ }^{48,49} \\
\text { Assimetria dos músculos da face. }{ }^{48,49} \\
\text { Modificação conjunta. }{ }^{48-50}\end{array}$ \\
\hline Mordida cruzada anterior. & $\begin{array}{l}\text { Envolvimento periodontal. }{ }^{51-54} \\
\text { Maior gravidade da má oclusão. }{ }^{51-54} \\
\text { Diminuição da altura facial anterior. }{ }^{51-54} \\
\text { Crescimento mandibular não controlado. }{ }^{51-54} \\
\text { Mudança no eixo de rotação mandibular. }{ }^{51-54} \\
\text { Estética. }{ }^{54}\end{array}$ \\
\hline $\begin{array}{l}\text { Hábitos Persistentes - } \\
\text { Mordida Aberta Associada. }\end{array}$ & $\begin{array}{l}\text { Overjet excessivo. }{ }^{55-58} \\
\text { Perda de espaço no arco inferior. }{ }^{55-58} \\
\text { Mordida cruzada posterior. }{ }^{55-58} \\
\text { Mordida anterior aberta. }{ }^{55-58}\end{array}$ \\
\hline Dentes decíduos anquilados. & $\begin{array}{l}\text { Infra-oclusão. }{ }^{59-61} \\
\text { Retenção prolongada de dentes decíduos. }{ }^{59-61} \\
\text { Perda significativa do comprimento do arco. }{ }^{59-61} \\
\text { Defeitos periodontais graves. }{ }^{59-61}\end{array}$ \\
\hline Overjet aumentado. & $\begin{array}{l}\text { Estabelecimento de hábitos. }{ }^{62-64} \\
\text { Trauma dentoalveolar. }{ }^{62-64} \\
\text { Envolvimento periodontal. }{ }^{62-64} \\
\text { Doença periodontal. }{ }^{62-64} \\
\text { Bullying. }{ }^{62-64} \\
\text { Distúrbios temporomandibulares. }{ }^{62-64}\end{array}$ \\
\hline $\begin{array}{l}\text { Erupção ectópica ou } \\
\text { aglomeração grave. }\end{array}$ & $\begin{array}{l}\text { Estética. }{ }^{65-67} \\
\text { Doença periodontal. }{ }^{65-67} \\
\text { Necessidade de extrações dentárias a médio ou longo prazo. }{ }^{65-67} \\
\text { Erupções ectópicas. }{ }^{65-67}\end{array}$ \\
\hline Bruxismo. & $\begin{array}{l}\text { Atrição. }{ }^{68,69} \\
\text { Perda da dimensão vertical. }{ }^{68,69} \\
\text { Doença periodontal. }{ }^{68,69} \\
\text { Hipertrofia dos músculos mastigatórios. }{ }^{68,69} \\
\text { Dor de cabeça. }{ }^{68,69} \\
\text { Distúrbios temporomandibulares. }{ }^{68,69}\end{array}$ \\
\hline
\end{tabular}

Durante o exame, a mandíbula da criança deve ser guiada para uma posição centralizada, onde será observada a linha média inferior, a mandíbula atrésica com mordida cruzada bilateral em uma posição instável que leva a criança a procurar contato oclusal movendo a mandíbula para o lado cruzado. Isto é, uma mordida dupla é observada com uma diferença entre a interpretação máxima e a relação central e o movimento condilar assimétrico. ${ }^{73}$ Essa situação causa alterações musculares significativas a médio prazo, alterações na posição articular e pode gerar crescimento facial assimétrico e assimetria dos músculos da face. Por esses motivos, é necessária uma abordagem assim que for diagnosticada, ${ }^{50}$ com a recomendação de intervenção precoce nas diretrizes de prática clínica das associações ortodônticas em todo o mundo. ${ }^{48,49}$ 


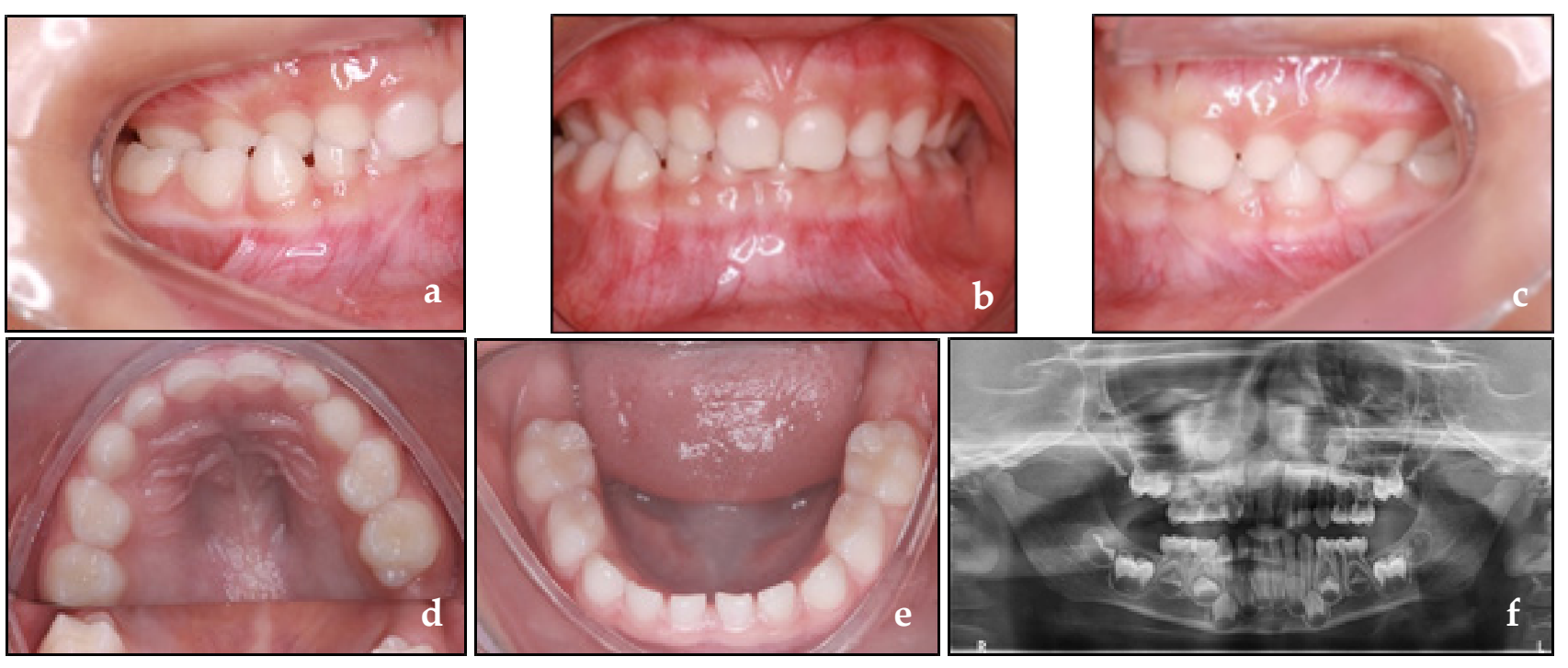

Figura 2: Mordida cruzada funcional, cruz unilateral $(a, b, c)$, desvio inferior da linha média $(b, f)$, maxila com distância transversal menor que a mandíbula $(d, e)$.

As medidas ortodônticas para correção da mordida cruzada priorizam primeiro a eliminação do contato prematuro pelo desgaste oclusal dos caninos. Se este procedimento não resolver o problema, são indicadas medidas terapêuticas. Nos casos de expansores removíveis de menor magnitude com revestimento oclusal, o uso de expansores fixos do tipo Haas ${ }^{74}$ ou Hyrax ${ }^{75}$ que podem ser associados a um disjuntor McNamara ${ }^{76}$ cuja característica envolve a cobertura oclusal dos dentes.

Na perspectiva do momento da pandemia, duas alternativas podem ser consideradas, a primeira delas é a orientação preventiva no sentido de eliminar hábitos associados e, no tratamento, seguir por videochamadas as expansões realizadas pelos pais, periodicamente para o tempo para interromper a ativação do expansor é definido.

Nas manobras de correção da mordida cruzada posterior, funcionais ou não, deve-se considerar a necessidade de revisão excessiva do movimento e orientação sobre a eliminação de agentes etiológicos, por meio da atuação de profissionais de outras áreas, como a terapia otorrinolaringologista, além de observações sobre questões posturais que podem ser orientadas pelo próprio ortodontista aos pais e responsáveis.

No caso de desgaste oclusal, uma opção é usar a peça de mão em baixa rotação sem o uso de água, apenas ar, fazendo uma pausa a cada 10 segundos para permitir o resfriamento da coroa. O uso de brocas de borracha, que normalmente não é indicado, pode ser uma alternativa durante a pandemia.

\section{Mordida cruzada anterior}

Entre as más oclusões que requerem uma abordagem precoce, é necessária atenção à presença de mordida cruzada anterior. Essa má oclusão deve ser diagnosticada o mais rápido possível e os componentes dentários, funcionais e esqueléticos serão avaliados, o que será decisivo na 
escolha das manobras ortodônticas e na definição do prognóstico e do tempo de acompanhamento após a avaliação do tratamento.

Com base nesses critérios, a mordida cruzada anterior pode ser classificada como: mordida anterior dentária, pseudoclasse III e esquelética classe III. ${ }^{77}$

a. Mordida cruzada anterior dentária.

A mordida cruzada anterior dentária é caracterizada pelo cruzamento de um ou dois incisivos ${ }^{78}$ e pela relação dos molares e caninos classe I ou plano terminal reto nos molares decíduos, além de uma relação maxilo-mandibular adequada (Figura 3).

A mordida cruzada anterior dentária tem a etiologia associada a fatores ambientais, como retenção prolongada de dentes decíduos e traumatismo dentário. Essa condição, apesar de sua baixa complexidade, requer uma abordagem assim que é diagnosticada, evitando alterações periodontais e o desenvolvimento de alterações funcionais que podem levar à pseudoclasse III.

O tratamento da mordida cruzada anterior dentária pode ser realizado com dispositivos removíveis, usando molas digitais, parafusos expansores e, quando apenas um elemento dentário é cruzado, manobras preventivas podem ser adotadas com dispositivos simples, como espátulas abaixadoras de língua. ${ }^{79}$

Mais uma vez, através do monitoramento periódico por videochamadas das expansões realizadas pelos pais (ao usar um parafuso expansor) em relação ao grau de ativação da mola, é necessário definir o tempo para interromper a ativação do expansor.

b. Pseudoclasse III

A pseudoclasse III, também chamada classe III funcional ou neuromuscular III, é caracterizada pela presença da mordida cruzada anterior em função de
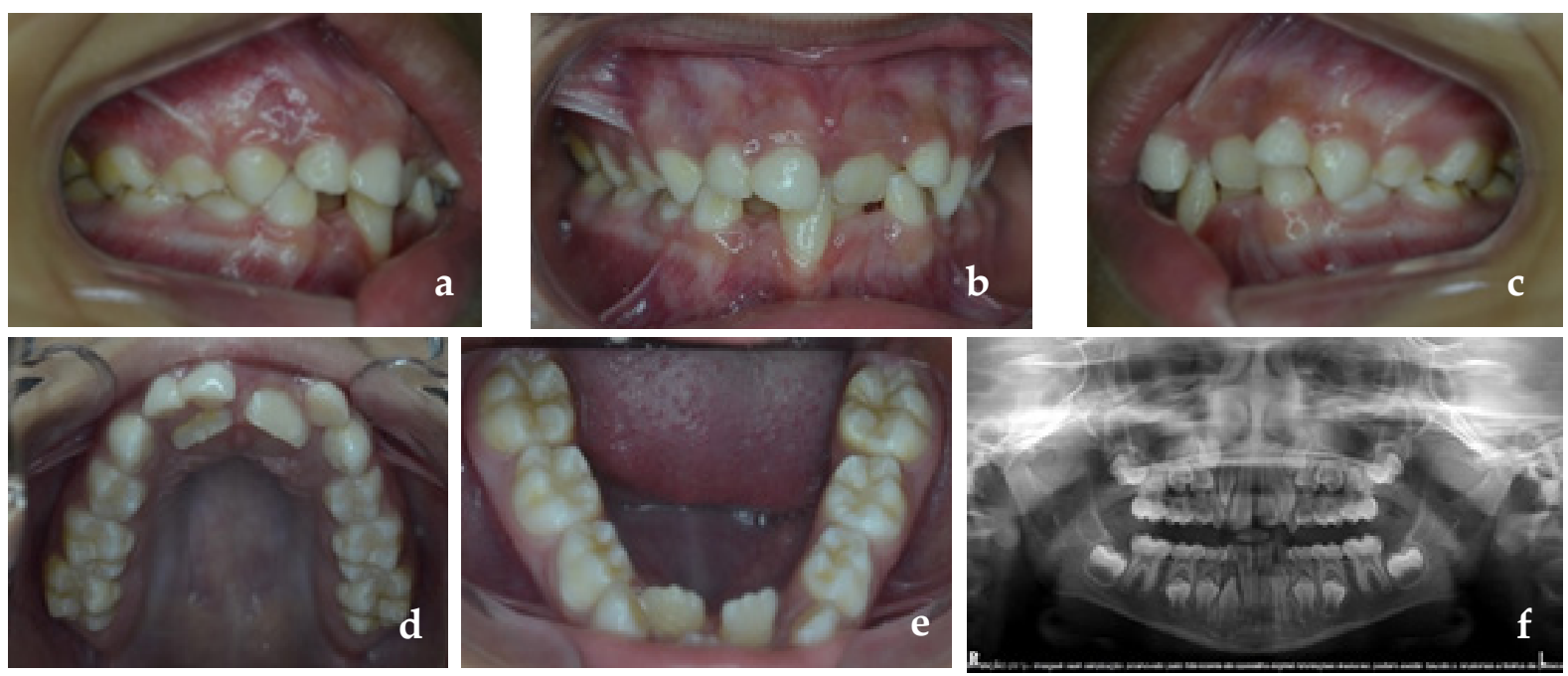

Figura 3. Mordida cruzada anterior dentária, existe uma relação posterior classe I e cruzamento dentário dos incisivos centrais superiores e trauma oclusal com recessão gengival no incisivo inferior $(a, b, c)$, atresia maxilomandibular $(d, e)$ e retenção prolongada de dentes decíduos $(d, f)$. 
interferências oclusais. ${ }^{80}$ Essa alteração é apresentada como um diagnóstico clínico diferencial da classe III esquelética, a presença de discrepância entre a máxima intercuspidação habitual (MIH) e a relação cêntrica (RC). ${ }^{78,81}$

No exame clínico, na posição $\mathrm{MIH}$, há uma relação de molares e caninos na classe III (ou degrau mesial no caso de molares decíduos) e, ao posicionar o paciente na $\mathrm{RC}$, a relação molar passa a ser a classe I e será verificada a presença do contato oclusal que gera o deslizamento mandibular para anterior. ${ }^{82}$ Nesses casos, as inclinações linguais são geralmente encontradas nos incisivos superiores e a presença de desgaste nesses elementos dentários, além da inclinação vestibular nos incisivos inferiores devido à postura mandibular. ${ }^{81}$ Foi observada uma boa relação maxilomandibular e a presença de mordida cruzada anterior dos 4 incisivos (Figura 4).

A pseudoclasse III apresenta como fatores etiológicos: erupção ectópica dos incisivos superiores, ${ }^{82}$ perda precoce dos molares decíduos superiores, alterações funcionais, como respiração oral e anomalias na posição lingual, bem como alterações neuromusculares. ${ }^{80} \mathrm{~A}$ abordagem ortodôntica nesses casos está relacionado à eliminação da interferência oclusal e correção da posição do incisivo, e dispositivos removíveis, como o dispositivo Eschler associado ou não a mentoneira, ${ }^{78}$ dispositivos de expansão ou dispositivos funcionais e sinais diretos são indicados e devem ser realizados assim que forem diagnosticados, uma vez que a persistência dessa má oclusão pode levar ao desenvolvimento de classe III esquelética. ${ }^{82,83}$
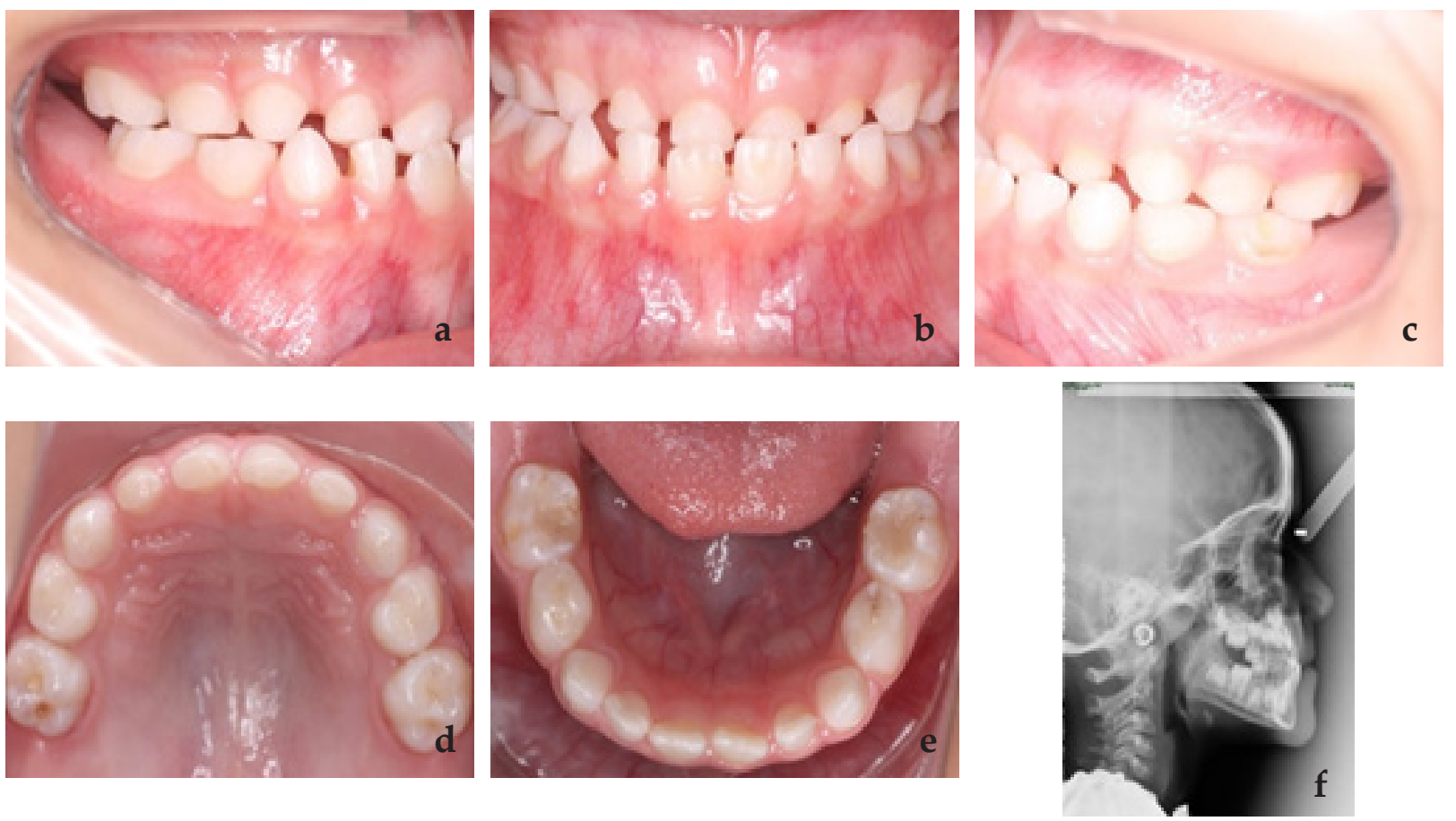

Figura 4. Pseudo classe III, degrau mesial dos segundos molares decíduos em intercuspidação máxima $(a, c)$, mordida cruzada anterior (b), desgaste incisal dos incisivos superiores (d), inclinação vestibular dos incisivos inferiores e inclinação lingual dos incisivos superiores (f). 
Nesses casos, o desgaste oclusal não é uma opção, pois a interferência geralmente ocorre entre os incisivos permanentes. Conforme proposto anteriormente, o monitoramento periódico por videochamadas é definido quanto ao grau de ativação, para que seja definido o tempo para interromper a ativação do expansor.

\section{c. Classe III esquelética}

A classe III esquelética é uma má oclusão caracterizada por uma relação maxilomandibular alterada, perfil côncavo e, na maioria dos casos, presença de mordida cruzada anterior. Pode ser composto de retrognatismo maxilar associado a mandíbulas bem posicionadas, mandíbula prognata $\mathrm{e}$ maxila retrognata ou bem posicionada ${ }^{84}$ e tem uma prevalência de 3 a $26 \%{ }^{85}$ que varia entre populações ao redor do mundo e com critérios diagnósticos, sendo mais frequente em países asiáticos. ${ }^{86}$

Do ponto de vista etiológico, a classe III esquelética pode estar relacionada a fatores hereditários ${ }^{87}$ (principalmente casos de prognatismo mandibular) e a fatores ambientais, como respiração oral, alterações funcionais e presença de mordida anterior ou classe III não tratada.

Com base na combinação dos componentes ósseos anteroposterior e sagital, o prognóstico do tratamento pode ser mais ou menos agravado. ${ }^{51}$ Entre os fatores prognósticos, podemos citar que quanto maior o envolvimento mandibular, o crescimento vertical da face e a deterioração funcional, pior o prognóstico. $^{52}$

Além das características esqueléticas e dos componentes etiológicos envolvidos, o tempo de tratamento pode contribuir para o melhor ou o pior prognóstico do tratamento, e a dentição primária e mista é o melhor momento para o tratamento, uma vez que o estabelecimento da correta relação maxilo-mandibular contribui com o crescimento facial adequado. ${ }^{53}$ De um modo geral, quando há apenas envolvimento devido à deficiência maxilar, a intervenção precoce pode ser útil em casos de deficiência maxilar leve. Quando o problema é crescimento mandibular excessivo ou deficiências maxilares moderadas a graves, o monitoramento e a prevenção são mais indicados.

O padrão ouro de tratamento para a classe III de origem maxilar, a ortopedia mecânica utilizando expansores fixos associados à máscara facial é amplamente referenciado na literatura e, a possibilidade de incluir protocolos com o uso de ancoragem esquelética, permite expandir o grupo de correção da idade e pode ser usado na fase posterior da dentição mista com resultados positivos. ${ }^{88,} 89$ No entanto, considerando que a classe III é uma má oclusão que tende a piorar com a idade e que traz numerosos problemas estéticos e funcionais ao diagnóstico e intervenção precoces, assim que a criança amadurece para a aceitação do tratamento (Figura 5), pode contribuir muito para um bom resultado do tratamento. Vale ressaltar a importância do acompanhamento após tratamento periódico até o final do crescimento facial, devido às possibilidades de recorrência na mordida cruzada, devido ao crescimento mandibular. ${ }^{54}$

Dado o cenário atual da pandemia, a abordagem ortopédica de Classe III pode ser monitorada por meio de consultas virtuais, especialmente quando o período ativo de expansão já foi concluído e o paciente está na fase de uso da máscara 

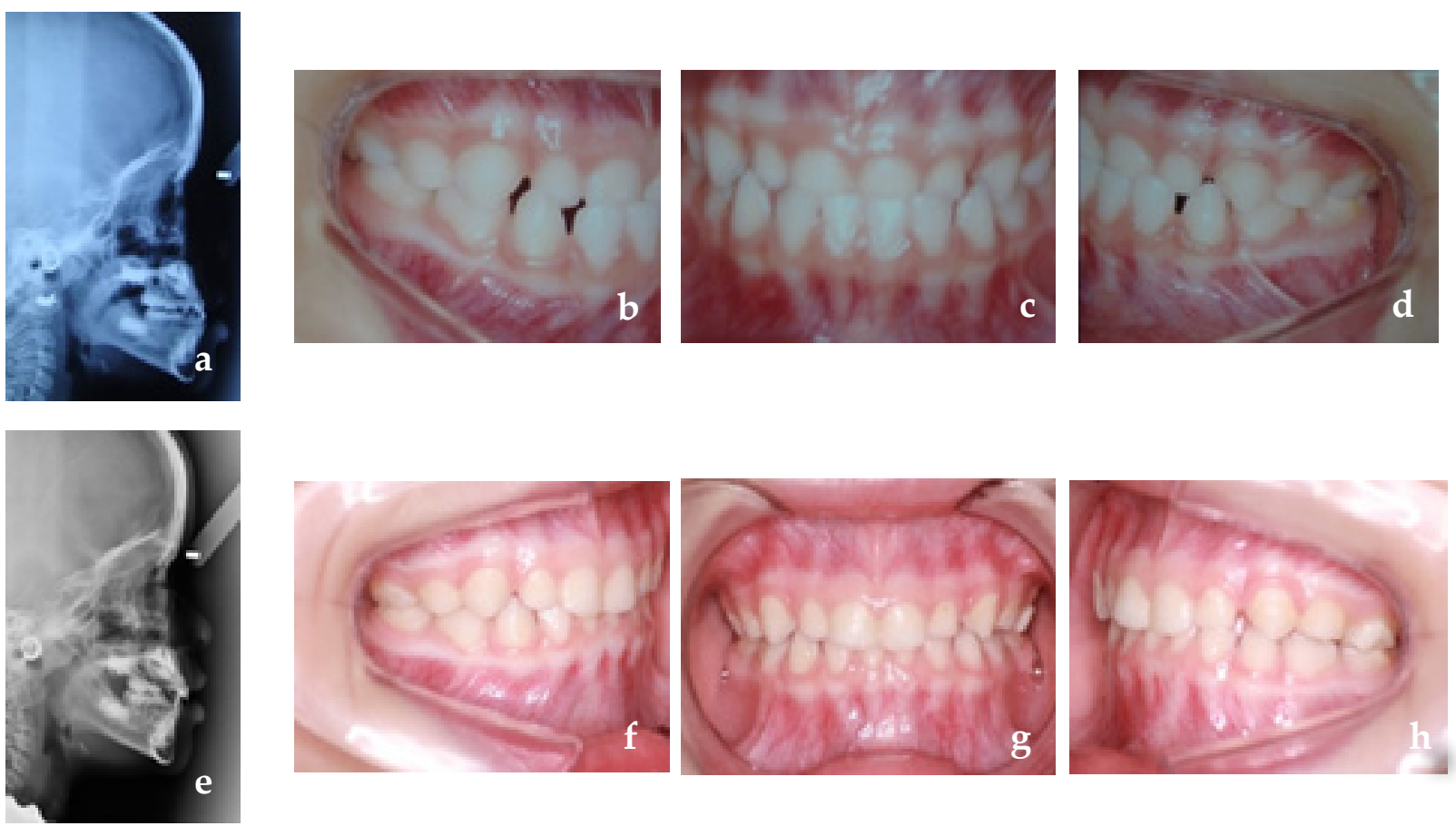

Figura 5. Clase III esquelética diagnosticada en edad temprana. Se observa retrognatismo maxilar (a), relación de mordida cruzada anterior y escalón mesial de molares y caninos $(b, c, d)$; Post tratamiento con uso de máscara facial y disyuntor maxilar, mejora en la relación maxilo-mandibular (e) corrección de mordida cruzada y relación dentaria posterior $(f, g, h)$.

facial. Nesse estágio, o monitoramento de overjet deve ser realizado e pode ser monitorado em intervalos mensais. Em caso de dúvida, com o diagnóstico que provavelmente tem envolvimento mandibular, seria melhor não intervir imediatamente, aguardando alguns meses para tratar o caso. Deve-se considerar o risco de falta de acompanhamento correto, acrescido ao fato de que a alta probabilidade de modificação esquelética não é suficiente para evitar tratamento adicional.

\section{Hábitos persistentes - Mordida aberta associada}

A literatura mostra que existe uma relação consolidada entre o desenvolvimento de certas características oclusais e os hábitos alimentares e de sucção em crianças. ${ }^{55-57,90}$

A amamentação é um fator protetor no aparecimento de más oclusões e essa associação é mais forte com o aumento da duração da amamentação..$^{90}$ As crianças que experimentam a amamentação exclusiva por mais de seis meses têm menor probabilidade de uso diário da chupeta. ${ }^{55,57}$ Esse hábito pode estar relacionado a outros, porque as crianças que usam chupeta diariamente têm possibilidades significativamente maiores de ter hábitos diários de sucção digital. ${ }^{57}$

O uso diário de chupeta e a sucção digital podem estar associados a excesso de sobressaliência, perda de espaço 
na arcada inferior, mordida cruzada posterior e mordida aberta anterior, afetando o desenvolvimento harmonioso das estruturas orofaciais. ${ }^{55-58}$ Algumas dessas características podem ser vistas na Figura 6.

A mordida aberta anterior também mostra associação com fatores sociodemográficos, como frequentar uma pré-escola pública, ter maior número de residentes em casa, menor escolaridade da mãe, menor renda familiar e idade do cuidador menor ou igual a 30 anos..$^{58}$

Existem diferentes intervenções que podem contribuir para a intercepção do hábito de sucção não nutritiva que pode estar relacionado à mordida aberta anterior. Aparelhos ortodônticos, como arco e grade palatinos, são benéficos nesse cenário, pois o número de crianças que descontinuam a sucção aumenta a curto e longo prazo. Pode ser usado sozinho ou em combinação com uma intervenção psicológica, que também demonstrou promover a interceptação de hábitos, ${ }^{91,92}$
$\mathrm{O}$ uso da tela palatal em pacientes em crescimento, um dispositivo amplamente difundido na rotina clínica, mostra um aumento significativo na sobremordida em comparação com controles não tratados, independentemente do design do dispositivo, e esse resultado permanece estável mesmo após alguns anos de acompanhamento. É o tratamento mais eficaz de acordo com os estudos disponíveis na literatura atual. ${ }^{92}$

Considerando o cenário da pandemia do COVID-19, o comprometimento dos pais e responsáveis no processo de eliminação do hábito de sucção não nutritiva das crianças e a disponibilidade do cirurgiãodentista responsável pelo caso, por teleodontologia, podem contribuir para modificar essa condição. Além disso, sabendo que fatores psicológicos estão diretamente relacionados a esses hábitos, a ajuda de um psicólogo, se for uma criança sujeita a situações que despertam algum tipo de instabilidade emocional, é de considerável relevância. Como esses dispositivos são independentes, ou seja,
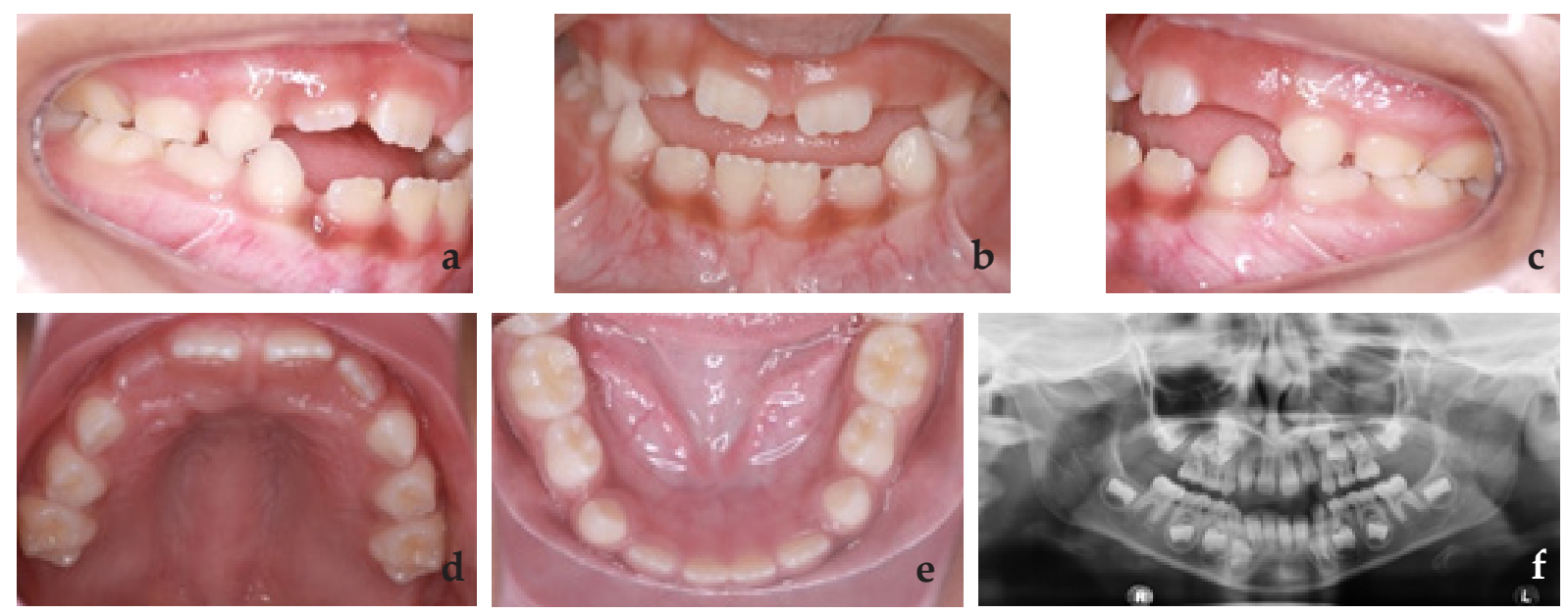

Figura 6. Mordida anterior aberta associada ao hábito de chupar chupeta 
não há risco de correção excessiva, seu uso na pandemia se torna mais fácil. Embora a teleconsulta indique a correção do hábito, a necessidade de ver o paciente e remover o dispositivo provavelmente não é urgente.

\section{Dentes decíduos anquilosados}

A retenção prolongada de dentes decíduos pode estar relacionada a vários fatores. A anquilose é uma delas que, embora não tenha uma etiologia bem definida, várias teorias já foram propostas, como fator genético envolvido, deficiência no crescimento ósseo alveolar, problemas relacionados ao metabolismo e inflamação, infecção, irritações químicas ou térmicas localizadas, alteração na interação entre reabsorção normal e reparo de tecido duro que ocorre nos molares primários durante a erupção dos dentes sucessores e a força eruptiva dos dentes. ${ }^{59}$

A anquilose dos dentes decíduos pode influenciar o desenvolvimento do a parelho estomatognático do paciente. Um exemplo disso é a infraoclusão, uma condição que pode estar associada à anquilose nos dentes decíduos retidos. Há uma frequência mais alta de dentes decíduos retidos na mandíbula em comparação com a maxila e, dentre eles, os molares são os dentes desse grupo com maior prevalência de retenção prolongada. . $^{\text {- } 61}$

A literatura sugere que, nos casos de anquilose dentária primária, uma das principais abordagens que pode ser adotada é o acompanhamento, uma vez que a esfoliação dentária geralmente ocorre espontaneamente. Se a esfoliação não ocorrer, a extração se tornará uma alternativa importante e necessária.
O odontopediatra deve considerar a extração com manutenção de espaço adequado se o sucessor permanente apresentar uma trajetória de erupção alterada, o que dificultará a reabsorção do primário, se o dente primário apresentar um atraso considerável na esfoliação ou se estiver em grave infraoclusão, com dentes adjacentes altamente inclinados, que podem causar perda clinicamente significativa do comprimento do arco e dificultar a erupção do sucessor permanente. ${ }^{61} \mathrm{Um}$ problema importante é o desenvolvimento de um defeito periodontal vertical grave em casos de molares retidos com inclinação de elementos dentários adjacentes na coroa em infraoclusão.

No cenário atual, o monitoramento da esfoliação esperada de um dente primário anquilosado deve ser feito por meio de consulta remota. É pertinente que o dentista pediátrico esteja ciente do período esperado de esfoliação e instrua os pais da criança a relatar quaisquer alterações odontológicas. E se algo acontecer, avalie a possível consulta presencial da criança. Se a pandemia durar 6 a 8 meses, é improvável que um atraso no desenvolvimento de qualquer ação seja crítico. Esperar um pouco é uma opção relevante neste momento.

\section{Redução de overjet}

O overjet dos dentes anterosuperiores é um problema comum em crianças em todo o mundo.A correção dessa condiçãoconstitui um dos tratamentos mais comumente realizados por odontopediatras e ortodontistas. Essa condição se desenvolve quando os dentes permanentes do paciente entram em erupção. Os dentes 
anterosuperiores salientes são mais propensos a traumatismos dentários e sua aparência pode causar baixa auto-estima e desconforto. ${ }^{47}$

O overjet corresponde à relação horizontal entre os incisivos superiores e inferiores, com um valor normal de 2 a $4 \mathrm{~mm}$. Um overjet aumentado pode estar relacionado a más oclusões de Classe II geralmente acompanhadas de relações esqueléticas sagitais de Classe II e retrognatismo mandibular. ${ }^{62} \mathrm{Na}$ má oclusão de Classe II de acordo com Angle, todos os dentes inferiores ocluem distalmente, produzindo uma desarmonia acentuada na região do incisivo e no aspecto facial. ${ }^{63}$ Este tipo de má oclusão não corresponde a uma única entidade. Essa discrepância pode ser o resultado de inúmeras combinações de componentes dentários (protrusão dos dentes anteriores superiores, hábitos, etc.) e esqueléticas (deficiência de crescimento mandibular, crescimento maxilar excessivo, combinação de ambos). Os fatores etiológicos podem ser hereditários ou ambientais (hábito de chupar dedos, chupeta, chupar lábios, respirar pela boca, entre outros). ${ }^{63-64}$

Pacientes com overjet aumentado apresentam maior incidência de trauma dentoalveolar, nos incisivos superiores permanentes, durante o crescimento. As fraturas dentárias são três vezes mais propensas a ocorrer em crianças com overjet aumentado, por esse motivo é importante considerar o tratamento precocemente. Ao mesmo tempo, é bom estar ciente de que um fator mais importante do que a redução do próprio overjet é o gerenciamento preventivo de atividades de risco que predispõem a impactar diretamente os dentes. À medida que o paciente cresce, podem ocorrer danos periodontais à medida que o ligamento periodontal se torna menos resistente à pressão atípica dos lábios, relacionada à dificuldade de realizar uma vedação labial adequada. ${ }^{62}$

A protrusão dos incisivos superiores também está relacionada ao acúmulo de biofilme dentário, gengivite elesões iniciais de cárie na mancha branca (ICDAS 1 e 2). ${ }^{62}$ Essa incapacidade de realizar o vedamento labial pode ser embaraçosa para muitos pacientes e a sociedade pode classificálos como pouco atraentes, tornando-os alvo de bullying, afetando sua qualidade de vida. ${ }^{62,64}$ Além disso, um overjet pronunciado pode estar relacionado a desordens temporomandibulares, pois o contato dos incisivos não ocorre durante a mastigação, aumentando o movimento da mandíbula e a pressão sobre os músculos da mastigação, gerando instabilidade ortopédica devido ao desvio da oclusão cêntrica. ${ }^{62}$

A determinação do plano de tratamento apropriado deve ser estabelecida com base no problema específico do paciente, com base em evidências clínicas, cefalométricas e funcionais de C. As opções para corrigir um overjet aumentado são baseadas nos objetivos de cada tratamento e em como eles podem ser alcançados usando: ortodontia interceptiva, ortopedia funcional ou ortodontia corretiva. ${ }^{62} \mathrm{~A}$ escolha da mecânica para o tratamento desse tipo de má oclusão dependerá de: tipo de má oclusão, idade do paciente, grau de colaboração e nível socioeconômico do núcleo familiar. Em alguns casos, a simples observação e monitoramento é uma opção razoável.

Durante o confinamento, os pais / responsáveis podem procurar ajuda 
devido à aparência física da criança que afeta sua qualidade de vida. Durante uma videochamada, é possível consultar os componentes hereditários e/ou ambientais que a má oclusão pode ter. Nesse cenário, basta explicar aos pais / responsáveis a natureza da má oclusão e alertá-los para a probabilidade de impactos dentários nos incisivos salientes. $\mathrm{O}$ uso de protetores bucais pode ser recomendado para crianças em idade escolar (nos países em que algumas medidas de contenção foram levantadas e certos tipos de atividades ao ar livre podem ser realizadas, mas a abertura de clínicas dentárias não foi autorizada para tratamentos eletivos), que podem ser adquiridos facilmente em farmácias ou lojas on-line e seu valor é acessível. No entanto, é importante destacar que o uso do protetor bucal é único e exclusivo para a prevenção de trauma dentoalveolar e que seu uso não reduz a sobremordida em si mesmo em comparação com o uso de ortodontia para correção da má oclusão. ${ }^{93}$

Embora os pais / responsáveis procurem especialistas com o objetivo de melhorar a qualidade de vida do paciente precocemente, não há contraindicação para adiá-la até o final da pandemia de COVID-19 ou mesmo, até que a má oclusão possa ser corrigida fase única de tratamento. ${ }^{93}$ Há um alto nível de evidência científica relatando que atrasar o tratamento até que ele possa ser realizado em um único momento de tratamento pode ser o mais apropriado e benéfico para alguns pacientes. ${ }^{47}$

Nos casos em que os pacientes estão em tratamento, o especialista indicará por videochamada as etapas a serem seguidas de acordo com cada aparelho. Placas ativas removíveis e dispositivos ortopédicos funcionais podem ser ativados em casa, de acordo com as instruções do especialista, com os devidos registros e consentimento informado.

\section{Correção de dentes com erupção ecotópica ou apinhamento severo}

A discrepância entre o tamanho do dente e o comprimento do arco é conhecida como apinhamento. $\mathrm{O}$ apinhamento e irregularidade dos incisivos são o componente mais prevalentena má oclusão dentária. ${ }^{94}$ A aglomeração dentária ao nível dos incisivos permanentes, que mal erupcionaram, é um incidente que é tão frequente de observar quanto preocupante e muitas vezes inesperado para os pais. ${ }^{95,96}$ O apinhamento dentário é considerado uma má oclusão que não se corrige, mas piora com o tempo. Se presente na dentição decídua, piorará nos próximos dois estágios da dentição mista. ${ }^{65}$

Além de afetar a estética do paciente, também pode prejudicar a higiene dentária na região anterior, dificultando ainda mais o desempenho em pacientes em idade precoce. No momento da escovação, é difícil alcançar a área interproximal dos dentes apinhados; portanto, o acúmulo de biofilme dentário e cálculo dentário acabará evoluindo para doença periodontal (gengivite) e aumentará o risco de cárie para o paciente. ${ }^{66}$

De acordo com sua etiologia, o apinhamento pode ser classificado como primário, secundário e terciário. Primário, como resultado da discrepância entre o tamanho dos dentes e o comprimento disponível no arco, de origem genética. Secundário, causado por fatores ambientais (cárie, extração dentária, perda prematura, entre outros) e terciário, que ocorre no período pós-adolescente. ${ }^{94}$ 
Os fatores que influenciam o apinhamento durante a fase de erupção da dentição permanente são: posição anormal dos germes dos dentes permanentes, erupção ectópica dos incisivos laterais, caninos e molares, momento da esfoliação dos dentes decíduos e erupção dentária substitutiva permanente, dentes supranumerários, anomalia de transposição dentária, reabsorção irregular das raízes dos dentes decíduos, perda prematura de dentes decíduos, lesões cariosas de dentes decíduos e permanentes e suas complicações, hábitos, predisposição genética. ${ }^{94,67,97}$ Outros fatores também incluem: crescimento, comprimento reduzido do arco, maturação, movimento mesial dos dentes, pressão dos tecidos moles, largura mesiodistal dos dentes, além do tamanho e morfologia do dente. ${ }^{96}$

A literatura relata a necessidade de intervenção precoce em alguns pacientes com apinhamento. Uma correção oportuna da má oclusão na dentição mista poderia permitir a obtenção de resultados estáveis de tratamento, reduzindo a taxa de extração dentária em dentes permanentes e reduzindo o tempo na segunda fase do tratamento. Isso pode ser alcançado através de uma série de estratégias que dependem da análise de cada caso específico. Estes incluem: inclinação dos incisivos inferiores, desenvolvimento transversal do arco, distalização do primeiro molar permanente, desgaste seletivo dos dentes decíduos e permanentes, manutenção do comprimento do arco, extrações guiadas dos dentes, extrações dentárias seriadas, entre outros. ${ }^{67}$

Durante o confinamento, é possível controlar os dispositivos fixos (passivos e pré-ativados) destinados a manter ou aumentar (conforme o caso) o comprimento do arco através da teleodontologia.
Da mesma forma, é possível controlar as expansões transversais de placas ativas removíveis, desde que os pais / responsáveis sejam colaboradores das videochamadas e registros. No caso de expansores fixos, é aconselhável interromper as ativações do paciente para evitar emergências futuras. O especialista deve enfatizar especialmente a higiene bucal, reforçando as técnicas de escovação e o uso de fio dental para prevenir doenças periodontais e cárie dentária.

Nos pacientes em que foram realizadas extrações guiadas de dentes, os controles podem ser realizados remotamente. No entanto, deve-se ter cautela no momento apropriado para o controle radiográfico, pois podem ocorrer erupções ectópicas dos dentes permanentes. $O$ tratamento do apinhamento deve ser iniciado o mais rápido possível, uma vez levantadas as medidas de quarentena da pandemia do COVID-19.

\section{Controle do bruxismo}

A Academia Americana de Dor Orofacial 98 define bruxismo como: uma atividade parafuncional diurna ou noturna que inclui cerrar, ranger ou arrastar inconscientemente os dentes. De acordo com as evidências, a prevalência de bruxismo em crianças varia amplamente, variando entre $5 \%$ e $40 \%$ na população mundial, e também é descrito que diminui com a idade de. ${ }^{68,69} \mathrm{O}$ bruxismo apresenta duas manifestações circadianas diferentes: a) ocorre durante a vigília (BV), ou b) ocorre durante o sono (SB), sendo o último o mais frequente. ${ }^{69} \mathrm{~A}$ classificação mais recente e atualmente aceita para o bruxismo do sono corresponde a: possível, provável e definitiva. ${ }^{99}$ 
As crianças devem realizar movimentos anteroposteriores dos maxilares e desgaste dos dentes durante a dentição temporária e mista, para realizar o segundo avanço fisiológico da oclusão. Por esse motivo, vários autores concordam que, se o atrito e os ruídos oclusais forem prolongados além de 8 anos, pode-se considerar que a criança exerce uma atividade parafuncional semelhante à do adulto, embora seja relativa, portanto deve ser avaliado pelo especialista. ${ }^{69}$

O motivo mais frequente para a consulta dos pais / responsáveis é o ruído intenso e repetido produzido por seus filhos durante a retificação dentária, principalmente à noite. Isso pode causar problemas dentários e neuromusculares, incluindo: desgaste dentário, doença periodontal, hipertrofia dos músculos mastigatórios, dores de cabeça e distúrbios temporomandibulares. ${ }^{68,69}$

O bruxismo é classificado como cêntrico e excêntrico. O bruxismo cêntrico é descrito como o aperto dos dentes na oclusão cêntrica ou na máxima intercuspidação sem causar deslocamento. O bruxismo excêntrico é definido como um deslizamento dos órgãos dentários na posição protrusiva e na lateroprotusão, geralmente causando facetas de desgaste nos dentes anteriores e posteriores. ${ }^{100}$

A literatura é extensa e contraditória com relação à etiologia do bruxismo infantil, portanto, concluiu-se que sua origem é multifatorial eenvolve fatores hereditários, psicológicos (ansiedade, estresse, características da personalidade etc.) e comportamentais. ${ }^{69}$ Destacam-se como fatores etiológicos: período de substituição dentária, más oclusões, desenvolvimento da ATM, estresse emocional, hábitos orais, ansiedade, medicamentos que causam estimulação no sistema nervoso central, processos alérgicos, asma e infecção no trato respiratório. ${ }^{100}$

Como o bruxismo é uma atividade parafuncional multifatorial, seu tratamento deve ser focado na resolução de fatores etiológicos. É por isso que existem diferentes modalidades terapêuticas para o bruxismo em crianças, entre as quais: educação do paciente e da família, estratégias odontológicas (talas oclusais, ortodontia interceptiva, ortopedia funcional), psicológicas (mudança de hábitos e redução do estresse e ansiedade do paciente), cirúrgico (pacientes com obstrução grave das vias aéreas) e farmacológico (melhora os níveis de estresse e ansiedade e aumenta o número de horas de sono e sua qualidade). ${ }^{68}$

A educação do paciente e da família é voltada para o estabelecimento de rotinas de sono e para o controle de outros hábitos orais durante o dia, como onicofagia, mastigação de objetos e chiclete. ${ }^{99} \mathrm{Em}$ crianças com dentição decídua ou cujos primeiros molares permanentes não estão totalmente erupcionados, onde se observa desgaste considerável, o tratamento de escolha são as coroas de aço cromado e com isso recuperam a dimensão vertical. ${ }^{100}$ É importante ressaltar que o tratamento ortopédico-ortodôntico é indicado no caso de se apresentarem anomalias dentomaxilares como a compressão maxilar, uma vez que a expansão do complexo nasomaxilar pode ser bemsucedida no tratamento de distúrbios respiratórios durante o sono, a curto prazo, podendo ter um efeito positivo no bruxismo, entre outros fatores. ${ }^{68}$

O odontopediatra deve levar em 
consideração fatores psicológicos durante a consulta, prestando atenção ao estado mental geral do paciente, observando processos incomuns de nervosismo, irritabilidadeeoutrosindicadoresdetensão indicados pela aplicação de tratamento especializado. Pais e filhos devem estar cientes dos distúrbios causados pelo bruxismo no sistema estomatognático e da atividade parafuncional em que foi realizada durante o dia, a fim de reduzi-lo ou eliminá-lo. ${ }^{100,101}$

O diagnóstico de bruxismo pode ser feito por teleodontologia. $\mathrm{O}$ seu tratamento dependerádagravidadeeidadedopaciente. $\mathrm{O}$ especialista deve fazer uma anamnese completa para determinar hábitos na rotina do sono que podem ser modificados durante a temporada de confinamento. Se, no momento da teleconsulta, o especialista determinar a necessidade de tratamento multidisciplinar, os pais / responsáveis poderão ser orientados a fazer consultas por telemedicina para terapias psicológicas ou avaliação pelo otorrinolaringologista, conforme o caso. Nesses pacientes, onde o bruxismo com desgaste significativo dos dentes foi diagnosticado, pode-se aconselhar o uso de protetores bucais, que podem ser facilmente adquiridos em farmácias ou lojas com um método de compra on-line e acessível, enquanto durar a pandemia. No entanto, os pais / responsáveis devem ser alertados para a importância de receber tratamento prioritário quando as medidas de isolamento social forem levantadas.

\section{Considerações especiais em ortodontia interceptiva durante a pandêmica de COVID-19}

$\mathrm{Na}$ prática odontológica habitual, profissionais e pacientes são constantemente expostos a patógenos que habitam a cavidade oral e o trato respiratório devido às condições particulares de geração de aerossóis, distância curta de trabalho e uso de vários instrumentos e suprimentos. Por sua vez, o contato próximo com fluidos como sangue e saliva que contêm uma carga viral considerável em pacientes infectados, mesmo em pacientes assintomáticos, acarreta um alto risco de infecção por COVID-19. ${ }^{12}$

Devidoàpandemiaeaoaumentodonúmero de casos, medidas de confinamento podem ser tomadas novamente. Por esse motivo, os especialistas devem estar preparados para os efeitos da ortodontia sem supervisão. Portanto, deve-se reconsiderar o uso de qualquer mecanismo ortodôntico que, se não for controlado, poderá gerar efeitos prejudiciais, principalmente nos dispositivos não autolimitados, como: tração de caninos, controle de erupções, arcos de curva reversa, torques auxiliares e aparelhos funcionais fixos. ${ }^{102}$

Embora o panorama mundial se torne complicado no que diz respeito aos profissionais de saúde especificamente na área da odontologia, existem más oclusões de natureza prioritária e que não devem ser deixadas sem vigilância quando voltarmos à chamada "nova normalidade". O COVID-19 está aqui, sem dúvida, para permanecer por um longo tempo e, como resultado, pode mudar para sempre a maneira como a ortodontia é praticada. ${ }^{102}$

Em pacientes que necessitam de extrações dentárias guiadas e / ou em série, elas podem ser realizadas com precauções padrão, mas devem ser planejadas, se possível, em uma única visita para 
reduzir o risco de exposição do paciente. No entanto, é necessário monitorar para controlar e orientar a erupção, de acordo com cada paciente, e no caso de reposição do isolamento social, medidas adicionais devem ser tomadas para evitar a perda do comprimento do arco ou erupções ectópicas dos dentes permanentes. ${ }^{102}$

A expansão maxilar ainda é possível, mas sob supervisão rigorosa, especialmente em casos de expansão rápida da maxila. $\mathrm{O}$ especialista deve instruir claramente os pais / responsáveis sobre os objetivos do tratamento de expansão. Uma vez concluída a expansão, é essencial manter os resultados alcançados, pois a superlativação pode criar uma vestibularização indesejada dos dentes posteriores que pode exigir uma visita extra no consultório e atrasar o tratamento. Por esse motivo, a mecânica de expansão lenta é preferida, pois é mais segura e não cria mudanças bruscas em curtos períodos de tempo, reduzindo a possibilidade de emergências ortodônticas. ${ }^{102}$

Pacientes que usam dispositivos funcionais removíveis podem ser monitorados remotamente por meio de chamadas de vídeo. Além disso, o uso desses dispositivos pode ser reduzido quando as metas de tratamento forem atingidas. ${ }^{102}$

Os aparelhos fixos estão associados a uma alta taxa de fraturas (especialmente em pacientes pequenos e pouco cooperativos), o que requer um número maior de visitas de emergência em comparação ao uso de aparelhos removíveis. ${ }^{102}$

Nos pacientes que entram em uma fase de contenção, o uso de contenções removíveis é preferível às fixas, para evitar contaminação desnecessária com aerossóis. Recomenda-se fornecer ao paciente um conjunto adicional de contenções removíveis em caso de perda ou fratura, especialmente durante e quando novamente confinado pelo COVID-19. ${ }^{102}$

Recomenda-se minimizar os procedimentos de geração de aerossóis, como: remoção de cimento, remoção de materiais adesivos, ameloplastias, microabrasão, desgaste interproximal e limpeza ultrassônica. Evite usar a seringa tríplice e substitua a secagem com ar por gaze ou cotonete. Se possível, considere não usar água durante a remoção de cimento ou materiais adesivos. ${ }^{103}$

\section{Considerações finais}

Essas recomendações foram feitas de forma independente e voluntária por pesquisadores da Associação LatinoAmericana de Odontopediatria, juntamente com especialistas nas diversas áreas médicas da América Latina, com arbitragem por pares, livre de conflitos de interesse.

Essas recomendações são baseadas na maior evidência disponível até o momento, sendo o COVID-19 uma doença emergente. As atualizações necessárias serão feitas de acordo com o estado da ciência a esse respeito e a evolução da doença.

O grupo de especialistas responsáveis pela curadoria permanece ativo e monitora constantemente as informações publicadas sobre o COVID-19 para realizar as atualizações e anexos necessários. 


\section{Autores}

Esse artigo foi desenvolvido pelo grupo liderado Marina Tavares Costa Nóbrega (Canada), Rosa Helena Wanderley Lacerda (Brasil), Carlos FloresMir (Canadá), Andrea Virgina González Carfora (Chile), Luzia Ana Da Silva de Carballo (Venezuela), como parte da Equipe Interdisciplinar COVID-19 da Associação Latinoamericana de Odontopediatria.

Equipe Interdisciplinar COVID-19 da Associação latinoamericana de Odontopediatria: Jenny Abanto (Brasil), Mariana Armada (Argentina), Paola Beltri (España), Marisol Carrillo Tabakman (Paraguay), Haydée Casaretto (Argentina), Jorge Luis Castillo (Perú), Mónica Gladys Cesetti (Argentina), Bertha Angélica Chávez González (Perú), Ana Claudia Rodrigues Chibinski (Brasil), Salomon Alberto Cohen (Argentina), Olga Cortés Lillo (España), Luzia Ana Da Silva de Carballo (Venezuela), Gonzalo De la Fuente Alvarez (Chile), Renée Di Nallo (Argentina), María Débora Elizabeth Dricas (Argentina), Sandra Echevarria (Brasil), Piedad Cecilia Echeverry Marin (Colombia), Laura Fedelli (Argentina), Carlos Flores-MIr (Canadá), Andrea Virgina González Carfora (Chile), Lina
María Hernández Salas (Colombia), Francisco José Hernández Restrepo (Colombia), Maria Teresa Ibañez Rodriguez (Bolivia), José Carlos Pettorossi Imparato (Brasil), Alejandra Lipari Valdés (Chile), Daniela Madrigal López (Costa Rica), Daniela Catalina Martínez Camus (Chile), María Gabriela Martínez Vásquez (Venezuela), A. Carolina Medina Díaz (Venezuela), Kelly Maria Silva Moreira (Brasil), Elías M. Morón (Estados Unidos de América), Martha Mutis (Estados Unidos de América), Camila Palma (Perú), Gladys Mabel Peña (Argentina), Adriana Pistochini (Argentina), Paloma Planells (España), Gabriel Politano (Brasil), Matias RiosErazo (Chile), Adriana Maria Rubiano Pinzon (Colombia), Karla Mayra Rezende (Brasil), Rosa Gabriela Rondón (Venezuela), Gabriela Scagnet (Argentina), Rosemary Sogbe de Agell (España), Marina Tavares Costa Nóbrega (Canadá), Jorgelina Valente (Argentina), Ernesto Venegas De Herrera (República Dominicana), Rosa Helena Wanderley Lacerda (Brasil), Ana Clara Zabala (Argentina), Gabriel Zambrano (Venezuela).

Información completa del Grupo Interdisciplinario COVID-19 de la Asociación Latinoamericana de Odontopediatría

\section{Bibliografia}

1. Asociación Latinoamericana de Odontopediatría. Grupo COVID-19. Ruta de atención para procedimientos de Odontología Pediátrica durante la etapa de confinamiento o cuarentena de la pandemia COVID-19. Rev Odontoped Latino. 2020;10(2):https://www.revistaodontopediatria.org/ediciones/2020/2/art-1/.

2. Asociación Latinoamericana de Odontopediatria. Tratamiento de la enfermedad de caries en época de COVID-19: protocolos clínicos para el control de aerosoles. Rev Odontoped Latino. abril 2020;10(2):https://www.revistaodontopediatria.org/ediciones/2020/2/art-2/\#.

3. Asociación Latinoamericana de Odontopediatría ALOP. Modelos de Consentimiento Informado para la Atención de Urgencias en tiempos de COVID-19. abril 4, 2020. Available at: https://www.alopodontopediatria.org/noticias/consentimiento-informado-indicados-especialmente-atenci\%C3\%B3n-emergencias-odontologicas/.

4. Turkistani KA. Precautions and recommendations for orthodontic settings during the COVID-19 outbreak: A review. Am J Orthod Dentofacial Orthop. 2020.

5. Yang Y PFWRGKJTXGSJCC. The Deadly Coronaviruses: The 2003 SARS Pandemic and the 2020 Novel Coronavirus Epidemic in China. J Autoimmun. 2020.

6. Lu R ZXLJNPYBWHWWSHHBZea. Genomic characterisation and epidemiology of 2019 novel coronavirus: implications for virus origins and receptor binding. Lancet. 2020;395.

7. Guo YR CQHZTYCSJHea. The origin, transmission and clinical therapies on coronavirus disease 2019 (COVID-19) outbreak- A n update on the status. Mil Med Res. 2020;7(1):1-10.

8. Zhang W DRLBZXYXLHBeaMasio2nipiomsrEMI2, 9(1):386-9. Molecular and serological investigation of 2019-nCoV infected patients: implication of multiple shedding routes. Emerg Microbes Infect. 2020;9(1):386-9.

9. Zhou PYXLWXHBZLZWeaApoawancopboN[2, http://dx.doi.org/10.1038/s41586-020-2012-75Af. A pneumonia outbreak associated with a new coronavirus of probable bat origin. Nature. 2020;579(7798):270273. 
10. Liu M CSXKYYZQZHea. Use of personal protective equipment against coronavirus disease 2019 by healthcare professionals in Wuhan, China: cross sectional study. J Hosp Infect. 2020;105:100-1.

11. Ge ZY YLXJFXZY. Possible aerosol transmission of COVID-19 and special precautions in dentistry. J Zhejiang Univ Sci B. 2020:1-8.

12. Suri S VYKABRAM. Clinical Orthodontic Management During the COVID-19 Pandemic. Angle Orthod. 2020.

13. Matus CP NMIM. Atención de Pacientes en Tratamiento de Ortodoncia Durante la Pandemia COVID-19 (SARS-CoV-2). Presentación de un Algoritmo. Int J Odontostomat. 2020;14(4):489-494.

14. Caprioglio A PGZPFRMGNR. Management of orthodontic emergencies during 2019-NCOV. Prog Orthod. 2020;21.

15. Asociación Latinoamericana de Odontopediatría. Teleodontología: Aplicación a la Odontopediatría durante la pandemia COVID-19. Rev Odontoped Latino. 2020;10(2).

16. Kravitz ND, Burris B, Mayordomo D, Dabney CW. Teledentistry Ortodoncia de bricolaje y Monitoreo de tratamiento remoto. J Clin Orthod. 2016;50:718-726.

17. Cotrin PP PRORORPNVFea. Impact of coronavirus pandemic in appointments and anxiety/concerns of patient regarding orthodontic treatment. Orthod Craniofac Res. 2020.

18. Saccomanno SV, Quinzi V, Sarhan S, Laganà S. Perspectives of Tele-Orthodontics in the COVID-19 Emergency and as a Future Tool in Daily Practice. Eur J Paediatr Dent. 2020;21(2):157-162.

19. Odontopediatría ALd. Estrategias Psicoconductuales e información para Odontólogos y pacientes que requieran procedimientos de Odontología Pediátrica durante la etapa de la pandemia COVID-19. Rev Odontoped Latino. 2020;10(2).

20. Society BO. www.bos.org.uk. Patients' Home Videos Repairs. Available at: https://www.bos.org.uk/COVID19-BOS-Advice/Patients-Advice/Patients-Home-Videos-Repairs. Accessed Julio 10, 2020.

21. Asociación Colombiana de Infectología. Consenso Colombiano de atención, diagnóstico y manejo de la infección por SARS-CoV-2/COVID-19 en establecimientos de atención de la salud. 2da Edición. Recomendaciones basadas en el consenso de expertos e informadas en la evidencia. Infectio. 2020;24(3):S2.

22. Consejo General de Dentistas de España / Association Dentaire Française. COVID-19 Guía practica en base a las recomendaciones de expertos validados. 2020.

23. Chile SdOyODd. Protocolo Bioseguridad Sugerido Para Atención en Ortodoncia durante Periodo de Pandemia

24. Royal College Of Surgeons of England. Recommendations for Orthodontics during COVID-19 pandemic. 2020. Available at: file:///C:/Users/nebn8/Downloads/Orthodontics\%20COVID19.pdf.

25. Lucea A. El manejo de las urgencias en ortodoncia. Ortodoncia clínica. 2003;6(3):159-164.

26. Centers for Disease Control and Prevention CDC. Interim Infection Prevention and Control Recommendations for Patients With Suspected or Confirmed Coronavirus Disease 2019 (Covid-19) in Healthcare Settings. abril 2020. Available at: https://www.cdc.gov/coronavirus/2019-ncov/hcp/infection-control-recommendations.html?CDC_AA_refVal=https\%3A\%2F\%2Fwww.cdc.gov\%2Fcoronavirus\%2F2019-nco$\mathrm{v} \% 2$ Finfection-control\%2Fcontrol-recommendations.html.

27. Dave M, Seoudi N, Coulthard P. Urgent dental care for patients during the COVID-19 pandemic. The Lancet. Abril 2020:DOI:https://doi.org/10.1016/S0140-6736(20)30806-0.

28. Xu H, Zhong L, Deng J, Peng J, et al. High expression of ACE2 receptor of 2019-nCoV on the epithelial cells of oral mucosa. Intl J Oral Sci. 2020;12(8):https://doi.org/10.1038/s41368-020-0074-x.

29. Mallineni SK, Innes NP, Raggio DP, Araujo MP, Robertson MD, Jayaraman J. Coronavirus Disease (COVID-19): Characteristics in children and considerations for dentists providing their care. Int J Paed Dent. abril 2020:doi: 10.1111/ipd.12653.

30. American Dental Association (ADA). Interim Guidance for Minimizing Risk of COVID-19 Transmission. abrl 7, 2020. Available at: https://www.ada.org/ /media/CPS/Files/COVID/ADA_COVID_Int_Guidance_Treat_Pts.pdf?utm_source=adaorg\&utm_medium $=$ covid-resources-lp\&utm_content=cv-pm-ebd-interim-response\&utm_campaign=covid-19?utm_source=adaorg\&utm_medium=adanews\&utm_conten$\mathrm{t}=\mathrm{cv}$-pm-ebd-interi. Accessed abril 8, 2020.

31. Consejo General de Dentistas de España. Informe Técnico II del Consejo General de Dentistas de España: Desafíos emergentes del nuevo Coronavirus COVID-19 en la clínica dental 2020.

32. Meng L, Hua F, Bian Z. Coronavirus Disease 2019 (COVID-19): Emerging and Future Challenges for Dental and Oral Medicine Treatment of Emergency Cas. J Dent Res. 2020:DOI: 10.1177/0022034520914246.

33. Peng X, Xu X, Li Y, Cheng L, Zhou X, Ren B. Transmission routes of 2019-nCoV and controls in dental practice. Intl J Oral Sci. 2020;12:https://doi.org/10.1038/s41368-020-0075-9. 
34. Cochrane. COVID-19 Dental Services Evidence Review (CoDER) Working Group. Recommendations for the re-opening of dental services: a rapid review of international sources. Mayo 06, 2020. Available at: https://oralhealth.cochrane.org/sites/oralhealth.cochrane.org/files/public/uploads/covid19_dental_review_16_may_2020_update.pdf. Accessed Mayo 15, 2020.

35. Orthodontic convit.. Available at: www.rcseng.ac.uk/dental-faculties/fds/coronavirus.

36. Sunnak R JAFP. Is orthodontics prior to 11 years of age evidence-based? A systematic review and meta-analysis. J Dent. 2015;43(5):477-86.

37. Tecco S BANEPJ. Orthodontics in Growing Patients: Clinical/Biological Evidence and Technological Advancement. Biomed Res Int. Biomed Res Int 2018:10-3.

38. PS F. Timing orthodontic treatment: early or late? Aust Dent J. 2017;62:11-9.

39. Rapeepattana S TASS. Etiology of malocclusion and dominat orthodontic problems in mixed dentition: A cross-sectional study in a group pf Thai children aged 8-9 years. J Int Soc Prev Community Dent. 2019;9:383-9.

40. Al Nimri K, Richardson A. Interceptive orthodontics in the real world of community dentistry. Intl J Paed Dent. 2000(10):88-108.

41. Maspero C, Abate A, Cavagnetto D, El Morsi M, Fama A, Farronato M. Available technologies, applications and benefits of teleorthodontics. A review of the literature and possible applications during the COVID-19 pandemic. J. Clin. Med. 2020;9(6):E-1981.

42. Seehra J, Fleming PS, Newton T, Di Biase AT. Bullying in orthodontic patients and its relationship to malocclusion, self- esteem and oral health-related quality of life. J Orthod. 2011;38:247-256.

43. Dutra SR, Pretti H, Martins MT, Bendo CB, Vale MP. Impact of malocclusion on the quality of life of children aged 8 to 10 years. Dental Press J Orthod. 2018;23(2):46-53.

44. Agou S, Locker D, Steiner DL, Tompson B. Impact of self-esteem on the oral-health-related quality of life of children with malocclusion. Am J Orthod Dentofacial Orthop. 2008;134:484-489.

45. Araki M, Yasuda Y, Ogawa T, et al. Associations between Malocclusion and Oral Health-Related Quality of Life among Mongolian Adolescents. Int J Environ.Res Public Health. 2017;14:902: doi:10.3390/ ijerph14080902.

46. Kragt L, Dhamo B, Wlovius EB, Ongkosuwito EM. The impact of malocclusions on oral health-related quality of life in children-a systematic review and meta-analysis. Clin Oral Invest. 2016;20:1881-194.

47. Batista KBSL, Thiruvenkatachari B, Harrison JE, O'Brien KD. Orthodontic treatment for prominent upper front teeth (Class II malocclusion) in children and adolescents. Cochrane Database of Systematic Reviews. 2018: DOI: 10.1002/14651858.CD003452.pub4.

48. ANAES. Indications de l'Orthoped'die Dento-Faciale et Dento-Maxilo-Faciale

49. American Association of Orthonontists AAO. linical Practice Guidelines for Orthodontics and Dentofacial Orthopedics

50. Fleming P. Timing orthodontic treatment: early or late? Aust Dent J. 2017;62:11-9.

51. Reyes BC BTMJJ. An Estimate of Craniofacial Growth in Class III Malocclusion. Angle Orthod. 2006;76(4):577-84.

52. Salazar L PMAESAMROJO. Effect of face mask therapy on mandibular rotation considering initial and final vertical growth pattern: A longitudinal study. Clin Exp Dent Res. 2019;5(4):343-9.

53. P A. Early Treatment for Class III Malocclusions: The Facts. Orthod Fr. 2013;84(1):41-52.

54. Li N ZWSHZJ. The stability of soft tissue changes in patients with skeletal Angle Class III malocclusion after orthodontic-orthognathic treatments. Shanghai J Stomatol. 2009;18(4):350-4.

55. Chen X XBGL. Effects of breast-feeding duration, bottle-feeding duration and non-nutritive sucking habits on the occlusal characteristics of primary dentition. BMC Pediatr. 2015;15(1):1-9.

56. Schmid KM KRNPBCVC. The effect of pacifier sucking on orofacial structures: a systematic literature review. Prog Orthod. 2018;19(1).

57. Ling HTB SFZLYCLKWH. The association between nutritive, non-nutritive sucking habits and primary dental occlusion. BMC Oral Health. 2018;18(1):1-10.

58. Gomes MC NEPMMCPSGGA. Association between psychological factors, socio-demographic conditions, oral habits and anterior open bite in five-year-old children. Acta Odontol Scand. 2018;76(8):553-8.

59. Arhakis A BE. Etiology, Diagnosis, Consequences and Treatment of Infraoccluded Primary Molars. Open Dent J. 2017;10(1):714-9.

60. Aktan AM KISIBCCSKMea. An evaluation of factors associated with persistent primary teeth. Eur J Orthod. 2012;34(2):208-12. 
61. Tieu LD WSMMFMC. Management of ankylosed primary molars with premolar successors: A systematic review. J Am Dent Assoc. 2019;144(6):602-11.

62. Achmad M. Overjet problems at the growing child, case report using the twin block appliance. J Dentomaxillofac Sci. 2017;2(1):49-53.

63. Silva-Esteves J, Aliaga R, Aliaga A. Tratamiento de una maloclusión Clase II División 1 en dentición mixta. Odontol Pediatr. 2013;12(1).

64. Cirgic E. Studies of treatment effects, cost assessment and patient perceptions - a comparison of two removable functional appliances

65. Quinzi V, Caruso S, Mummolo S, et al. Evaluation of Lower Dental Arch Crowding and Dimension after Treatment with Lip Bumper versus Schwarz Appliance. A Prospective Pilot Study. Dent J. 2020;8(34).

66. Indriyanti R, Hidajat S, Maskoen A, Riyanti E. Predisposing factors analysis of mandibular anterior tooth crowding in the mixed dentition period by the tooth size and dental arch width. Padjadjaran journal of dentistry. 2018;30(3):207-213.

67. Tokarevich I, Rublevsky D. Mandibular incisor crowding in the mixed dentition. Advances in etiology, early diagnosis and orthodontic treatment. Dental Science ad practice. 2014;5(5).

68. Firmani M, Reyes M, Becerra N, Flores G, Weitzman M, Espinosa P. Bruxismo de sueño en niños y adolescentes. Rev chil pediatri. 2015;86(5).

69. Rojas D, Teran K, Alvarez C. Bruxismo del sueño en niños: actualización de la literatura. Odontol Pediatr. 2017;25(3):209-216.

70. Bjoerk A KASB. A method for epidemiological registration of malocclusion. Acta Odontol Scand. 196;22:27-41.

71. Kecik D KISI. Evaluation of the treatment changes of functional posterior crossbite in the mixed dentition. Am J Orthod Dentofac Orthop. 2007;131(2):202-15.

72. Myers DR BJBRWE. Condylar position in children with functional posterior crossbites: before and after crossbite correction. Pediatr Dent. 1980;2:190-4.

73. Lippold C STMUVAMTDG. Early treatment of posterior crossbite - a randomised clinical trial. Trials. 2013;14(1):1-10.

74. AJ H. Rapid expansion of the maxillary dental arch and nasal cavity by opening the mid-palatal suture. Angle Orthod. 1961;31:73-90.

75. Farronato I MCELBEFDGL. Rapid maxillary expansion in growing patients. Hyrax versus transverse sagittal maxillary expander: a cephalometric investigation. Eur J Prthod. 2011;33(2):185-9.

76. JA MJ. Maxillary transverse deficiency. Am J Orhod Dentofac Orthop. 2000;117:567-70.

77. Proffit W FH. Contemporary Orthodontics. 5th ed: Mosby; 2012.

78. Almeida MR ARINPCANRCJ. Early treatment of Class III malocclusion: 10-year clinical follow-up. J Appl Pral Sci. 2001;19(4):431-9.

79. RR A. Ortodontia preventiva e interceptadora. Mito ou realidade. Dental Press. 2015:657.

80. Negi KS SK. Treatment of pseudo Class III malocclusion by modified Hawleys appliance with inverted labial bow. J Indian Soc Pedod Prev Dent. 2011;29:57-61.

81. Di Palma E TMCCTGSC. Longitudinal effects of rapid maxillary expansion on masticatory muscles activity. J Clin Exp Dent. 2017;9:635-40.

82. Pereira Da Silva HCF DPJRNJ. Anterior crossbite treatment in the primary dentition: Three case reports. Int Orthod. 2018;16(3):514-29.

83. Rossi LB PKBELNGA. Correção da mordida cruzada anterior funcional com terapia de pistas diretas de planas- relato de caso. Rev Faculdade Odontol Lins. 2012;22:45-50.

84. M J. n Overview of Class III Malocclusion (Prevalence, Etiology and Management). Br J Med Res. 2018;25(7):1-13.

85. Alhammadi MS HEFMLAEsC. Global distribution of malocclusion traits: A systematic review. Dental Press J Orthod. 2018;23(6):1-10.

86. Ngan P MW. Evolution of Class III treatment in orthodontics. Am J Orthod Dentofac Orthop. Am J Orthod Dentofac Orthop. 2015;148:22-36.

87. AR V. Orthodontics and Genetics. Dental Press J Orthod. 2019;24(2):92-7.

88. Muthukumar K VNSM. Management of skeletal Class III malocclusion with face mask therapy and comprehensive orthodontic treatment. Contemp Clin Dent. 2016;7(1):98-102.

89. W M. Class III treatment by combining facemask (FM) and maxillary skeletal expander (MSE). Semin Orthod. 2018;24(1). 
90. Thomaz EBAF ACGeSLRdACSdBAMHJ. Breastfeeding Versus Bottle Feeding on Malocclusion in Children: A Meta-Analysis Study. J Hum Lact. 2018;34(4):768-88.

91. Borrie FRP BDINIEZ. Interventions for the cessation of non-nutritive sucking habits in children. Cochrane Database Syst Rev. 2015;2015(3).

92. Feres MFN ALINDAMFMC. Effectiveness of open bite correction when managing deleterious oral habits in growing children and adolescents: A systematic review and meta-analysis. Eur J Orthod. 2017;39(1):3142.

93. Brierley C, DiBiase A, Sandler P. Early Class II treatment. Australian Dental Journal. 2017;62(1 Suppl):4-10.

94. Ocampo A, Parra N, Botero M. Guía de erupción y extracción seriada: una mirada desde el desarrollo de oclusión. Rev Nac Odontol. 2013;9(edición especial):25-35.

95. M R. Tratamiento precoz del apiñamiento dental en dentición mixta: procedimientos de intervención no habituales sin tocar los dientes permanentes. Rev Esp Ortod. 2003;33:203-14.

96. Santiesteban F, Gutiérrez M, Gutiérrez J. Crowding severity associated with dental mass. Revista mexicana de ortodoncia. 2016;4(3):e163-e165.

97. Al-Sehaibany F. Assessment of incisor crowding in mixed dentition among saudi schoolchildren attending college of dentistry clinics at king saud university. pakistan Oral \& Dental Journal. 2011;31(1).

98. Bertrand P, Black D, Carlson C. American Academy of Orofacial Pain Guidelines for Assessment, Diagnosis, and Management. Quintesence Publ Co. 2008;22:190-200.

99. Hermida M, Cortese S, Kalil S, Ferreira R, Spatakis L. Tratamiento del bruxismo del sueño en niños. Rev Odontop Latino. 2020;10(1).

100.Mota B, Gomez N. Bruxismo en niños: a propósito de un caso. Odontol Pediatr. 2016;24(3).

101.Bolaños E, Del Castillo R, Rodriguez E. El bruxismo infantil. Odontol Pediatr. 2002;10(3):135-41.

102.Srirengalakshmi M, Venupagal A, Pangilinan P, et al. Orthodontics in the COVID-19 Era: The Way Forward. Part 2 Orthodontic Treatment Considerations. J Clin Orthod. 2020;54(6).

103.Park J, Kim J, Kai A, Rogowski L, Liu A. Post-COVID-19 Clinical and Management Guidelines for Orthodontic Practices. Journal of Clinical Orthodontics. 2020. https://www.jco-online.com/covid19-resources/ post-covid-19-clinical-and-management-guidelines-for-orthodontic-practices/. Accessed Julio 11, 2020.

104.Batista K, Thiruvenkatachari B, Harrison J, O'Brien K. Orthodontic treatment for prominent upper front teeth (Class II malocclusion) in children and adolescents (Review). Cochrane Database Syst Rev. Marzo 2018;3(3).

Recibido: 10/06/2020

Aceptado: 30/06/2020

Correspondencia: e-mail: editor@revistaodontopediatria.org 


\section{Interceptive orthodontics during COVID-19 pandemic: emergencies and priority treatments.}

\section{Introduction}

Different international and local health organizations have published recommendations, regulations, and protocols for dental care during the COVID-19 pandemic.

Due to the unprecedented nature of this pandemic and the rapid evolution of COVID-19, the temporary suspension of regularly scheduled oral examinations, as in orthodontics, is a reason of concern as orthodontics is a long and continuous process. We currently face limited information on the management of interceptive orthodontics during the pandemic. There is a need to consider available scientific knowledge that can guide dentists, pediatric dentists and orthodontists.

The Latin American Association of Pediatric Dentistry, in its mission to support and bring the best information available to all Latin colleagues, has published practice guidelines and supporting documents that are easy to use and share with the entire dental community that works in hospitals, government clinics, educational and private clinical institutions. ${ }^{1,2,3}$

The purpose of this specific document is to provide guidelines for the management of patients undergoing interceptive orthodontic treatments during the COVID-19 pandemic, considering the available literature and expert opinion.

The treatment of malocclusions in pediatric patients through Interceptive Orthodontics includes different therapeutic approaches using a fixed and removable device that have been widely supported in the literature. Many pediatric patients carry devices or need short-term therapy, situations that require treatment planning according to their developmental stage during the pandemic.

Interceptive Orthodontics requires close follow-up between the dentist and patient, which contravenes social distance rules. In addition, most patients undergoing orthodontic treatment are children, reported in several studies as potential asymptomatic carriers, increasing the risk of contagion. Among the possible contamination sources, the following stand out the patient's saliva, aerosols and materials, and instruments used. ${ }^{4}$

Although orthodontic procedures are considered generally optional, there are situations where they are necessary. Thus, this document seeks to clarify what scenarios can be regarded as orthodontic emergencies during the COVID-19 pandemic. Suggest which conditions can be managed at home through teledentistry and which scenarios require an in-person assessment. Likewise, we will suggest which the malocclusions should require priority management, suggesting some therapeutic recommendations based on different evidence levels during primary or mixed dentition.

The recommendations proposed below are linked to an exceptional situation and may differ from normal clinical practices. They 
do not constitute an exhaustive clinical protocol of all possible treatments. Still, an orientation guide, without replacing local regulations, specific protocols or the laws in force in each country, is subject to evolution. They may continuously change depending on the public health situation. We encourage dental professionals to follow updates.

\section{Interceptive orthodontics the COVID-19 pandemic times}

The definition of coronavirus includes a variety of viruses that affect airways ${ }^{5}$. On January 9, 2020, the World Health Organization( $\mathrm{WHO}$ ) declared the discovery of a new coronavirus, called SARS-CoV-2, that had never been identified in humans before. Subsequently, on February 11, the respiratory disease caused by infection with SARS-CoV-2 was called COVID-19. ${ }^{6}$

SARS-CoV-2 can be found in human secretions such as blood, saliva and feces. Therefore, it can be transmitted by direct contact with an infected individual and by secretions produced by the same individual. ${ }^{7-9}$

Several studies have reported the crosstransmission of COVID-19 between health professionals 10 . The disease can be transmitted from one health professional to another, from a health professional to a patient or from patient to patient. ${ }^{11}$

Everyone who attends a dental office is directly exposed to this virus's transmissibility on its different routes. Therefore, dentists should be aware of the available evidence to provide a safe environment for themselves, their staff, their patients and their families. ${ }^{1-4,12}$

Given the strong recommendation for confinement during the COVID-19 pandemic, dentistry was limited to only emergency dental care. It is known that orthodontic treatment can cause discomfort in the patient. On some occasions, it can facilitate lesions in the oral mucosa, loss or fracture of orthodontic accessories, or loss of orthodontic retainers. These treatment complications generate anxiety in the patient and families and involve an extra visit to the dental office.

To plan patients' care during the pandemic, it is first necessary to classify orthodontic appointments as high or low risk, identify the treatment need (urgency that requires face-to-face consultation in the office) and evaluate the moment when the emergency arises. The latter should be classified as the care needed during confinement and after the confinement stage. ${ }^{13}$

During the confinement period, it is recommended to postpone any routine consultation and restrict treatment to emergency cases, which cannot be remotely resolved by the patient, following $\mathrm{WHO}$ and local authorities. ${ }^{13}$

Once confinement is complete, even in a period of pandemic or slowdown, biosafety protocolsand care recommendationsshould still be followed. This condition will require a different office organization for several months, and remote patient management can efficiently use teledentistry platforms to offer health care. ${ }^{14}$

\section{Teledentistry}

The best way to deal with interceptive orthodontic emergencies is to follow an ordered sequence step by step. It has been used to obtain direct and quick contact between the patient under treatment and his dentist, managing to transmit simple to follow instructions that can support 
patients and help manage emergencies ${ }^{15}$. Unfortunately, during confinement, emergencies persist. The dentist must know how these emergencies can be assessed and treated without the patient physical presence and the family in the office.

After confinement, there will be an increase in the number of patients needing dental care. It was decided to discuss the malocclusion types that should be prioritized during this pandemic phase since their immediate growth development will depend on certain cases on immediate management.

Several studies have described teledentistry as an effective tool that allows treatment control in situations where the patient cannot go to the clinic. ${ }^{16}$

Contrin et al. ${ }^{17}$ carried out a study on the level of anxiety and concern of Brazilian orthodontic patients regarding the COVID-19 pandemic and the impact of this period on consultations and treatment. It was observed that $60 \%$ of patients studied were willing to go to an orthodontic consultation during the pandemic, with delay in treatment as their main concern. The average anxiety level related to orthodontic treatment's pandemic impact was 4.04 , being 0 without anxiety and 10 with extreme anxiety.

Routine monitoring of teledentistry will depend on the clinical situation to be assessed, and follow-up control appointments are usually required every one or two months.

The first step should always be virtual management using WhatsApp, or similar software can be considered a good tool to do it. Virtual management can be done through photos, videos, or video calls ${ }^{14}$. It is important to get informed consent before setting up a face-to-face consultation. 3, 15, 18
During the second step, it is recommended to perform a remote screening by phone, video call, email or other online modalities with the patient or his parents. The problem will be identified and determine if it is an emergency or not. A face-toface consultation is justified or if there is a feasible way of providing virtual management. ${ }^{16,18}$

To increase children's participation and improve communication, emojis can be used ${ }^{18}$ they are also used in psychology and health sciences to identify the degree of pain or measure levels of anxiety. The use of emojis in instant messaging services and in-app chats is useful to facilitate communication with patients.

Audiovisual resources can be a source of support for pediatric dentists for their patients and parents/guardians, which can be easily distributed through instant messages. It makes it possible to anticipate the patient's situations in the consultation during the COVID-19 confinement stage, which will facilitate communication. This support material was developed by the Latin American Association of Odontopediatrics ${ }^{19}$ and is available at the link: https://www.revistaodontopediatria. o r g / e d i c i o n e s / $2020 / 2$ / a r t 5/\#art1\%23anexos-es

Likewise, the specialist can count on audiovisual resources available on orthodontic associations websites as soon as he determines that the emergency can be resolved at home ${ }^{12}$. Audiovisual aids can be converted into supporting material for various orthodontic emergencies. The specialist will explain the procedure more simply, making communication much more effective, providing security and confidence to parents/guardians when performing the procedure and reducing fear and anxiety. These are available at 
https://www.bos.org.uk/COVID19-BOSAdvice/Patients-Advice/Patients-HomeVideos-Repairs ${ }^{20}$

The third step is that if it is confirmed that the orthodontic emergency must be attended to in person, a questionnaire should be sent to the patient, who must answer yes or no to a series of questions about their signs and symptoms last 14 days. Suppose the patient answers positively to one or more questions and is classified as a high-risk patient. In that case, the option of postponing the service and providing virtual support should be evaluated and, if this is not possible, the care should be provided under a strict protocol with the incorporation of additional measures ${ }^{21,22}$. Among them, immediate admission to the office, being attended with the door closed and without the presence of other patients at the same time, strictly resolving the emergency, spatial biosafety measures and avoiding usage of aerosols.

For patients with a history of COVID-19, it is recommended that patients leave home isolation when at least 72 hours have elapsed since recovery (resolution of fever without using drugs to reduce and improve symptoms). ${ }^{12}$

If radiographic examinations are necessary, extraoral dental radiographs, such as panoramic radiography and tomography, are appropriate alternatives during COVID-19.

\section{Dental emergencies in interceptive orthodontics}

An orthodontic emergency can be described as a problem that arises from an orthodontic appliance that requires an unscheduled visit to resolve the problem ${ }^{14}$, which can be associated with severe physical discomfort (mucosa, lips and tongue irritation), an infectious process, aesthetic impact (severe aesthetic deterioration) or related scenarios that if left untreated can have serious consequences for the completion of orthodontic therapy ${ }^{23}$. In an emergency, the patient must contact the clinic by phone or by teledentistry methods to discuss ways to solve the problem at home. Almost all orthodontic emergencies can be managed through appropriate advice from a qualified health professional.

The most common orthodontic problems, such as detached brackets or tubes and removable appliances or lost or fractured retainers, can initially be managed remotely through a video call or consultation ${ }^{24}$. In this way, special emphasis is placed on the use of teledentistry, to achieve the best possible diagnosis through screening and thus be able to determine whether patients/ guardian guidance is feasible to resolve the emergency or if there is a need for care in the dental office. ${ }^{15}$

In orthodontic emergencies, the specialist must first try to manage the emergency over the phone or remotely. Consent given via telephone conversation or electronically must be obtained to provide guidance. The specialist should chart all the instructions given to keep records of the treatment's evolution, as would be done regularly. ${ }^{12,15}$

When the professional use telecommunications, the patient's health history must be obtained to collect symptoms or history relevant to COVID-19. Suppose the patient must be seen in person. In that case, the medical history will also allow the specialist to assess the possible transmission risks and ensure that the clinic is adequately equipped with Personal Protective Equipment (PPE). The following is a flow chart for the care of patients with orthodontic emergencies during the COVID-19 pandemic (Figure 1). 


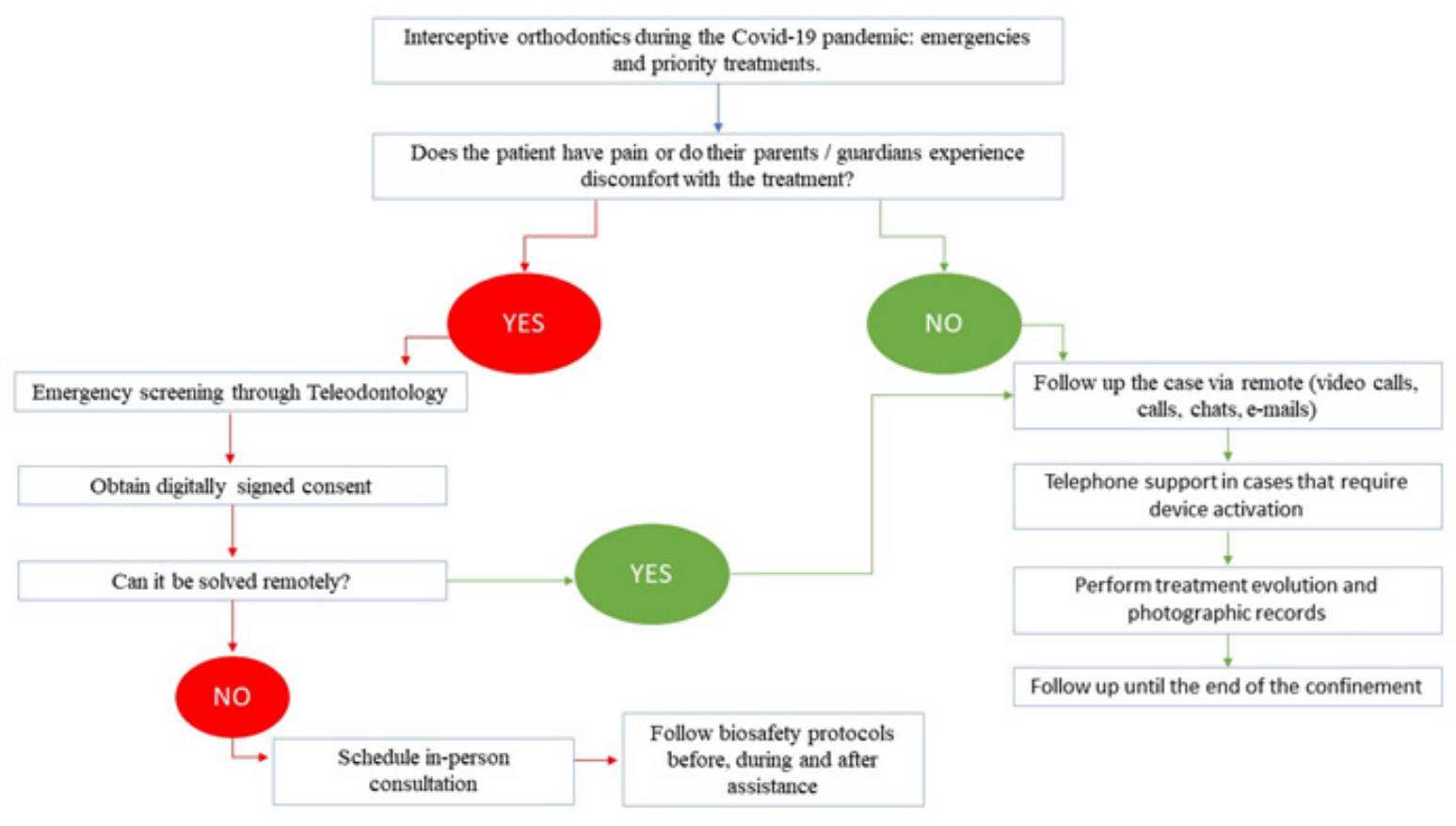

Figure 1. Flowchart of emergency care in interceptive orthodontics during the COVID-19 pandemic. ${ }^{4,12,13}$

\section{Emergency categorization and management in orthodontics}

Once teleconsultation and screening have been carried out, the emergency that requires face-to-face care can be identified and prioritized using the urgency criteria.

Orthodontic emergencies can be classified according to the type of device used by the patient, which can be fixed or removable ${ }^{14}$. As mentioned above, most of these emergencies can be resolved at home through teledentistry. The specialist can also provide his patients and representatives with links to information related to solving the emergency through audiovisual resources that may be available on the websites of professional orthodontic associations. ${ }^{12}$

Some of the emergencies that require scheduling a visit to the dental clinic are highlighted below ${ }^{12-14,24}$ :
- Severe pain, discomfort or significant intraoral trauma from a sharp arch/ wire associated with a fixed appliance or associated retainer where the orthodontic wax application has failed to provide relief.

- Band, bracket or broken tube of a fixed device that has come loose and, therefore, there is the possibility of inhaling a foreign body.

- Partial decementation of an orthodontic band / TPA / quadrilateral / RME / lingual cannot be repositioned.

- Dentoalveolar trauma in patients with orthodontic appliances.

- Abscesses or infectious processes associated with orthodontic appliances.

- Complications of recent surgical procedures related to orthodontic treatment. 
- Severe pain or discomfort, in which the application of wax or analgesics' use did not provide enough relief.

- Assessment of ectopic teeth traction progress due to the risk of ankylosis, excessive eruption or displacement.

- Another very common problem in fixed orthodontics is the protrusion of the wire at their distal ends, causing trauma and/or ulcers in the soft tissues.

During the confinement period, emergency treatment should be limited to cutting and tightening the trauma wires or simply removing any loose components from the device. If the patient breaks a removable device or experiences significant discomfort when using it, it is recommended to discontinue its usage for the time being to reduce emergencies.

Suppose the patient feels pain, redness or edema near a fixed orthodontic appliance. In that case, it must be ruled out that it is a periodontal abscess, suggesting a personal consultation to eliminate the cause, for example, a band under the gums.

Tables 1, 2 and 3 show some of the most common emergencies that can arise during confinement and various counselling options given by specialists to be solved at home. ${ }^{12,14,25}$

Table 1: Orientation for orthodontic emergencies in patients with fixed appliances during the COVID-19 pandemic. ${ }^{12,14,25}$

\begin{tabular}{|l|l|}
\hline $\begin{array}{c}\text { Orthodontic emergency in patients with } \\
\text { fixed appliances: expanders, lingual / } \\
\text { transpalatal arches, lip-active plates, etc. }\end{array}$ & Guidance during confinement due to COVID-19 \\
\hline $\begin{array}{l}\text { Fixed devices are activated by the patient } \\
\text { (maxillary expanders, face masks, etc.). }\end{array}$ & $\begin{array}{l}\text { Take pictures every 20-40 days. If the patient } \\
\text { experiences pain or inflammation, the consultation } \\
\text { should be seen as an emergency, and the device } \\
\text { should be removed. }\end{array}$ \\
\hline $\begin{array}{l}\text { Pre-activated fixed devices (transpalatal } \\
\text { bars, etc.) }\end{array}$ & $\begin{array}{l}\text { Realizar monitoreo con Teleodontología, solicitando } \\
\text { imágenes cada 15 dias y realizar evaluaciones para } \\
\text { determinar necesidad de consulta presencial. } \\
\text { Si el paciente experimenta dolor o inflamación, } \\
\text { debe verse en la consulta como una urgencia y } \\
\text { retirar el dispositivo. }\end{array}$ \\
\hline $\begin{array}{l}\text { Fixed expander or broken or loose lingual/ } \\
\text { palatal arch. }\end{array}$ & $\begin{array}{l}\text { Request a photo of the patient. } \\
\text { If it is partially detached and still present in the } \\
\text { mouth, reposition it, and suspend activations until } \\
\text { a specialist visit. } \\
\text { If it is completely out, keep it in a safe place until } \\
\text { you visit the orthodontist or pediatric dentist. }\end{array}$ \\
\hline
\end{tabular}


Table 2: Counseling for orthodontic emergencies in patients with a removable device during the COVID-19 pandemic. ${ }^{12,14,25}$

\begin{tabular}{|c|c|}
\hline $\begin{array}{l}\text { Orthodontic emergencies in patients } \\
\text { with removable appliances }\end{array}$ & Guidance during confinement due to COVID-19 \\
\hline $\begin{array}{l}\text { Interference of a tooth during the second } \\
\text { phase of mixed dentition }\end{array}$ & $\begin{array}{l}\text { Request a photo of the patient. } \\
\text { Stop using it to avoid future emergencies }\end{array}$ \\
\hline $\begin{array}{l}\text { Fracture or discomfort of the functional } \\
\text { appliance during use. }\end{array}$ & $\begin{array}{l}\text { Request a photo of the patient. } \\
\text { Stop using it to avoid future emergencies. }\end{array}$ \\
\hline $\begin{array}{l}\text { Lesions of the mucosa caused by parts of } \\
\text { the arch. }\end{array}$ & $\begin{array}{l}\text { Request a photo of the patient. } \\
\text { Instruct parents/caregivers on how to twist the bow } \\
\text { with light pressure from your fingers. } \\
\text { If the loop on the mucosa's pressure is not relieved, } \\
\text { discontinue its use to avoid future emergencies. }\end{array}$ \\
\hline Removable patient-activated devices & Suspend activations to avoid future emergencies. \\
\hline Unfiiting appliances & $\begin{array}{l}\text { Request a photo of the patient. } \\
\text { Ask by video call about the frequency of use. } \\
\text { Instruct to screw back the device and test the fit of the } \\
\text { plate. } \\
\text { If the appliance does not adapt, discontinue its use } \\
\text { until the next consultation. }\end{array}$ \\
\hline Lack of device retention & $\begin{array}{l}\text { Request a photo of the patient. } \\
\text { Stop using it to avoid future emergencies. }\end{array}$ \\
\hline Fractured retainers & $\begin{array}{l}\text { Request a photo of the patient. } \\
\text { Suggest to the patient the online purchase of heat- } \\
\text { formed retainers. } \\
\text { When the pandemic is over, the specialist can make } \\
\text { new retainers. } \\
\text { In the event of rupture or loss of a retainer, and there } \\
\text { is a risk of recurrence that irreversibly compromises } \\
\text { the treatment, the dentist can make an appointment in } \\
\text { person as soon as possible. }\end{array}$ \\
\hline
\end{tabular}


Table 3: Counseling of orthodontic emergencies in patients with fixed appliances for small movements during the COVID-19 pandemic. ${ }^{12,14}$

\begin{tabular}{|c|c|}
\hline $\begin{array}{l}\text { Orthodontic emergency in } \\
\text { patients with fixed appliances } \\
\text { for small movements }\end{array}$ & Guidance during confinement due to COVID-19 \\
\hline $\begin{array}{l}\text { Irritation of the lips or cheeks } \\
\text { due to accessories. }\end{array}$ & $\begin{array}{l}\text { Request a photo of the patient. } \\
\text { Place a small amount of orthodontic wax (relief wax) on the } \\
\text { accessory (bracket, bandage, bow) that is irritating. Pain } \\
\text { associated with traumatic injuries can be relieved by applying } \\
\text { topical anesthesia directly to the injury using a cotton swab. }\end{array}$ \\
\hline $\begin{array}{l}\text { Loose / disconnected } \\
\text { orthodontic accessory (bracket, } \\
\text { tube or band). }\end{array}$ & $\begin{array}{l}\text { Request a photo of the patient. } \\
\text { Suppose the bracket rotated around the arch, causing } \\
\text { discomfort. In that case, it could be repositioned with } \\
\text { disinfected pliers, rotating it around the arch at the point } \\
\text { where two teeth come into contact to provide more room for } \\
\text { maneuver. } \\
\text { If the bracket is used as a hook for intermaxillary elastics, stop } \\
\text { using them. } \\
\text { If the detached bracket is the arch's last accessory, you can } \\
\text { either slide it through the arch, remove it, cut the arch at the } \\
\text { last point with an attached bracket, and carefully remove it } \\
\text { from the mouth. } \\
\text { If a band or bracket remains level with the tooth, it can be left } \\
\text { for observation; if there is a risk of falling into the oral cavity } \\
\text { or tearing the mucosa, the patient can remove it carefully with } \\
\text { eyebrow tweezers. }\end{array}$ \\
\hline $\begin{array}{l}\text { Protruding arch at the end of } \\
\text { the bracket/tube. }\end{array}$ & $\begin{array}{l}\text { Request a photo of the patient. } \\
\text { Apply orthodontic wax or relief wax. } \\
\text { Use a cotton swab or a clean pencil eraser to push the arch } \\
\text { against the tooth. } \\
\text { If the discomfort is caused by the arch sliding from one end to } \\
\text { the other, use eyebrow tweezers to move it back until you are } \\
\text { comfortable on both sides. } \\
\text { If the arch is extremely irritating, you can cut it with a } \\
\text { disinfected nail clipper with extreme care not to swallow the } \\
\text { cutting segment. } \\
\text { If the wire tears the soft tissue, the patient or professional can } \\
\text { use a sterile nail clipper to cut it if the specialist cannot make } \\
\text { the face-to-face consultation. }\end{array}$ \\
\hline Band decemented. & $\begin{array}{l}\text { Request a photo of the patient. } \\
\text { If the band is loose, remove it with disinfected forceps. } \\
\text { If the band is only partially loose, it can be repositioned with } \\
\text { a cotton swab or a clean pencil eraser. }\end{array}$ \\
\hline $\begin{array}{l}\text { Aspiration an orthodontic } \\
\text { accessory. }\end{array}$ & $\begin{array}{l}\text { Keep calm. Due to these accessories' small size, they end up } \\
\text { passing through the digestive tract when ingested. } \\
\text { Confirm that the patient has no breathing problems or } \\
\text { coughs when swallowing the device. If these symptoms } \\
\text { occur, instruct the patient to go to a hospital's emergency } \\
\text { department. }\end{array}$ \\
\hline
\end{tabular}




\section{Biosafety}

When providing face-to-face dental care to the patient, all biosafety measures recommended by health agencies must be strictly followed, with the highest level of personal protection, surface disinfection, adequate ventilation and decontamination of instruments and supplies 1,26-35. Minimizing aerosol production is emphasized, and it should only be used when no other options are available. ${ }^{13}$

Based on this, some actions to reduce the risk of contagion include:

1. Keep the patient aware of recommendations of the agencies that regulate health services in general and, more specifically, dental services. ${ }^{1,22,26,31}$

2. Active communication with the patient, clarifying everything that can be done without a personal visit to the dental office, and accessing the professional by email or phone for any questions.

3. Make use of teledentistry through phone calls or video calls in case of an emergency that can be managed at home.

4. Confirm negative symptoms of COVID-19, without contact with an infected person and without travelling in the last 14 days.

5. Avoid aerosols' use, always with all individual safety equipment and updated disinfection and sterilization protocols. ${ }^{4,12}$

\section{Priorities in interceptive orthodontics during COVID-19 pandemic}

In the confinement period, the recommendation, in many cases, is to avoid starting treatments. However, different countries are at different stages of the pandemic. Once confinement is released, cases requiring priority orthodontic care should be considered.

Some situations can be further complicated by the lack of face-to-face consultations, such as certain scenarios in which early orthodontic intervention is necessary through interceptive orthodontics. The delay in this action can have negative consequences. For example, there are situations in which the patient may benefit from a more efficient response to growth modification in younger individuals, taking advantage of a longer period to cause significant skeletal changes. ${ }^{36-38}$

The early identification of certain occlusal situations reduces the severity of future malocclusions ${ }^{39}$, which requires intervention as soon as they are diagnosed. Some of these conditions will be described here, and, as far as possible, management recommendations are proposed during the pandemic.

Interceptive Orthodontics encompasses the treatment of malocclusions in the primary and mixed dentition for the growing patient to eliminate unfavourable characteristics for the occlusion adequate development ${ }^{40}$. There is scientific evidence that supports the approach of some malocclusions at this stage, to minimize its complexity, promote the growth and proper development of maxillary support tissues, eliminate harmful habits and minimize the future need for complex orthodontic therapies.

The goal is to reduce unnecessary followup visits, maintaining regular monitoring without compromising the expected results, for example, evaluating the activations to be performed on the palatal expander screw. This type of approach can significantly help manage all removable 
dentofacial orthopedic devices and orthodontic treatments requiring little maintenance in office. ${ }^{41}$

Malocclusions can negatively affect the quality of life life-related oral health as children can suffer from bullying that facilitates low self-esteem ${ }^{42,43}$. The presence of increased overjet and overbite has been associated with a lower quality of life and poorer oral health. The more severe the malocclusion, the greater the negative

impact on the quality of life ${ }^{42-45}$. An inverse relationship between quality of life and severity of malocclusion, depending on the patient's age and cultural environment, has been evidenced by systematic reviews and meta-analyzes ${ }^{46}$. It has also been suggested that an increased overjet can predispose to dental trauma in some cases. Early orthodontic treatment can reduce the upper incisors' protrusion, reducing trauma damage ${ }^{47}$ (Table 4).

Table 4: Malocclusion's negative impact on pediatric patients.

\begin{tabular}{|c|c|}
\hline Malocclusion & Impact on the pediatric patient \\
\hline Functional posterior crossbite. & $\begin{array}{l}\text { Asymmetric facial growth } 48,49 \\
\text { Asymmetry of the facial muscles } 48,49 \\
\text { Joint modification } 48-50\end{array}$ \\
\hline Anterior crossbite. & $\begin{array}{l}\text { Periodontal involvement }{ }^{51-54} \\
\text { Increased malocclusion severity }{ }^{51-54} \\
\text { Decreased anterior facial height } \\
\text { Uncontrolled mandibular growth }{ }^{51-54} \\
\text { Change in the mandibular rotation axis }{ }^{51-54} \\
\text { Aesthetics }\end{array}$ \\
\hline Persistent Habits - Associated Open Bite. & $\begin{array}{l}\text { Excessive overjet }{ }^{55-58} \\
\text { Loss of space in the lower arch }{ }^{55-58} \\
\text { Posterior crossbite } \\
\text { Open anterior bite }{ }^{55-58}\end{array}$ \\
\hline Ankylized primary teeth. & $\begin{array}{l}\text { Infra-occlusion }{ }^{59-61} \\
\text { Prolonged retention of primary teeth }{ }^{59-61} \\
\text { Significant loss of arc length } \\
\text { Serious periodontal defects } \\
{ }^{59-61}\end{array}$ \\
\hline Increased overjet. & $\begin{array}{l}\text { Establishment of habits }{ }^{62-64} \\
\text { Dentoalveolar trauma }{ }^{62-64} \\
\text { Periodontal involvement }{ }^{62-64} \\
\text { Periodontal disease }{ }^{62-64} \\
\text { Bullying }{ }^{62-64} \\
\text { Temporomandibular disorders }{ }^{62-64}\end{array}$ \\
\hline Ectopic eruption or severe crowding. & $\begin{array}{l}\text { Aesthetics }{ }^{65-67} \\
\text { Periodontal disease }{ }^{65-67} \\
\text { Need for dental extractions in the medium or long term }{ }^{65-67} \\
\text { Ectopic eruptions }{ }^{65-67}\end{array}$ \\
\hline Bruxism. & $\begin{array}{l}\text { Attrition }{ }^{68,69} \\
\text { Loss of vertical dimension }{ }^{68,69} \\
\text { Periodontal disease }{ }^{68,69} \\
\text { Hypertrophy of the masticatory muscles }{ }^{68,69} \\
\text { Headache }{ }^{68,69} \\
\text { Temporomandibular disorders }{ }^{68,69}\end{array}$ \\
\hline
\end{tabular}


Based on the evidence available to date, it is suggested that priority situations that require interceptive orthodontic treatment to avoid adverse effects on the dentition development, promote a correct development of supporting tissues and promote correct maxillofacial growth include:

- Posterior crossbite correction.

- Anterior crossbite correction.

- Eradication of persistent habits associated with an open bite.

- Treatment of ankylosed primary teeth.

- Overjet reduction.

- Correction of teeth with ectopic eruption or severe crowding

- Bruxism control.

\section{Functional posterior cross bite}

The posterior crossbite is characterized by occlusion of the buccal cusps of canines, premolars and/or upper molars occluding over the lingual cusps of their lower antagonists ${ }^{70}$, with an average prevalence of 7 to $23 \%$ in primary and mixed dentition, respectively ${ }^{71}$. The risk factors most commonly related to this condition are the lower posture of the tongue, which disrupts the muscular balance between the tongue and buccinator muscles, generating a transversal deficiency of the maxilla, in addition to mouth breathing, which modifies the transverse growth of the mandible, further collapsing the maxilla and facilitating a deeper palate, in addition to postural habits, such as resting the hands-on one side of the face for long hours.

Functional posterior crossbite is characterized by a mandibular deviation with a consequent deviation of the lower midline due to premature contact, usually between the primary canines on the side showing the crossbite ${ }^{72}$. (Figure 2)

During the examination, the child's jaw should be guided to a centralized position, where the lower midline will be checked. A transversally atresic jaw with bilateral crossbite in an unstable position leads the child to seek occlusal contact by moving the jaw to improve occlusal contacts. A double bite is observed between the maximum intercuspation and the centric relationship and asymmetric condylar movement ${ }^{73}$. This situation causes significant muscle adaptations in the medium term, changes in ajoint position thatcangenerate asymmetric facial growth and asymmetry of the face's muscles. For these reasons, management is needed as soon as it is diagnosed ${ }^{50}$, with a worldwide recommendation of early intervention in the clinical practice guidelines of orthodontic associations. ${ }^{48,49}$

Orthodontic measures for crossbite correction prioritize the elimination of premature contact by grinding deciduous canine cusps first. If this procedure does not solve the problem, therapeutic measures are indicated that involve either removable or fixed expanders. ${ }^{74-76}$

During the duration of the pandemic perspective, two alternatives can be considered. The first one is preventive guidance to eliminate associated habits and, if treatment is needed, follow-up video calls are needed to interrupt the activation of the expansion when needed.

In the case of occlusal wear, an option is to use the handpiece at low speed without water, only air, taking a break every 10 seconds to allow the crown to cool. The use of rubber drills, which is not normally 

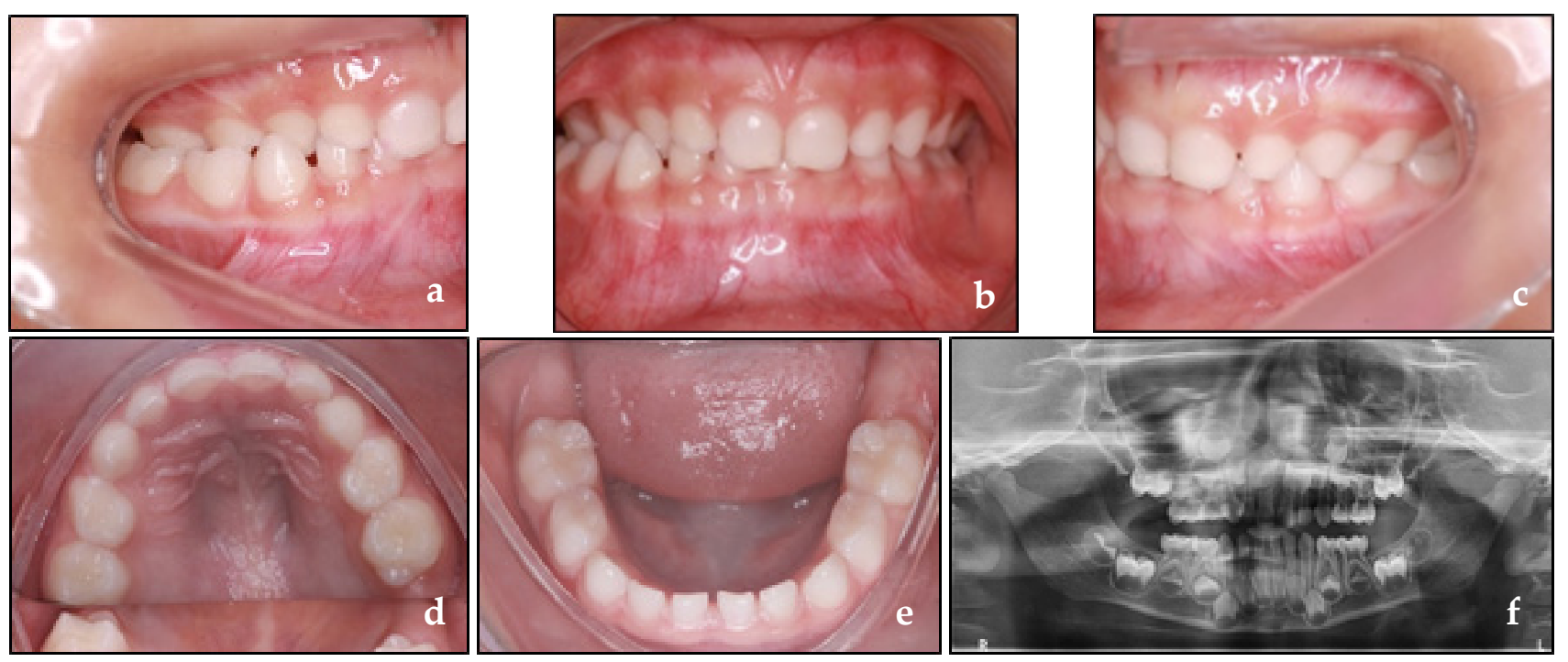

Figure 2: Functional crossbite, unilateral crossing $(a, b, c)$, lower deviation from the midline $(b, f)$, maxilla with a lower transverse distance than the mandible $(d, e)$.

indicated, can be an alternative during the pandemic.

\section{Anterior cross bite}

Among malocclusions that require early management, attention is needed to the presence of an anterior crossbite. This malocclusion must be diagnosed as soon as possible. The dental, functional, and skeletal components will be evaluated, which will be decisive in orthodontic management's choice to establish the prognosis definition and follow-up time.

Based on these criteria, the anterior crossbite can be classified as an anterior dental bite, a pseudoclass III or a skeletal class III. ${ }^{77}$

\section{a. Anterior dental crossbite.}

Theanterior dentalcrossbiteis characterized by the crossbite of one or two incisors ${ }^{78}$ and the presence of Class I molar and canine relationship or straight terminal plane in the primary molars, in addition to an adequate maxillomandibular relationship (Figure 3).

The etiology of the anterior dental crossbite can be associated with environmental factors, such as prolonged retention of primary teeth and dental trauma. Despite its low complexity, this condition requires management as soon as it is diagnosed, avoiding periodontal effects and the development of functional changes that can lead to pseudo-class III.

The treatment of anterior dental crossbite can be performed with removable devices, using digital springs, expander screws, and, when only one dental tooth is in crossbite, simpler devices, such as tongue lowering spatulas, can be used. ${ }^{79}$

Once again, through periodic monitoring by video calls, the amount of expansion facilitated by the parents (when using an expander screw) is necessary needed to decide the interruption of the expansion. 

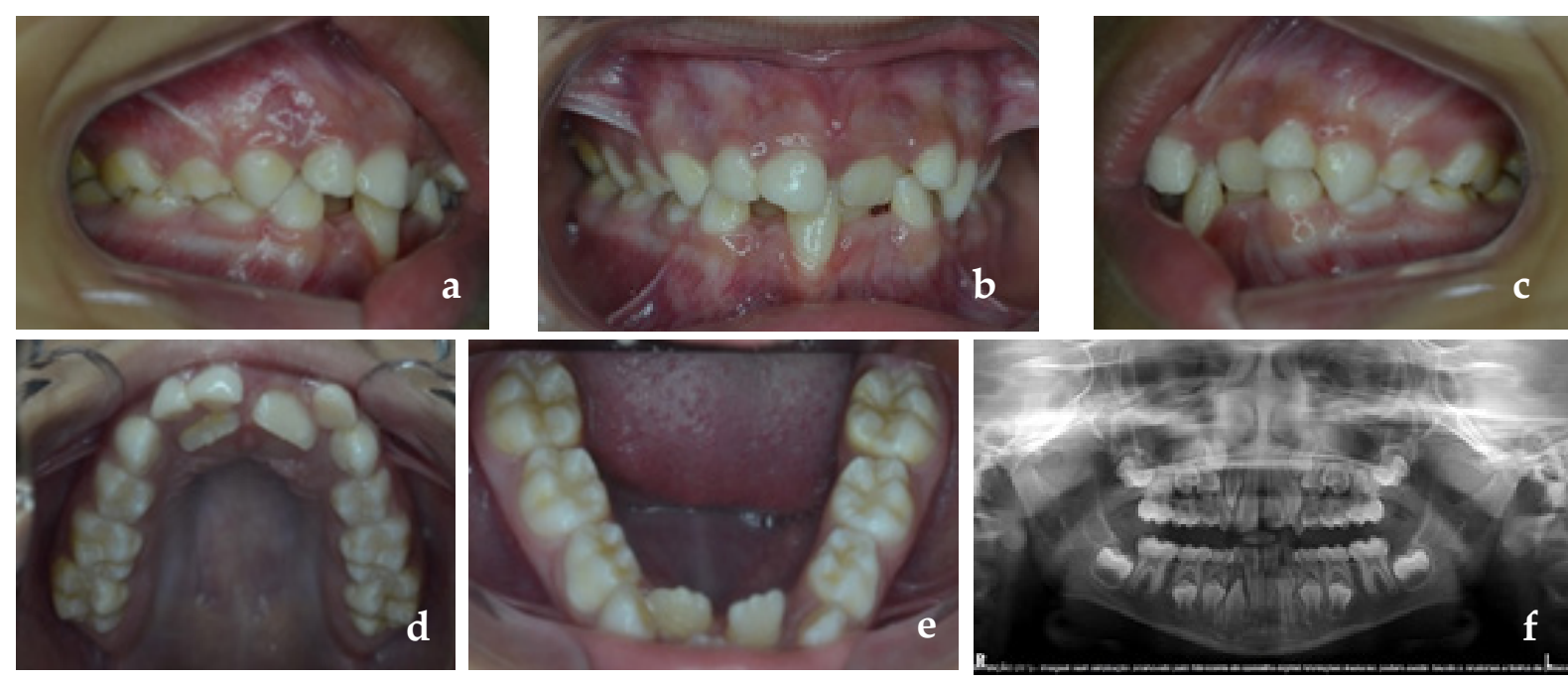

Figure 3. Dental anterior crossbite with a posterior class I relationship, dental crossbite of the upper central incisors and occlusal trauma with a gingival recession in the lower incisor $(a, b, c)$, maxillomandibular atresia $(d, e)$ and prolonged retention of primary teeth $(d, f)$.

\section{b. Pseudoclass III}

Pseudoclass III, also called functional class III or neuromuscular class III, is characterized by anterior crossbite presence due to an occlusal interference ${ }^{80}$. A differential clinical diagnosis of skeletal class III, the presence of a discrepancy between the maximum intercuspation habitual $(\mathrm{MIH})$ and the centric relation $(\mathrm{CR})$ is needed. ${ }^{78,81}$

During the clinical examination, in the MIC position, the molars and canines are in class III (or mesial step in the case of deciduous molars) and, when placing the patient in the $C R$, the molar relation becomes class I with the presence of occlusal contact that facilitates the mandible sliding forward ${ }^{82}$. In these cases, lingual inclinations are usually found for the upper incisors and the presence of wear in these teeth, in addition to the buccal inclination in the lower incisors due to the mandibular posture $^{81}$. (Figure 4).
Pseudoclass III has the following etiological factors: the ectopic eruption of the upper incisors ${ }^{82}$, early loss of maxillary primary molars, functional changes, such as mouth breathing and anomalies lingual position, as well as neuromuscular changes ${ }^{80}$. In these cases, the orthodontic approach is related to eliminating occlusal interference and correction of the incisor position. Removable devices, such as the Eschler device associated or not with the mouthpiece ${ }^{78}$, expansion devices or functional devices and direct signs, are indicated. They should be performed as soon as they are diagnosed, as this malocclusion's persistence can lead to skeletal class III. ${ }^{82,83}$

Occlusal adjustment is not an option in these cases, as the interference usually occurs between permanent incisors. As previously proposed, periodic monitoring by video calls is needed to stop the screw activation if such an approach is used. 

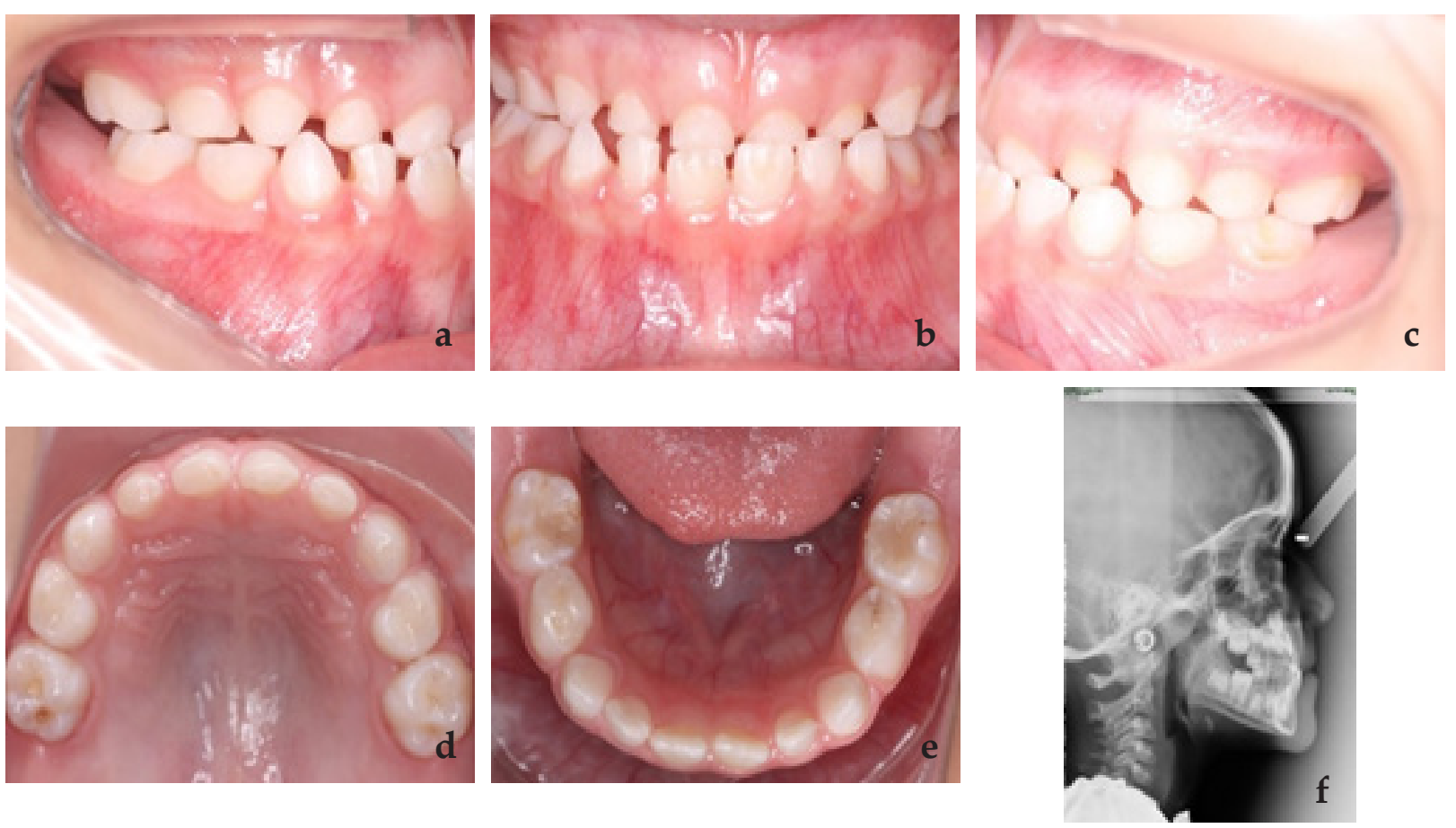

Figura 4 Pseudo classe III, escalón mesial de los segundos molares deciduos en máxima intercuspidacion $(a, c)$, mordida cruzada anterior (b), desgaste incisal de los incisivos superiores (d), inclinación vestibular de incisivos inferiores y lingual de incisivos superiores ( $f$ ).

\section{c. Skeletal Class III}

Skeletal class III is a malocclusion characterized by an altered maxillomandibular relationship, concave profile and, in most cases, the presence of an anterior crossbite. It can be composed of maxillary retrognathism associated with well-positioned mandibles, prognathic mandible and well-positioned maxilla ${ }^{84}$ and has a prevalence of 3 to $26 \%{ }^{85}$ that varies between populations around the world and with diagnostic criteria, being more frequent in Asian countries. ${ }^{86}$

From the etiological point of view, skeletal class III may be related to hereditary factors ${ }^{87}$ (mainly cases of mandibular prognathism) and environmental factors, such as oral breathing, functional changes and the presence of an untreated anterior bite or class III.
Based on the combination of the anteroposterior and sagittal bone components, the treatment prognosis can be more or less worse ${ }^{51}$. Among the prognostic factors, we can mention that the greater the mandibular involvement, the vertical growth of the face and the functional deterioration, the worse the prognosis. ${ }^{52}$

In addition to the skeletal characteristics and the etiological components involved, the treatment time can contribute to the best or the worst prognosis for treatment and. Primary mixed dentition is the best time for treatment since establishing the correct maxillary relationship mandibular contributes to adequate facial growth ${ }^{53}$. In general, when there is only involvement due to maxillary deficiency, early intervention can be useful in mild maxillary deficiency cases. When 
the problem is excessive mandibular growth or moderate to severe maxillary deficiencies, monitoring may be more appropriate.

The gold standard of treatment for class III of maxillary origin is the use of fixed maxillary expanders associated with the use of facial masks is widely referenced in the literature and, the possibility of including protocols with the use of skeletal anchorage allows to expand the age correction group and can be used in the later stage of mixed dentition still with promising results ${ }^{88,89}$. However, considering that Class malocclusions tend to worsen with age, numerous aesthetic and functional problems arise. Early diagnosis and intervention, as soon as the child matures for the acceptance of the treatment (Figure 5), can increase compliance. It is worth mentioning the importance of monitoring until the end of facial growth, as the anterior crossbite could relapse due to mandibular growth. ${ }^{54}$

Given the current pandemic scenario, Class III orthopedic management can be monitored through virtual consultations, especially after the active expansion period has been completed. The patient is in the face mask use phase. At this stage, overjet monitoring must be performed and can be monitored at monthly intervals. When in doubt, with a diagnosis that involves the mandible, it would be more prudent not to intervene immediately, waiting a few months to reassess the case. The risk of lack of correct follow-up must be considered, in addition to the fact that the high probability of skeletal modification is
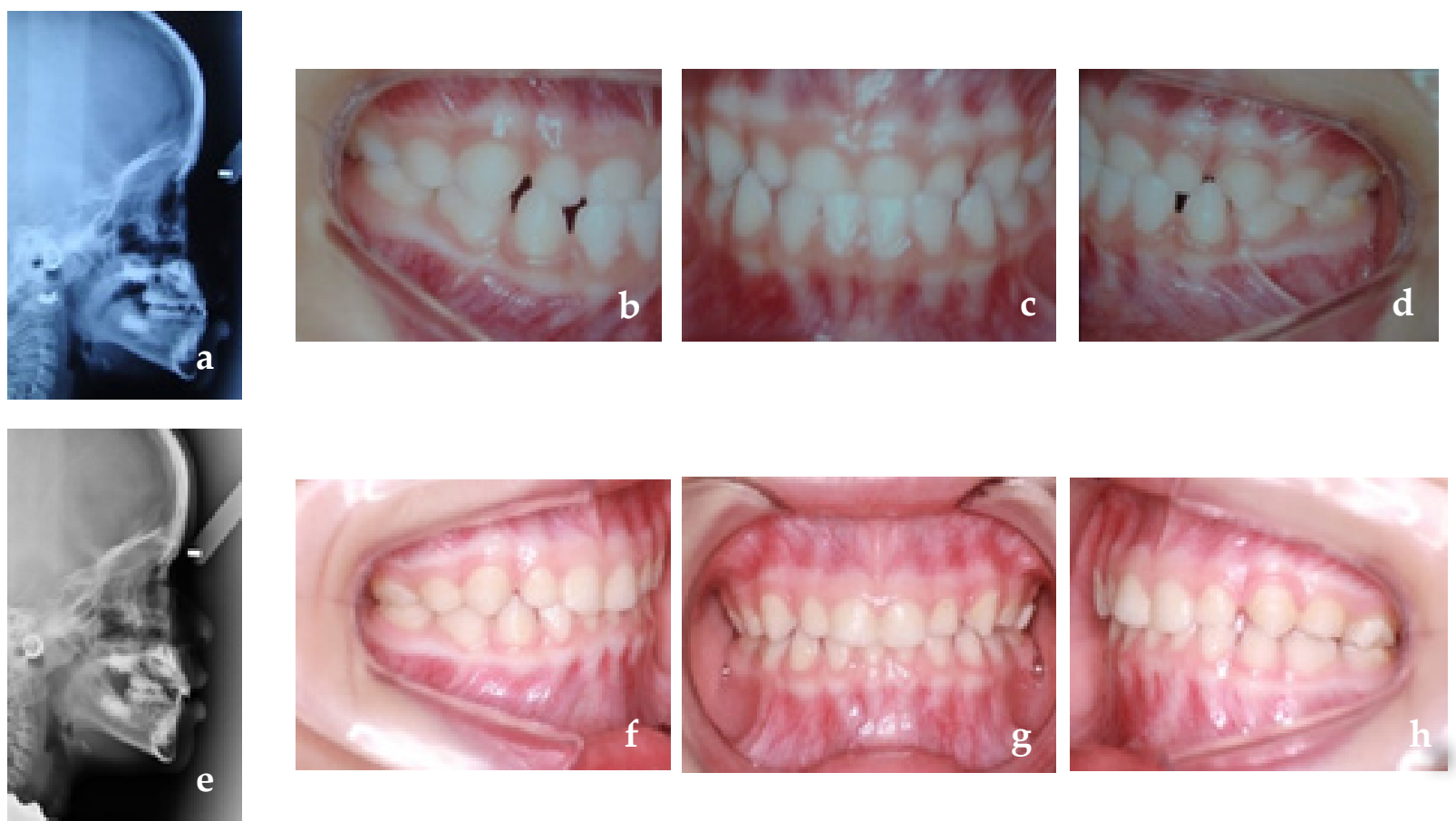

Figure 5. Class III was diagnosed at an early age. Maxillary retrognathism (a), the ratio of anterior crossbite and mesial step of molars and canines $(b, c, d)$ are observed; Post-treatment with the use of a face mask and maxillary expansion improved maxillomandibular relationship (e) crossbite correction and subsequent dental relationship $(f, g, h)$. 
not sufficient to avoid future additional treatment.

\section{Persistent habits - Associated open bite}

The literature shows a strong association between the ain occlusal characteristics and eating and sucking habits in children. ${ }^{55-57,90}$

Breastfeeding is a protective factor in the appearance of malocclusions, and this association is stronger with the increase in the duration of breastfeeding ${ }^{90}$. Children who experience exclusive breastfeeding for more than six months are less likely to use a pacifier daily ${ }^{55,57}$. This habit may be related to others because children who use a pacifier daily are significantly more likely to have daily habits of digital sucking. ${ }^{57}$

The daily use of a pacifier and digital suction may be associated with excessive overjet, loss of space in the lower arch, posterior crossbite and anterior open bite, affecting the harmonious development of orofacial structures ${ }^{55-58}$. Some of these characteristics may be seen in Figure 6.

The anterior open bite also shows an association with socio-demographic factors, such as attending a public preschool, having a higher number of residents at home, less education of the mother, lower family income and caregiver age less than or equal to 30 years. ${ }^{58}$

Different interventions can contribute to the interception of the non-nutritive sucking habits related to the anterior open bite. Orthodontic appliances, such as a palatal arch with a crib, are beneficial in this scenario, as the number of children who discontinue suction increases in the short- and long-term. It can be used alone or combined with a psychological intervention, which has also promoted habit cessation. ${ }^{91,92}$

The use of the palatal crib in growing patients, a device widely used in clinical practice, shows a significant increase in overbite compared to untreated controls, regardless of the device's design and results. Results even after a few years
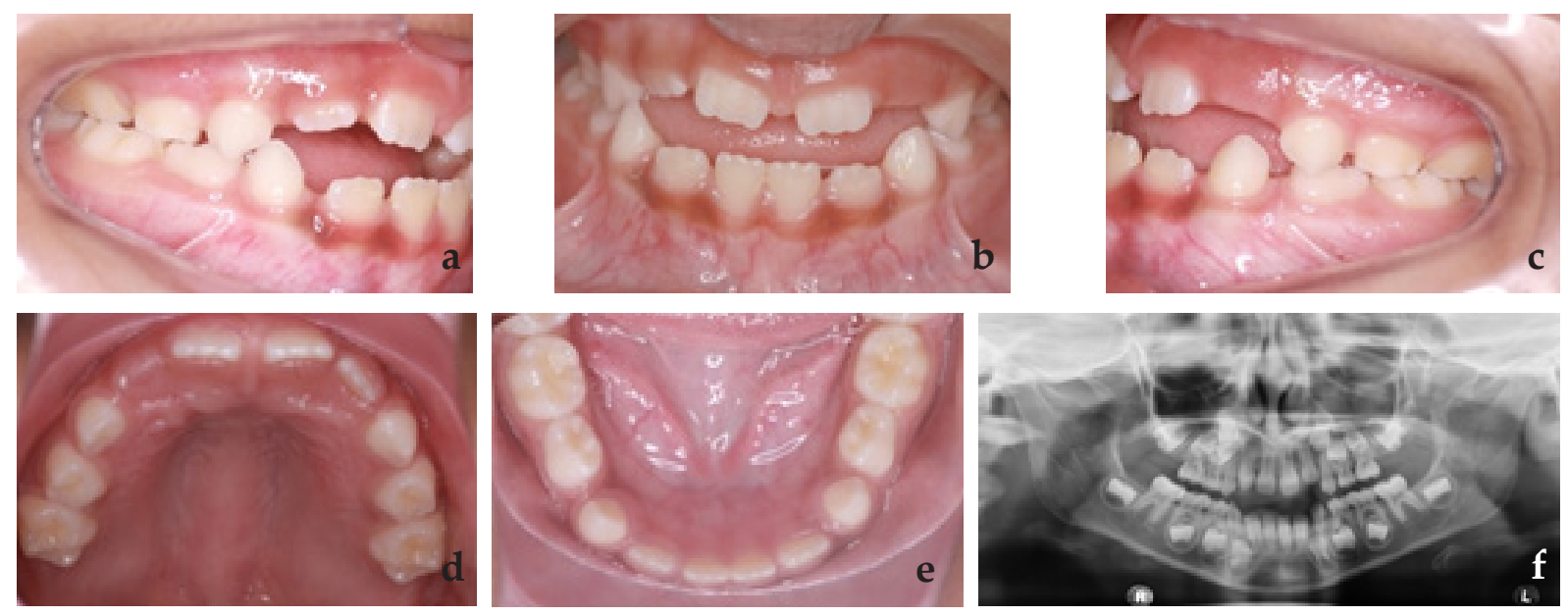

Figure 6. Open anterior bite associated with pacifier sucking 
of follow-up. It is the most effective treatment according to the available studies. ${ }^{92}$

Considering the pandemic scenario of COVID-19, the commitment of parents and guardians in eliminating the nonnutritive sucking habit of children and the dental surgeon's availability for the case through teledentistry can contribute to modify or monitor this condition. In addition, knowing that psychological factors are directly related to these habits, the help of a psychologist, if he is a child subject to situations that arouse some type of emotional instability, is of considerable relevance. As these devices are independent, there is no risk of over-correction,; their use in the pandemic could be encouraged. Although teleconsultation indicates habit correction, the necessity to see the patient and remove the device are probably not urgent.

\section{Ankylosed deciduous teeth}

The prolonged retention of primary teeth can be related to several factors. Ankylosis is one of them. Although ankylosis does not have a well-defined etiology, several theories have already been proposed, such as a genetic factor involved, deficiency in alveolar bone growth, problems related to metabolism and inflammation, infection, localized chemical or thermal irritations, changes in the interaction between normal resorption and repair of hard tissue that occurs in primary molars during the eruption of successor's teeth and the eruptive force of teeth. ${ }^{59}$

Ankylosis of primary teeth can influence the development of the patient's stomatognathic system. An example of this is infraocclusion, a condition associated with ankylosis in retained primary teeth. There is a higher frequency of primary teeth retained in the mandible than the maxilla, and, among them, molars are the teeth of this group with the highest prevalence of prolonged retention. ${ }^{59-61}$

The literature suggInylosis cases, one of the main app the literature suggests that roaches that can be adopted are a followup since dental exfoliation usually occurs spontaneously. If exfoliation does not occur, extraction will become an important and necessary alternative.

The pediatric dentist should consider the extraction with adequate space maintenance if the permanent successor has an altered eruption trajectory, which will make it difficult to resorb the primary, if the primary tooth has a considerable delay in exfoliation or if it is in severe infraocclusion, with adjacent teeth highly inclined, which can cause significant clinical loss of arch length and hinder the eruption of the permanent successor ${ }^{61}$. A major problem is the development of a severe vertical periodontal defect in cases of retained molars.

In the current scenario, monitoring the exfoliation expected from an ankylosed primary tooth should be done remotely. It is pertinent that the pediatric dentist is aware of the expected period of exfoliation and instructs the child's parents to report any dental changes. And if something happens, evaluate the child's possible faceto-face consultation. If the pandemic lasts 6 to 8 months, a delay in developing any action is unlikely to be critical. Waiting for a while is a relevant option at this point. 


\section{Overjet reduction}

Anterior teeth overjet is a common problem in children around the world. Correcting this condition is one of the most common treatments performed by pediatric dentists and orthodontists. This condition develops when the patient's permanent anterior teeth erupt. Protruding anterior superior teeth are more prone to dental trauma, and their appearance can cause low self-esteem and discomfort. ${ }^{47}$

The overjet corresponds to the horizontal relationship between the upper and lower incisors, with a normal value of 2 to $4 \mathrm{~mm}$. An increased overjet can be related to Class II malocclusions, usually accompanied by Class II sagittal skeletal relationships and mandibular retrognathism ${ }^{62}$. This malocclusion is multifactorial. This discrepancy may result from several combinations of dental components (protrusion of the upper anterior teeth, habits, etc.) and skeletal components (mandibular growth deficiency, excessive maxillary growth, a combination of both). Aetiological factors can be hereditary or environmental (habit of sucking fingers, pacifiers, sucking lips, breathing through the mouth, among others). ${ }^{63,64}$

Patients with increased overjet have a higher incidence of dentoalveolar trauma, in the permanent upper incisors, during growth. Dental fractures are three times more likely to occur in children with increased overjet, so it is important to consider early treatment. At the same time, it is good to be aware that a more important factor than overjet reduction itself is the preventive management of risky activities that predispose to impact the teeth directly. As the patient grows, periodontal damage may occur as the periodontal ligament becomes less resistant to atypical pressure on the lips, related to the difficulty of performing an adequate lip seal. ${ }^{62}$

The upper incisors' protrusion is also associated with the accumulation of dental biofilm, gingivitis, and initial white spot caries lesions (ICDAS 1 and 2) ${ }^{62}$. This inability to perform lip seal can be embarrassing for many patients, and it is perceived as unattractive, making patients target of bullying, likely affecting their quality of life ${ }^{62,64}$. In addition, a pronounced overjet may be related to temporomandibular disorders, as the incisors contact does not occur during chewing, increasing the jaw movement and the chewing muscles pressure, generating orthopedic instability due to the deviation of the centric occlusion. ${ }^{62}$

The determination of an appropriate treatment plan should be established based on the patient's specific problem based on clinical, cephalometric and functional evidence. The options for correcting an increased overjet are based on each treatment's objectives and how they can be achieved using: interceptive orthodontics, functional orthopedics, or corrective orthodontics. 62. The choice of mechanics for treating this type of malocclusion will depend on the type of malocclusion, patient age, degree of collaboration and the family socioeconomic level. In some cases, simple observation and monitoring is a reasonable option.

During confinement, parents/guardians may seek help due to their physical appearance that affects their quality of life. During a video call, it is possible to consult the hereditary and/or environmental components that the malocclusion may have. This scenario 
is enough to explain the malocclusion origin to parents/guardians about the probability of dental trauma on the protruding incisors. The use of mouthguards may be recommended for school-age children (in countries where some containment measures have been lifted and certain types of outdoor activities can be carried out, but the opening of dental clinics has not been authorized for elective treatments yet), which can be easily purchased at pharmacies or online stores and are affordable. However, it is important to highlight that mouthguards are unique and exclusive for preventing dentoalveolar trauma. Its use does not reduce overbite itself compared to the use of orthodontics to correct malocclusion. ${ }^{93}$

Although parents/guardians seek specialists to improve the patient's quality of life, there is no contraindication to postpone it until the end of the COVID-19 pandemic or even until the malocclusion can be corrected in a single-phase treatment ${ }^{93}$. There is scientific evidence suggesting that delaying treatment until it can be carried out at a single point of treatment may be the most appropriate and beneficial for some patients. ${ }^{47}$

In cases where patients are undergoing treatment, the specialist will indicate by video call the steps to be followed according to each device. According to the specialist's instructions, removable active plates and functional orthopedic devices can be followed at home with proper records and informed consent.

\section{Ectopic eruption teeth or severe dental crowding correction}

The discrepancy between tooth size and arch length is known as crowding.
Incisor crowding and irregularity are the most prevalent component in dental malocclusion ${ }^{94}$. Dental crowding at the level of permanent incisors, which have barely erupted, is an incident that is as frequent to observe as worrying and often unexpected for parents ${ }^{95,96}$. Dental crowding is considered a malocclusion that is not corrected but worsens with time. If present in the primary dentition, it will worsen in the next two mixed dentition. ${ }^{65}$

In addition to affecting the patient's aesthetics, it can also affect dental hygiene in the anterior region. When brushing, it is difficult to reach the crowded teeth; therefore, the accumulation of dental biofilm and dental calculus may eventually evolve into periodontal disease (gingivitis) and increase the risk of caries for the patient. ${ }^{66}$

According to its etiology, crowding can be classified as primary, secondary and tertiary. Primary, due to the discrepancy between the teeth' size and the available length in the arch of genetic origin. Secondary, caused by environmental factors (caries, tooth extraction, premature loss, among others) and tertiary, occurs in the post-adolescent period. ${ }^{94}$

The factors that influence crowding during the eruption phase of permanent dentition are abnormal position of permanent teeth germs, lateral ectopic eruption, canine and molar incisors, moment of exfoliation of deciduous teeth and permanent replacement tooth eruption, supernumerary teeth, anomaly tooth transposition, irregular resorption of the roots of primary teeth, premature loss of primary teeth, carious lesions of primary and permanent teeth and their complications, habits, genetic 
predisposition ${ }^{94,67,97}$. Other factors also include growth, reduced arch length, maturation, mesial movement of the teeth, soft tissue pressure, mesiodistal width of the teeth, in addition to tooth size and morphology. ${ }^{96}$

The literature reports the need for early intervention in some patients with crowding. A timely correction of malocclusion in mixed dentition could allow obtaining more stable treatment results, reducing the rate of tooth extraction in permanent teeth and reducing the time in the second phase of treatment. This can be achieved through a series of strategies that depend on the analysis of each specific case. These include the buccal inclination of the lower incisors, transversal development of the arch, distalization of the first permanent molar, selective wear of the deciduous and permanent teeth, maintenance of the arch length, guided tooth extractions, serial tooth extractions, among others. ${ }^{67}$

During confinement, it is possible to control fixed devices (passive and pre-activated) designed to maintain or increase (as appropriate) the arch's length through teledentistry. Likewise, it is possible to control the transverse expansions of removable active plates, as long as the parents/guardians engage in video calls. In the case of fixed expanders, it is advisable to interrupt the patient's activations to avoid future emergencies. The specialist should emphasize oral hygiene, reinforcing brushing techniques, and dental floss to prevent periodontal diseases and tooth decay.

In patients with selected tooth extractions, controls can be performed remotely. However, caution should be exercised at the appropriate time for radiographic control, as ectopic eruptions of permanent teeth may occur. Crowding treatment should start as soon as possible, once the quarantine measures of the COVID-19 pandemic have been lifted.

\section{Bruxism control}

The American Academy of Orofacial Pain 98 defines bruxism as a day or night parafunctional activity that includes clenching, grinding or unconsciously dragging teeth. According to the evidence, the prevalence of bruxism in children varies widely, varying between $5 \%$ and $40 \%$ in the world population. It is also described that it decreases at the age of 68,69 . Bruxism has two different circadian manifestations: a) it occurs during wakefulness (BV), or b) occurs during sleep (SB), the latter being the most frequent ${ }^{69}$. The most recent and currently accepted classification for sleep bruxism corresponds to possible, probable and definitive. ${ }^{99}$

Children normally perform antero posterior movements of the jaws associated with the teeth' occlusal wear during deciduous and mixed dentition. For this reason, several authors agree that, if grinding and occlusal noise are prolonged beyond eight years, it can be considered that the child performs a parafunctional activity. This should be evaluated by the specialist. ${ }^{69}$

The most frequent reason for consulting parents/guardians is the loud and repeated noise produced by their children at night. This can cause dental and neuromuscular problems, including tooth wear, periodontal disease, masticatory muscle hypertrophy, headaches and temporomandibular disorders. ${ }^{68,69}$ 
Bruxism is classified as centric and eccentric. Centric bruxism is described as clenching teeth in centric occlusion or at maximum intercuspation without causing displacement. Eccentric bruxism is defined as sliding teeth in the protrusive position and the lateroprotusion, generally causing facets of wear on the anterior and posterior teeth. ${ }^{100}$

The literature is extensive and contradictory regarding the etiology of childhood bruxism. Therefore, it was concluded that its origin is multifactorial and involves hereditary, psychological (anxiety, stress, personality characteristics, etc.) and behavioural factors ${ }^{69}$. Noted etiological factors are malocclusion type, TMJ development, emotional stress, oral habits, anxiety, drugs that cause stimulation in the central nervous system, allergic processes, asthma and respiratory tract infections. ${ }^{100}$

As bruxism is a multifactorial parafunctional activity, its treatment should be focused on resolving aetiological factors. That is why there are different therapeutic modalities for bruxism in children, including patient and family education, dental strategies (occlusal splints, interceptive orthodontics, functional orthopedics), psychological (change of habits and reduction of stress and anxiety), surgical (patients with severe airway obstruction) and pharmacological (improves stress and anxiety levels and increases the number of hours of sleep and their quality). ${ }^{68}$

Patient and family education is focused on establishing sleep routines and controlling other oral habits during the day, such as onychophagy, chewing objects and gum ${ }^{99}$. In children with primary dentition or whose first permanent molars are not fully erupted, where considerable wear is observed, the treatment of choice is the cementation of chromed steel crowns. The vertical dimension Is recovered ${ }^{100}$. It is important to note that orthopedic-orthodontic treatment is indicated in dentomaxillary anomalies such as maxillary constriction since maxillary expansion may help manage respiratory sleep disorders' positive effect on bruxism. ${ }^{68}$

The pediatric dentist must take psychological factors into account during the consultation, paying attention to the patient's general mental state, observing unusual nervousness, irritability and other tension indicators indicated by the application of specialized treatment. Parents and children should be aware of bruxism disorders in the stomatognathic system and the parafunctional activity. It was performed during the day to reduce or eliminate it. ${ }^{100,101}$

The diagnosis of bruxism can be made by teledentistry. The treatment will depend on the severity and age of the patient. The specialist must perform a complete anamnesis to determine routine sleep habits that could have been modified during the confinement season. Suppose that at the time of the teleconsultation, the specialist determines the need for interdisciplinary treatment. In that case, parents/guardians may be instructed to consult by telemedicine for psychological therapies or evaluation by an otorhinolaryngologist, as appropriate. In those patients where bruxism with significant tooth wear has been diagnosed, the use of mouthguards can be advised, which can be easily purchased at pharmacies or stores with an affordable and online method of purchase while the pandemic lasts. 
However, parents/guardians should be aware of the importance of receiving priority treatment when social isolation measures are lifted.

\section{Special considerations in interceptive orthodontics during the COVID-19 pandemic - summary}

During normal dental practice, professionals and patients are constantly exposed to pathogens that inhabit the oral cavity and the respiratory tract due to aerosol generation's particular conditions, short working distance, and use of various instruments and supplies. In turn, close contact with fluids such as blood and saliva that contain a considerable viral load in infected patients, even in asymptomatic patients, carries a high risk of COVID-19 infection ${ }^{12}$.

Due to the pandemic and the increasing number of cases, containment measures have been revised. For this reason, specialists must be prepared for the management of the effects of orthodontics without supervision. Therefore, the use of any orthodontic mechanism should be reconsidered, which, if not controlled, may have harmful effects, especially in non-selflimited devices, such as canine traction, eruption control, reverse curve arcs, auxiliary torques and functional devices 102.

Although the world panorama becomes complicated regarding health professionals, specifically in dentistry, some malocclusions should be prioritized when we return to the so-called "new normality". COVID-19 is undoubtedly here to stay for a long time, and, as a result, it can change the way orthodontics is practiced forever. ${ }^{102}$

In patients requiring guided and/or serial tooth extractions, they can be performed with standard precautions but should be planned, if possible, in a single visit to reduce the patient's risk of exposure. However, it is necessary to monitor to control and guide the eruption, according to each patient. In the case of a reimposition of social isolation, additional measures must be taken to prevent loss of arch length or ectopic eruptions of permanent teeth. ${ }^{102}$

Maxillary expansion is still possible but under strict supervision, especially in cases of rapid maxillary expansion. The specialist must clearly instruct the parent/ guardian about the treatment goals. Once the expansion is complete, it is essential to maintain the results achieved, as overactivation can create unwanted vestibularization of the posterior teeth that may require an extra visit to the office and delay treatment. For this reason, slow expansion mechanics is preferred, as it is safer and does not create sudden changes in short periods, reducing the possibility of orthodontic emergencies. ${ }^{102}$

Patients using removable functional devices can be monitored remotely via video calls. In addition, the use of these devices can be reduced when treatment goals are reached. ${ }^{102}$

Fixed appliances are associated with a high rate of complications (especially in small and uncooperative patients), which requires a greater number of emergency visits than the use of removable appliances. ${ }^{102}$

In patients entering a containment phase, the use of removable retainers is preferable to fixed ones to avoid unnecessary contamination with aerosols. It is recommended to provide the patient with an additional set of removable retainers in case of loss or fracture, especially during and when confined again by COVID-19. ${ }^{102}$ 
It is recommended to minimize aerosol generation procedures, such as removal of cement, adhesive materials, ameloplasties, microabrasion, interproximal wear and ultrasonic cleaning. Avoid using the triple syringe and replace air drying with gauze or cotton swab. If possible, consider not using water when removing cement or adhesive materials. ${ }^{103}$

\section{Conclusions}

These recommendations were made independently and voluntarily by researchers from the Latin American Association of Pediatric Dentistry, together with specialists in Latin America's various medical areas, with peer arbitration, free of conflicts of interest.

These recommendations are based on the greatest evidence available to date, with COVID-19 being an emerging disease. The necessary updates will be made according to the state of science and the evolution of the disease.

The specialists responsible for the curation remain active and constantly monitor the published information about COVID-19 to carry out the necessary updates and attachments.

\section{Autors}

Development of this article led by: Marina Tavares Costa Nóbrega (Canada), Rosa Helena Wanderley Lacerda (Brasil), Carlos Flores-Mir (Canadá), Andrea Virgina González Carfora (Chile), Luzia Ana Da Silva de Carballo (Venezuela), on behalf of the COVID-19 Interdisciplinary team, LatinAmerican Pediatric Dentistry Association (Asociación Latinoamericana de Odontopediatría)

COVID-19 Interdisciplinary team, Latin-American Pediatric Dentistry Association (Asociación Latinoamericana de Odontopediatría): Jenny Abanto (Brasil), Mariana Armada (Argentina), Paola Beltri (España), Marisol Carrillo Tabakman (Paraguay), Haydée Casaretto (Argentina), Jorge Luis Castillo (Perú), Mónica Gladys Cesetti (Argentina), Bertha Angélica Chávez González (Perú), Ana Claudia Rodrigues Chibinski (Brasil), Salomon Alberto Cohen (Argentina), Olga Cortés Lillo (España), Luzia Ana Da Silva de Carballo (Venezuela), Gonzalo De la Fuente Alvarez (Chile), Renée Di Nallo (Argentina), María Débora Elizabeth Dricas (Argentina), Sandra Echevarria (Brasil), Piedad Cecilia Echeverry Marin (Colombia), Laura Fedelli (Argentina), Carlos Flores-MIr (Canadá), Andrea Virgina González Carfora (Chile), Lina María Hernández Salas (Colombia), Francisco José Hernández Restrepo (Colombia), Maria Teresa Ibañez Rodriguez (Bolivia), José Carlos Pettorossi Imparato (Brasil), Alejandra Lipari Valdés (Chile), Daniela Madrigal López (Costa Rica), Daniela Catalina Martínez Camus (Chile), María Gabriela Martínez Vásquez (Venezuela), A. Carolina Medina Díaz (Venezuela), Kelly Maria Silva Moreira (Brasil), Elías M. Morón (Estados Unidos de América), Martha Mutis (Estados Unidos de América), Camila Palma (Perú), Gladys Mabel Peña (Argentina), Adriana Pistochini (Argentina), Paloma Planells (España), Gabriel Politano (Brasil), Matias RiosErazo (Chile), Adriana Maria Rubiano Pinzon (Colombia), Karla Mayra Rezende (Brasil), Rosa Gabriela Rondón (Venezuela), Gabriela Scagnet (Argentina), Rosemary Sogbe de Agell (España), Marina Tavares Costa Nóbrega (Canadá), Jorgelina Valente (Argentina), Ernesto Venegas De Herrera (República Dominicana), Rosa Helena Wanderley Lacerda (Brasil), Ana Clara Zabala (Argentina), Gabriel Zambrano (Venezuela).

Información completa del Grupo Interdisciplinario COVID-19 de la Asociación Latinoamericana de Odontopediatría

\section{References}

1. Asociación Latinoamericana de Odontopediatría. Grupo COVID-19. Ruta de atención para procedimientos de Odontología Pediátrica durante la etapa de confinamiento o cuarentena de la pandemia COVID-19. Rev Odontoped Latino. 2020;10(2):https://www.revistaodontopediatria.org/ediciones/2020/2/art-1/. 
2. Asociación Latinoamericana de Odontopediatria. Tratamiento de la enfermedad de caries en época de COVID-19: protocolos clínicos para el control de aerosoles. Rev Odontoped Latino. abril 2020;10(2):https://www.revistaodontopediatria.org/ediciones/2020/2/art-2/\#.

3. Asociación Latinoamericana de Odontopediatría ALOP. Modelos de Consentimiento Informado para la Atención de Urgencias en tiempos de COVID-19. abril 4, 2020. Available at: https://www.alopodontopediatria.org/noticias/consentimiento-informado-indicados-especialmente-atenci\%C3\%B3n-emergencias-odontologicas/.

4. Turkistani KA. Precautions and recommendations for orthodontic settings during the COVID-19 outbreak: A review. Am J Orthod Dentofacial Orthop. 2020.

5. Yang Y PFWRGKJTXGSJCC. The Deadly Coronaviruses: The 2003 SARS Pandemic and the 2020 Novel Coronavirus Epidemic in China. J Autoimmun. 2020.

6. Lu R ZXLJNPYBWHWWSHHBZea. Genomic characterization and epidemiology of 2019 novel coronavirus: implications for virus origins and receptor binding. Lancet. 2020;395.

7. Guo YR CQHZTYCSJHea. The origin, transmission and clinical therapies on coronavirus disease 2019 (COVID-19) outbreak- A n update on the status. Mil Med Res. 2020;7(1):1-10.

8. Zhang W DRLBZXYXLHBeaMasio2nipiomsrEMI2, 9(1):386-9. Molecular and serological investigation of 2019-nCoV infected patients: implication of multiple shedding routes. Emerg Microbes Infect. 2020;9(1):386-9.

9. Zhou PYXLWXHBZLZWeaApoawancopboN[2, http://dx.doi.org/10.1038/s41586-020-2012-7 5Af. A pneumonia outbreak associated with a new coronavirus of probable bat origin. Nature. 2020;579(7798):270273.

10. Liu M CSXKYYZQZHea. Use of personal protective equipment against coronavirus disease 2019 by healthcare professionals in Wuhan, China: cross sectional study. J Hosp Infect. 2020;105:100-1.

11. Ge ZY YLXJFXZY. Possible aerosol transmission of COVID-19 and special precautions in dentistry. J Zhejiang Univ Sci B. 2020:1-8.

12. Suri S VYKABRAM. Clinical Orthodontic Management During the COVID-19 Pandemic. Angle Orthod. 2020.

13. Matus CP NMIM. Atención de Pacientes en Tratamiento de Ortodoncia Durante la Pandemia COVID-19 (SARS-CoV-2). Presentación de un Algoritmo. Int J Odontostomat. 2020;14(4):489-494.

14. Caprioglio A PGZPFRMGNR. Management of orthodontic emergencies during 2019-NCOV. Prog Orthod. 2020;21.

15. Asociación Latinoamericana de Odontopediatría. Teleodontología: Aplicación a la Odontopediatría durante la pandemia COVID-19. Rev Odontoped Latino. 2020;10(2).

16. Kravitz ND, Burris B, Mayordomo D, Dabney CW. Teledentistry Ortodoncia de bricolaje y Monitoreo de tratamiento remoto. J Clin Orthod. 2016;50:718-726.

17. Cotrin PP PRORORPNVFea. Impact of coronavirus pandemic in appointments and anxiety/concerns of patient regarding orthodontic treatment. Orthod Craniofac Res. 2020.

18. Saccomanno SV, Quinzi V, Sarhan S, Laganà S. Perspectives of Tele-Orthodontics in the COVID-19 Emergency and as a Future Tool in Daily Practice. Eur J Paediatr Dent. 2020;21(2):157-162.

19. Odontopediatría ALd. Estrategias Psicoconductuales e información para Odontólogos y pacientes que requieran procedimientos de Odontología Pediátrica durante la etapa de la pandemia COVID-19. Rev Odontoped Latino. 2020;10(2).

20. Society BO. www.bos.org.uk. Patients' Home Videos Repairs. Available at: https://www.bos.org.uk/COVID19-BOS-Advice/Patients-Advice/Patients-Home-Videos-Repairs. Accessed Julio 10, 2020.

21. Asociación Colombiana de Infectología. Consenso Colombiano de atención, diagnóstico y manejo de la infección por SARS-CoV-2/COVID-19 en establecimientos de atención de la salud. 2da Edición. Recomendaciones basadas en el consenso de expertos e informadas en la evidencia. Infectio. 2020;24(3):S2.

22. Consejo General de Dentistas de España / Association Dentaire Française. COVID-19 Guía practica en base a las recomendaciones de expertos validados. 2020.

23. Chile SdOyODd. Protocolo bioseguridad sugerido Para Atención en Ortodoncia durante Periodo de Pandemia

24. Royal College Of Surgeons of England. Recommendations for Orthodontics during COVID-19 pandemic. 2020. Available at: file:///C:/Users/nebn8/Downloads/Orthodontics\%20COVID19.pdf.

25. Lucea A. El manejo de las urgencias en ortodoncia. Ortodoncia clínica. 2003;6(3):159-164.

26. Centers for Disease Control and Prevention CDC. Interim Infection Prevention and Control Recommen- 
dations for Patients With Suspected or Confirmed Coronavirus Disease 2019 (Covid-19) in Healthcare Settings. abril 2020. Available at: https://www.cdc.gov/coronavirus/2019-ncov/hcp/infection-control-recommendations.html?CDC_AA_refVal=https\%3A\%2F\%2Fwww.cdc.gov\%2Fcoronavirus\%2F2019-nco$\mathrm{v} \% 2$ Finfection-control\%2Fcontrol-recommendations.html.

27. Dave M, Seoudi N, Coulthard P. Urgent dental care for patients during the COVID-19 pandemic. The Lancet. Abril 2020:DOI:https://doi.org/10.1016/S0140-6736(20)30806-0.

28. Xu H, Zhong L, Deng J, Peng J, et al. High expression of ACE2 receptor of 2019-nCoV on the epithelial cells of oral mucosa. Intl J Oral Sci. 2020;12(8):https://doi.org/10.1038/s41368-020-0074-x.

29. Mallineni SK, Innes NP, Raggio DP, Araujo MP, Robertson MD, Jayaraman J. Coronavirus Disease (COVID-19): Characteristics in children and considerations for dentists providing their care. Int J Paed Dent. abril 2020:doi: 10.1111/ipd.12653.

30. American Dental Association (ADA). Interim Guidance for Minimizing Risk of COVID-19 Transmission. abrl 7, 2020. Available at: https://www.ada.org/ /media/CPS/Files/COVID/ADA_COVID_Int_Guidance_Treat_Pts.pdf?utm_source=adaorg\&utm_medium $=$ covid-resources-lp\&utm_content=cv-pm-ebd-interim-response\&utm_campaign=covid-19?utm_source=adaorg\&utm_medium=adanews\&utm_conten$\mathrm{t}=\mathrm{cv}$-pm-ebd-interi. Accessed abril 8, 2020.

31. Consejo General de Dentistas de España. Informe Técnico II del Consejo General de Dentistas de España: Desafíos emergentes del nuevo Coronavirus COVID-19 en la clínica dental 2020.

32. Meng L, Hua F, Bian Z. Coronavirus Disease 2019 (COVID-19): Emerging and Future Challenges for Dental and Oral Medicine Treatment of Emergency Cas. J Dent Res. 2020:DOI: 10.1177/0022034520914246.

33. Peng X, Xu X, Li Y, Cheng L, Zhou X, Ren B. Transmission routes of 2019-nCoV and controls in dental practice. Intl J Oral Sci. 2020;12:https://doi.org/10.1038/s41368-020-0075-9.

34. Cochrane. COVID-19 Dental Services Evidence Review (CoDER) Working Group. Recommendations for the re-opening of dental services: a rapid review of international sources. Mayo 06, 2020. Available at: https://oralhealth.cochrane.org/sites/oralhealth.cochrane.org/files/public/uploads/covid19_dental_review_16_may_2020_update.pdf. Accessed Mayo 15, 2020.

35. Orthodontic convit.. Available at: www.rcseng.ac.uk/dental-faculties/fds/coronavirus.

36. Sunnak R JAFP. Is orthodontics before 11 years of age evidence-based? A systematic review and meta-analysis. J Dent. 2015;43(5):477-86.

37. Tecco S BANEPJ. Orthodontics in Growing Patients: Clinical/Biological Evidence and Technological Advancement. Biomed Res Int. Biomed Res Int 2018:10-3.

38. PS F. Timing orthodontic treatment: early or late? Aust Dent J. 2017;62:11-9.

39. Rapeepattana S TASS. Etiology of malocclusion and dominat orthodontic problems in mixed dentition: A cross-sectional study in a group pf Thai children aged 8-9 years. J Int Soc Prev Community Dent. 2019;9:383-9.

40. Al Nimri K, Richardson A. Interceptive orthodontics in the real world of community dentistry. Intl J Paed Dent. 2000(10):88-108.

41. Maspero C, Abate A, Cavagnetto D, El Morsi M, Fama A, Farronato M. Available technologies, applications and benefits of teleorthodontics. A review of the literature and possible applications during the COVID-19 pandemic. J. Clin. Med. 2020;9(6):E-1981.

42. Seehra J, Fleming PS, Newton T, Di Biase AT. Bullying in orthodontic patients and its relationship to malocclusion, self- esteem and oral health-related quality of life. J Orthod. 2011;38:247-256.

43. Dutra SR, Pretti H, Martins MT, Bendo CB, Vale MP. Impact of malocclusion on the quality of life of children aged 8 to 10 years. Dental Press J Orthod. 2018;23(2):46-53.

44. Agou S, Locker D, Steiner DL, Tompson B. Impact of self-esteem on the oral-health-related quality of life of children with malocclusion. Am J Orthod Dentofacial Orthop. 2008;134:484-489.

45. Araki M, Yasuda Y, Ogawa T, et al. Associations between Malocclusion and Oral Health-Related Quality of Life among Mongolian Adolescents. Int J Environ.Res Public Health. 2017;14:902: doi:10.3390/ ijerph14080902.

46. Kragt L, Dhamo B, Wlovius EB, Ongkosuwito EM. The impact of malocclusions on oral health-related quality of life in children-a systematic review and meta-analysis. Clin Oral Invest. 2016;20:1881-194.

47. Batista KBSL, Thiruvenkatachari B, Harrison JE, O'Brien KD. Orthodontic treatment for prominent upper front teeth (Class II malocclusion) in children and adolescents. Cochrane Database of Systematic Reviews. 2018: DOI: 10.1002/14651858.CD003452.pub4.

48. ANAES. Indications de l'Orthoped'die Dento-Faciale et Dento-Maxilo-Faciale 
49. American Association of Orthonontists AAO. linical Practice Guidelines for Orthodontics and Dentofacial Orthopedics

50. Fleming P. Timing orthodontic treatment: early or late? Aust Dent J. 2017;62:11-9.

51. Reyes BC BTMJJ. An Estimate of Craniofacial Growth in Class III Malocclusion. Angle Orthod. 2006;76(4):577-84.

52. Salazar L PMAESAMROJO. Effect of face mask therapy on mandibular rotation considering initial and final vertical growth pattern: A longitudinal study. Clin Exp Dent Res. 2019;5(4):343-9.

53. P A. Early Treatment for Class III Malocclusions: The Facts. Orthod Fr. 2013;84(1):41-52.

54. Li N ZWSHZJ. The stability of soft tissue changes in patients with skeletal Angle Class III malocclusion after orthodontic-orthognathic treatments. Shanghai J Stomatol. 2009;18(4):350-4.

55. Chen X XBGL. Effects of breast-feeding duration, bottle-feeding duration and non-nutritive sucking habits on the occlusal characteristics of primary dentition. BMC Pediatr. 2015;15(1):1-9.

56. Schmid KM KRNPBCVC. The effect of pacifier sucking on orofacial structures: a systematic literature review. Prog Orthod. 2018;19(1).

57. Ling HTB SFZLYCLKWH. The association between nutritive, non-nutritive sucking habits and primary dental occlusion. BMC Oral Health. 2018;18(1):1-10.

58. Gomes MC NEPMMCPSGGA. Association between psychological factors, socio-demographic conditions, oral habits and anterior open bite in five-year-old children. Acta Odontol Scand. 2018;76(8):553-8.

59. Arhakis A BE. Etiology, Diagnosis, Consequences and Treatment of Infraoccluded Primary Molars. Open Dent J. 2017;10(1):714-9.

60. Aktan AM KISIBCCSKMea. An evaluation of factors associated with persistent primary teeth. Eur J Orthod. 2012;34(2):208-12.

61. Tieu LD WSMMFMC. Management of ankylosed primary molars with premolar successors: A systematic review. J Am Dent Assoc. 2019;144(6):602-11.

62. Achmad M. Overjet problems at the growing child, case report using the twin block appliance. J Dentomaxillofac Sci. 2017;2(1):49-53.

63. Silva-Esteves J, Aliaga R, Aliaga A. Tratamiento de una maloclusión Clase II División 1 en dentición mixta. Odontol Pediatr. 2013;12(1).

64. Cirgic E. Studies of treatment effects, cost assessment and patient perceptions - a comparison of two removable functional appliances

65. Quinzi V, Caruso S, Mummolo S, et al. Evaluation of Lower Dental Arch Crowding and Dimension after Treatment with Lip Bumper versus Schwarz Appliance. A Prospective Pilot Study. Dent J. 2020;8(34).

66. Indriyanti R, Hidajat S, Maskoen A, Riyanti E. Predisposing factors analysis of mandibular anterior tooth crowding in the mixed dentition period by the tooth size and dental arch width. Padjadjaran journal of dentistry. 2018;30(3):207-213.

67. Tokarevich I, Rublevsky D. Mandibular incisor crowding in the mixed dentition. Advances in etiology, early diagnosis and orthodontic treatment. Dental Science ad practice. 2014;5(5).

68. Firmani M, Reyes M, Becerra N, Flores G, Weitzman M, Espinosa P. Bruxismo de sueño en niños y adolescentes. Rev chil pediatri. 2015;86(5).

69. Rojas D, Teran K, Alvarez C. Bruxismo del sueño en niños: actualización de la literatura. Odontol Pediatr. 2017;25(3):209-216.

70. Bjoerk A KASB. A method for epidemiological registration of malocclusion. Acta Odontol Scand. 196;22:27-41.

71. Kecik D KISI. Evaluation of the treatment changes of functional posterior crossbite in the mixed dentition. Am J Orthod Dentofac Orthop. 2007;131(2):202-15.

72. Myers DR BJBRWE. Condylar position in children with functional posterior crossbites: before and after crossbite correction. Pediatr Dent. 1980;2:190-4.

73. Lippold C STMUVAMTDG. Early treatment of posterior crossbite - a randomised clinical trial. Trials. 2013;14(1):1-10.

74. AJ H. Rapid expansion of the maxillary dental arch and nasal cavity by opening the mid-palatal suture. Angle Orthod. 1961;31:73-90.

75. Farronato I MCELBEFDGL. Rapid maxillary expansion in growing patients. Hyrax versus transverse sagittal maxillary expander: a cephalometric investigation. Eur J Prthod. 2011;33(2):185-9.

76. JA MJ. Maxillary transverse deficiency. Am J Orhod Dentofac Orthop. 2000;117:567-70.

77. Proffit W FH. Contemporary Orthodontics. 5th ed: Mosby; 2012.

78. Almeida MR ARINPCANRCJ. Early treatment of Class III malocclusion: 10-year clinical follow-up. J 
Appl Pral Sci. 2001;19(4):431-9.

79. RR A. Ortodontia preventiva e interceptadora. Mito ou realidade. Dental Press. 2015:657.

80. Negi KS SK. Treatment of pseudo Class III malocclusion by modified Hawleys appliance with inverted labial bow. J Indian Soc Pedod Prev Dent. 2011;29:57-61.

81. Di Palma E TMCCTGSC. Longitudinal effects of rapid maxillary expansion on masticatory muscles activity. J Clin Exp Dent. 2017;9:635-40.

82. Pereira Da Silva HCF DPJRNJ. Anterior crossbite treatment in the primary dentition: Three case reports. Int Orthod. 2018;16(3):514-29.

83. Rossi LB PKBELNGA. Correção da mordida cruzada anterior funcional com terapia de pistas diretas de planas- relato de caso. Rev Faculdade Odontol Lins. 2012;22:45-50.

84. M J. n Overview of Class III Malocclusion (Prevalence, Etiology and Management). Br J Med Res. 2018;25(7):1-13.

85. Alhammadi MS HEFMLAEsC. Global distribution of malocclusion traits: A systematic review. Dental Press J Orthod. 2018;23(6):1-10.

86. Ngan P MW. Evolution of Class III treatment in orthodontics. Am J Orthod Dentofac Orthop. Am J Orthod Dentofac Orthop. 2015;148:22-36.

87. AR V. Orthodontics and Genetics. Dental Press J Orthod. 2019;24(2):92-7.

88. Muthukumar K VNSM. Management of skeletal Class III malocclusion with face mask therapy and comprehensive orthodontic treatment. Contemp Clin Dent. 2016;7(1):98-102.

89. W M. Class III treatment by combining facemask (FM) and maxillary skeletal expander (MSE). Semin Orthod. 2018;24(1).

90. Thomaz EBAF ACGeSLRdACSdBAMHJ. Breastfeeding Versus Bottle Feeding on Malocclusion in Children: A Meta-Analysis Study. J Hum Lact. 2018;34(4):768-88.

91. Borrie FRP BDINIEZ. Interventions for the cessation of non-nutritive sucking habits in children. Cochrane Database Syst Rev. 2015;2015(3).

92. Feres MFN ALINDAMFMC. Effectiveness of open bite correction when managing deleterious oral habits in growing children and adolescents: A systematic review and meta-analysis. Eur J Orthod. 2017;39(1):3142.

93. Brierley C, DiBiase A, Sandler P. Early Class II treatment. Australian Dental Journal. 2017;62(1 Suppl):4-10.

94. Ocampo A, Parra N, Botero M. Guía de erupción y extracción seriada: una mirada desde el desarrollo de oclusión. Rev Nac Odontol. 2013;9(edición especial):25-35.

95. M R. Tratamiento precoz del apiñamiento dental en dentición mixta: procedimientos de intervención no habituales sin tocar los dientes permanentes. Rev Esp Ortod. 2003;33:203-14.

96. Santiesteban F, Gutiérrez M, Gutiérrez J. Crowding severity associated with dental mass. Revista mexicana de ortodoncia. 2016;4(3):e163-e165.

97. Al-Sehaibany F. Assessment of incisor crowding in mixed dentition among saudi schoolchildren attending college of dentistry clinics at king saud university. pakistan Oral \& Dental Journal. 2011;31(1).

98. Bertrand P, Black D, Carlson C. American Academy of Orofacial Pain Guidelines for Assessment, Diagnosis, and Management. Quintesence Publ Co. 2008;22:190-200.

99. Hermida M, Cortese S, Kalil S, Ferreira R, Spatakis L. Tratamiento del bruxismo del sueño en niños. Rev Odontop Latino. 2020;10(1).

100. Mota B, Gomez N. Bruxismo en niños: a propósito de un caso. Odontol Pediatr. 2016;24(3).

101.Bolaños E, Del Castillo R, Rodriguez E. El bruxismo infantil. Odontol Pediatr. 2002;10(3):135-41.

102.Srirengalakshmi M, Venupagal A, Pangilinan P, et al. Orthodontics in the COVID-19 Era: The Way Forward. Part 2 Orthodontic Treatment Considerations. J Clin Orthod. 2020;54(6).

103.Park J, Kim J, Kai A, Rogowski L, Liu A. Post-COVID-19 Clinical and Management Guidelines for Orthodontic Practices. Journal of Clinical Orthodontics. 2020. https://www.jco-online.com/covid19-resources/ post-covid-19-clinical-and-management-guidelines-for-orthodontic-practices/. Accessed Julio 11, 2020.

104. Batista K, Thiruvenkatachari B, Harrison J, O'Brien K. Orthodontic treatment for prominent upper front teeth (Class II malocclusion) in children and adolescents (Review). Cochrane Database Syst Rev. Marzo 2018;3(3).

Received: 10/06/2020

Accepted: 30/06/2020

e-mail: editor@revistaodontopediatria.org 